\title{
TRAFFIC SIGNAL HARDWARE DEMONSTRATION
}

Final Peports

\section{CRITERIA FOR UPGRADING TRAFFIC SIGNAL HARDWARE}

Prepared by

RENSSELAER POLYTECHNIC INSTITUTE

Department of Civil Engineering

STATE-OF-THE-ART

TRAFFIC CONTROL SYSTEMS

and

\section{FINDINGS OF THE FIELD HARDWARE REVIEW \\ AND RECOMMENDATIONS}

Prepared by

JAMES H. KELL AND ASSOCIATES

118-35 Queens Boulevard

Forest Hills, NY 11375

Prepared for

NEW YORK STATE

ENERGY RESEARCH AND DEVELOPINENT AUTHORTY

Project Manager

Norine H. Karins

Energy Authority

Report 89-15

July 1988

1033-EEED-AEP-88 


\section{NOTICE}

These reports were prepared by Rensselaer Polytechnic Institute and James $\mathrm{H}$. Kell and Associates, respectively, in the course of performing work contracted for and sponsored by the New York State Energy Research and Development Authority (hereafter the "Energy Authority"). The opinions expressed in this report do not necessarily reflect those of the Energy Authority or the State of New York and reference to any specific product, service, process or method does not necessarily constitute an implied or expressed recommendation or endorsement of same. Further, the Energy Authority, the State of New York and the contractors make no warrantics or representations, expressed or implied, as to the fitness for particular purpose, merchantability of any product, apparatus or service or the usefulness, completeness or accuracy of any processes, methods or other information contained, described, disclosed or referred to in this report. The Energy Authority, the State of New York and the contractors make no representation that the use of any product, apparatus, process, method or other information will not infringe privately owned rights and will assume no liability for any loss, injury, or damage resulting from, or occurring in connection with, the use of information contained, described, disclosed, or referred to in this report. 
1.0 INTRODUCTION . . . . . . . . . . . . . . . . . . . . 1

2.0 UPGRADING OPTIONS AND THEIR APPLICATION. . . . . . . . . . 2

2.1 UPGRADING OPTIONS FOR THE INDIVIDUAL SIGNALIZED INTERSECTION . . . . . . . . . . . . . . . 2

2.2 OPTIONS THAT ENHANCE COORDINATION. . . . . . . . . 5

2.3 SUMMARY . . . . . . . . . . . . . . . . 16

3.0 APPLICATIONS MATRIX. . . . . . . . . . . . . . . 18

3.1 THE CONCEPT. . . . . . . . . . . . . . . . . 18

3.2 DEFINITION OF THE NETWORK SETTINGS . . . . . . . . . . 18

3.3 SYSTEM OPTIONS . . . . . . . . . . . . . . . . . . . 20

3.4 SETTINGS AND TREATMENTS: THE APPLICATIONS MATRIX . . . 21

3.5 USE OF THE MATRIX. . . . . . . . . . . . . . . . 23

3.6 PRINCIPLES USED IN DEVELOPING THE MATRIX . . . . . . . 23

3.7 APPLICATION MATRIX DISCUSSION. . . . . . . . . . . 24

3.8 EXAMPLES . . . . . . . . . . . . . . . . . . . . . . . 26

3.9 CONCLUSION . . . . . . . . . . . . . . . . . . . . . . 28

4.0 SELECTION METHODOLOGY. . . . . . . . . . . . . . . . . . 29

4.1 THE DECISION PROCESS . . . . . . . . . . . . . . . 29

4.3 SYSTEM SELECTION PROCESS . . . . . . . . . . . . . 46

5.0 SUMMARY, CONCLUSIONS, AND RECOMMENDATIONS. . . . . . . . . 49

REFERENCES . . . . . . . . . . . . . . . . . . . . . 50 


\subsection{INTRODUCTION}

For a traffic engineer, the selection of new signal hardware is an exciting event. It represents an opportunity to fix annoying problems; modernize the physical plant, move closer to the state of the art, and makc one more portion of the street network function better. But, like most investments, it also involves making many difficult decisions: what goals and objectives to pursue, what hardware to consider, and what logic to use in identifying and justifying the ultimate choice. In the case of the analysis methodology, many factors have to be considered: the capabilities and limitations of the existing equipment, the traffic flow patterns, the funding available, and the municipality's ability to operate and maintain whatever equipment is selected [11].

Most traffic engineers use a set of criteria, either explicitly or implicitly, to decide what types of hardware might be suitable for a given setting. These are rules that take the form: if situation XYZ exists, then investment options $A, B$, and $C$ would be appropriate.

This report provides rules that are specifically aimed at selecting hardware that would save fuel, applicable to situations where "out-of-date" hardware is already installed. As a result, certain factors have received special attention because of their ability to generate $f$ el savings:

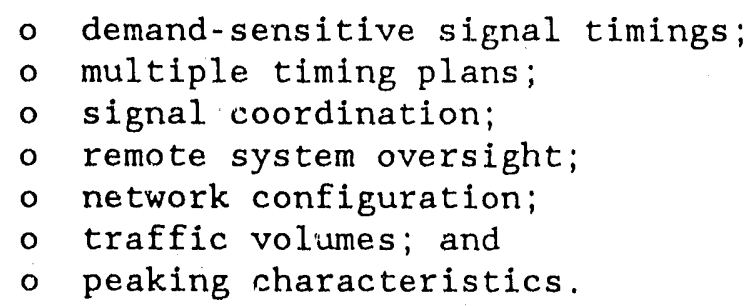

Also, since fuel-saving benefits are the main focus, costs and safety considerations have been given secondary importance. They have not, however, been overlooked.

Section 2.0 reviews the options available and presents the criteria for their selection; Section 3.0 reduces these rules to an applications matrix; Section 4.0 presents an analysis methodology which can help determine which option is best; and Section 5.0 summarizes the report's findings.

It is important to recognize that the material presented is not based on a quantitative analysis. Rather, it represents the opinions of several traffic engineers involved directly or indirectly in the project. A delphitype technique has been used to develop a consensus. Since it is just that, it is recognized that individual traffic engineers may have different opinions as to what options are most appropriate in a given setting, based on their personal experience. Feedback from readers regarding comments and suggestions is welcomed. 


\subsection{UPGRADING OPTIONS AND THEIR APPLICATION}

To select the best upgrading strategy, one needs a list of the options available and criteria for selecting them. This section presents such information based on two primary sources: a state of the art equipment survey prepared earlier at the Energy Authority's request (see Appendix A) and the Traffic Control Devices Handbook available from the Federal Highway Administration [4].

Existing options can be grouped into two categories: those that improve the performance of individual signalized intersections and those that enhance the coordination of such signals. The first consists of controllers and detectors; the second, time-based coordinators, field master systems, microcomputer-based "closed loop" systems, and mainframe-based centralized traffic control systems.

\subsection{UPGRADING OPTIONS FOR THE INDIVIDUAL SIGNALIZED INTERSECTION}

The options for individual intersections make them more sensitive to the traffic flow patterns they see. To put these uptions into perspective, Figure 2.1 shows an individual intersection in its fully configured form. The signal has a controller, a set of traffic lights, traffic detectors, and a "wiring harness". (often symbolized by the "back panel" in the controller cabinet). The controller cycles repeatedly through a set of phases and intervals, as shown in Figure 2.2, according to inputs provided by the user; the traffic lights display movement instructions to the motorists and pedestrians; the detectors sense the presence of traffic; and the back pane1 (symbolizing the wiring harness) serves as the communications network among these elements, performing both transmission and translation functions.

The controllers within such systems can be categorized according to how they control the signal indications. With pre-timed control, the timing of the indications (or more precisely, the intervals) is specified in advance through one or more timing plans, each consisting of a cycle length, a phase sequence, an interval sequence, and interval durations (see Figure 2.2 for definitions of these terms). This control is well-suited to situations where the traffic patterns are relatively stable or where the variations can be accommodated by a set of timing plans. In the latter case, the controller transitions from one timing plan to another based on time of day, day of the week, etc; the regime often being referred to as multiple-dial or multipletiming plan operation. Pre-timed control is particularly well suited to grids and arterials because the strict timing reinforces progression speeds and traffic flow patterns, facilitating smooth, efficient flow.

With actuated control, signal indications are determined by and conform to the changing traffic flows on a demand-responsive basis (within limits set by the user). No pre-arranged plan for transitions among timing plans exists. The interval lengths and their sequencing can vary from cycle to cycle, with some intervals even being omitted if there is no actuation or demand from waiting vehicles or pedestrians. Two types of such control exist: (1) fully actuated, where the controller rests in the last set of indications for which 


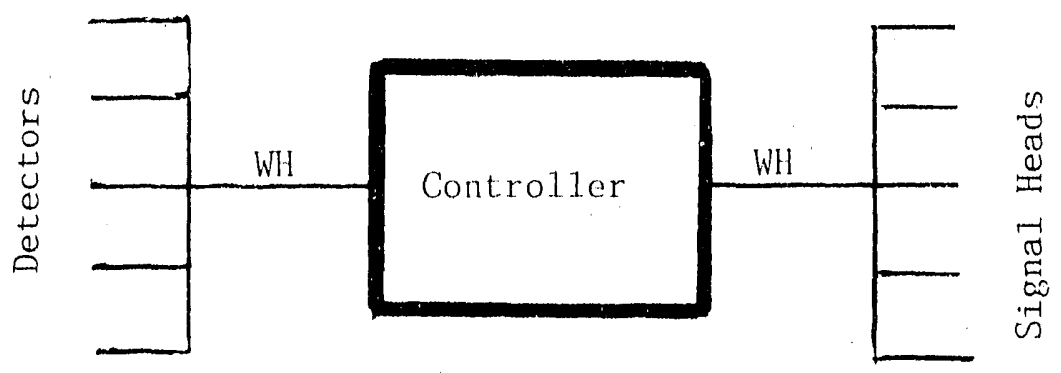

Figure 2.1: A fully configured isolated intersection. The wiring harness (WH), only partially shown, ties the components together.

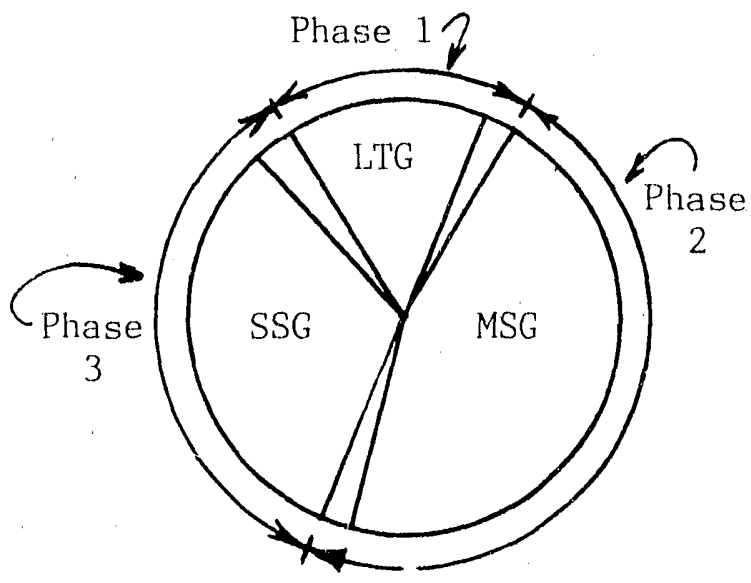

LTG=main street left left turn green

$M S G=m a i n$ street green

$S S G=$ side street green

One Cycle $=$ Phase $1+$ Phase $2+$ Phase 3

\begin{tabular}{|c|c|c|c|c|}
\hline $1 \quad|2|$ & 3 & 141 & 5 & $161 \leftarrow$ Interval \\
\hline \begin{tabular}{l|l|} 
LTG & $Y$ \\
\end{tabular} & \multicolumn{3}{|c|}{$\mathrm{R}$} & \\
\hline $\mathrm{R}$ & MSG & $Y$ & $\mathrm{R}$ & \\
\hline & $\mathrm{R}$ & & SSG & $\mathrm{Y}$ \\
\hline
\end{tabular}

Figure 2.2: Intervals, Phases, and the Cycle luength 
traffic was served, such as side street green; and (2) semi-actuated, where the controller always returns to a pre-determined interval, such as main street green. When actuated controllers are used in interconnected networks, they always operate in semi-actuated mode.

A quantitative comparison of actuated versus pre-timed control was recently reported in [12]. The report's main conclusion is that actuated control has widespread applicability, especially for isolated intersections that are below their capacity limits. As intersection capacity is reached, however, pre-timed operation becomes more efficient. Semi-actuated control, as opposed to fully actuated, is desirable when the main street volume heavily dominates that of the side street, so much so that if the street demands do not need servicing every cycle, they can be skipped.

It is also possible to categorize controllers by type: digital, solidstate, and electro mechanical. Digital controllers are the newest and the most sophisticated. They can operate fully actuated, semi-actuated, pretimed, or in a combination of these modes. They have a small computer (often with significant decision-making capabilities) that controls the traffic lights. Solid state controllers are somewhat older. They have more limiced capabilities, some being functional look-alikes for electro mechanical. predecessors: motors, gears, and cams having been replaced by solid-state logic circuits. Electro mechanical controllers are the oldest, and very limited in their actuated control capabilities. They can, however, be quite useful as individual intersection controllers in hardwire-interconnected systems. They are simple and reliable.

\section{1 .1 A New Controller}

Controller replacement is one of two ways in which the fuel efficiency of an individual intersection can be improved. However, a new controller is beneficial only if it permits either the use of multiple timing plans or operation in actuated mode. Either will reduce fuel consumption, delays, and stops.

Replacement of the controller is appropriate if:

1) the intersection sees time-varying volumes (almost all do), and

2) the existing controller cannot respond to detector inputs, or

3) it cannot implement more than one timing plan.

The strategy becomes even more powerful if it is part of a larger package that (1) replaces all the deficient controllers in a given network; (2) installs vehicle and pedestrian detectors as described in Section 2.1.2; (3) installs coordination software or hardware as described in section 2.2; or (4) some set of these.

The cost of a controller ranges from $\$ 5,000$ to $\$ 10,000$, installed.

\subsubsection{Traffic Detectors}

Traffic detectors can produce fuel savings if fully actuated or semiactuated operation then becomes possible. (Sometimes the controller has the capability to operate in an actuated mode but the bark panel must be modified 
to permit the necessary detector inputs.)

Detector installation is appropriate if:

1) the traffic flows are difficult to predict;

2) pre-timed control with multiple timing plans would not be satisfactory;

3 ) the controller is capable of receiving detector inputs; or

4) it is being replaced with one that can.

Studies have shown that actuated signals can significantly reduce delays and stops at isolated intersections [12].

Detectors cost between $\$ 2,000$ and $\$ 5,000$ installed and at least one is needed fur every approach that is to be made demand.sensitive. This means that for a signal at a four-legged intersection along an arterial that is to operate in semi-actuated mode, a minimum of two detectors are required, one for each side-street approach.

\subsection{OPTIONS THAT ENHANCE COORDINATION}

Coordination can be defined as the synchronization of signal timings on two or more signals so that the vehicles move smoothly and efficiently through the resulting network. The network can be an arterial, a grid, or even a diamond interchange. Typical objectives include minimizing fuel consumption, vehicular delay, and vehicular stops; weighted by the relative importance of these objectives and the priorities assigned to various flows in the network.

Coordination requires a synchrorization pulse and a set of offsets. The synchronization (synch) pulse ensures that the signals stay in step and that a pre-determined cycle length is maintained. The offsets tell each controller when to start its cycle, following receipt of the synch pulse. Each controller has a pre-designated interval which represents the beginning of its cycle. Often, this reference interval is main street graen, as shown in Figure 2.3(a), or main street yellow (i.e., the end of main street green), as shown in Figure 2.3(b). The former is typical of mainframe-based centralized traffic control systems; the latter, of field master and closed-loop systems.

The distribution of green time for each signal is either pre-timed, controlled by the central computer, or determined by detector inputs and the decision-making logic of the local controller. In the latter case, the local controller operates in semi-actuated mode, returning to main street when it finishes serving the minor movements.

It is possible to make coordinated systems sensitive to changes in traffic conditions either by (1) establishing a pre-arranged schedule for changing the network's timing plan by time of day, day of the week, etc., or (2) installing system detectors which sense the traffic levels at key locations and provide inputs to a logic subsystem which selects an appropriate timing plan from among a library of plans.

Coordination produces fuel savings above and beyond those achievable with multiple timing plans and detectors (see sections 2.1 .1 and 2.1 .2 above) if 


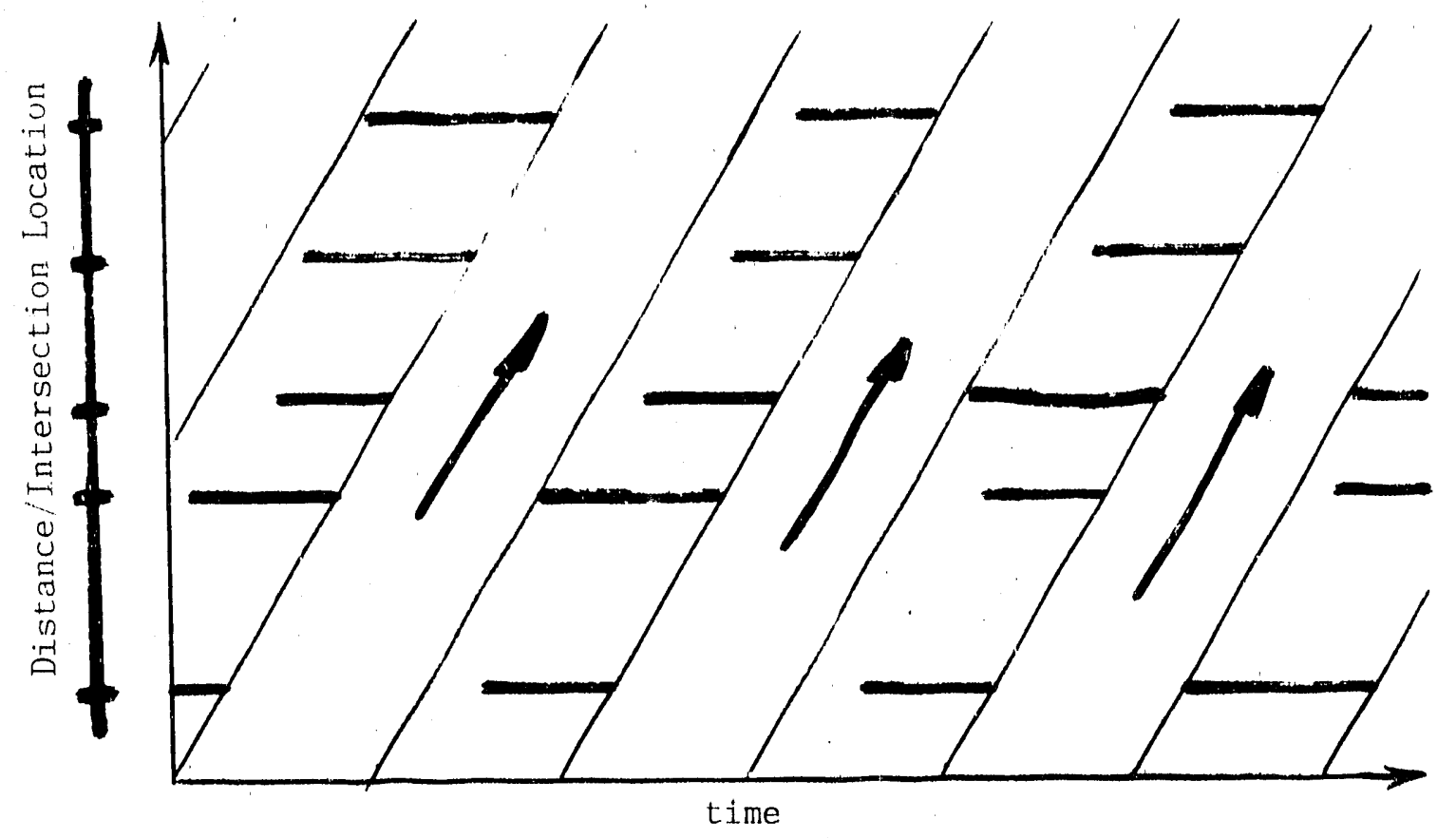

a) Coordination based on the beginning of main street green

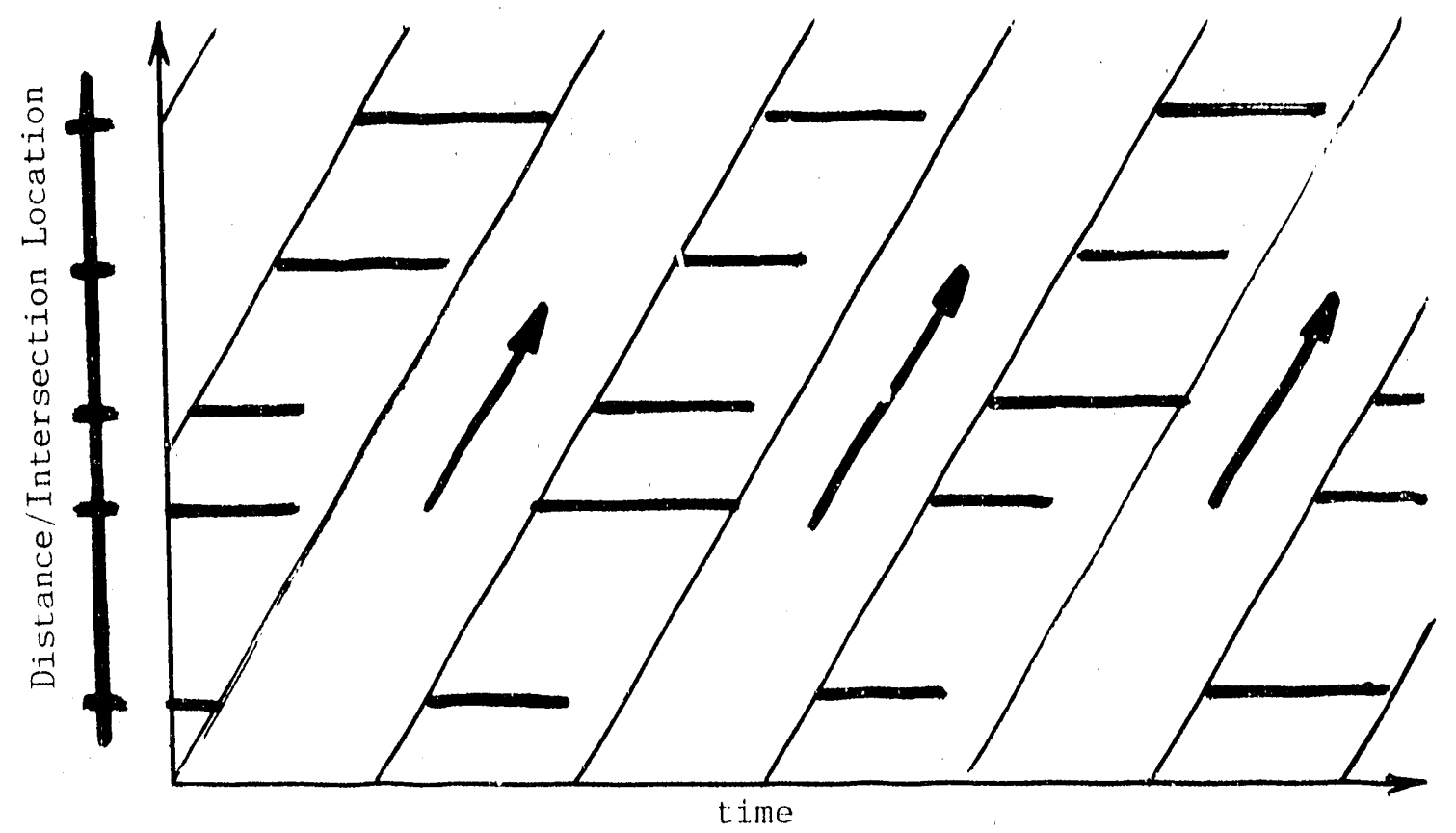

b) Coordination based on the end of main street green

Red for the main street

Figure 2.3: Signal Coordination Alternatives 
the traffic at one or more signals tends to arrive in platoons at the same time every cycle. Letting these platoons pass through the network uninterrupted saves fuel because it reduces both stops and delays. The ability to create and maintain such platoons is contingent on the network's traffic characteristics, topography, roadway condition, and roadside friction. In most cases, a well-designed network, without lots of driveways, with opportunities for passing, and with provisions for left turns can maintain definitive platoons for quite long distances. There are networks where platoons can be preserved for a mile or more. Long-distance coordination is possible when roadside friction is minimal, speeds are fairly high, and the traffic signals are visible for some distance in advance of the intersection.

Determining what intersections to interconnect is a complex problem. The objective is to find common traffic flows and similar cycle lengths, keeping the network size reasonable. A number of factors need to be considered, including:

- geographic relationships - distance between intersections, natural and artificial boundaries, such as rivers, and controlled-access facilities;

- volume levels - larger volume levels intensify the need for coordination among signals; and

- traffic flow characteristics - if traffic arrivals are uniform or random throughout the cycle, the red portion of the cycle would produce the same stops and delays rejardless of its position within the cycle. On the other hand, pulsed flow, in platoons, enhances the benefits of coordination.

\subsubsection{Options Available}

The number of ways in which signals can be coordinated has expanded recently and will probably continue to do so. For example, radio control, without hardwire interconnection, is being developed. Coordination options in prevalent use today include the following:

- time-based coordinators (TBC);

- field master systems;

- closed loop systems; and

- mainframe-based centralized traffic control systems.

Each of these is described below.

\subsubsection{Time-Based Coordinators}

Traffic engineers have tried for years to coordinate signals without the use of a hardwire interconnection. Until recently, however, they could only achieve moderate success. The principal problem was that the controllers would inevitably get out of step whenever a power failure, or even a brownout, occurred

Time-based coordinators (TBCs) have solved this problem in a very costeffective manner. Not only can they keep track of time very accurately, they 
can do so whether the norma $160-$ Hertz power supply is available or not. Each TBC has a battery that it can use to keep the clock operating even if a power failure occurs. This means that when power is restored, the signals will still be in synch.

As shown in Figure 2.4, a TBC-based network has a TBC unit attached to or contained within each controller. The TBC performs three functions: (1) it keeps track of time for the controller, (2) it provides the synch pulse when coordinated operation is in effect, and (3) it tells the controller what signal timing plan should be in use for the current date and time.

Since TBCs can send signal timing plan instructions to their controllers, they have a moderate degree of traffic condition sensitivity. Most TBCs can be programmed so that they change the signal timing plan in effect by time of day, day of the week or even day of the year, with special timing plan combinations being allowed for holidays and other special days during the year.

The main disadvaritage to a TBC is that its control settings must be changed manually in the field. In a network, each $\mathrm{TBC}^{\prime} \mathrm{s}$ datia must be changed individually.

Despite this limitation, TBCs have been proving themselves useful in many networks where the traffic conditions change predictably. They are probably the most popular coordination device on the market today. Obviously, they can only be effective if the contruller is capable of receiving the $\mathrm{TBC}^{\prime} \mathrm{s}$ signals, but this is typically the case. In many situations, the TBCs signal can then be fed in through what would normally be the receptacle for a hardwire interconnection cable.

Installation of TBCs is appropriate when:

1) the traffic flows are predictable;

2) interactive control (i,e., real time, by an operator at some remote location) is not important;

3 ) the system is not hardwired; and

4) the controller is capable of receiving synch pulses and cycle length/ offset instructions.

TBC units range in cost from $\$ 700$ to $\$ 3,000$ per intersection depending on their capabilities.

\section{2 .3 Field Master System}

A field master system, when completely configured, consists of one or more local controllers (each of which has its own local detectors), a master controller, a hardwire interconnection, and a set of system detectors which feed inputs directly into the master controller, as illustrated in Figure 2.5. The master controller relays cycle and offset instructions to the local signals using the hardwire interconnect. The master can be located in the field (as a so-called on-street master), in the traffic engineer's office, the maintenance shop, or some other convenient location. 

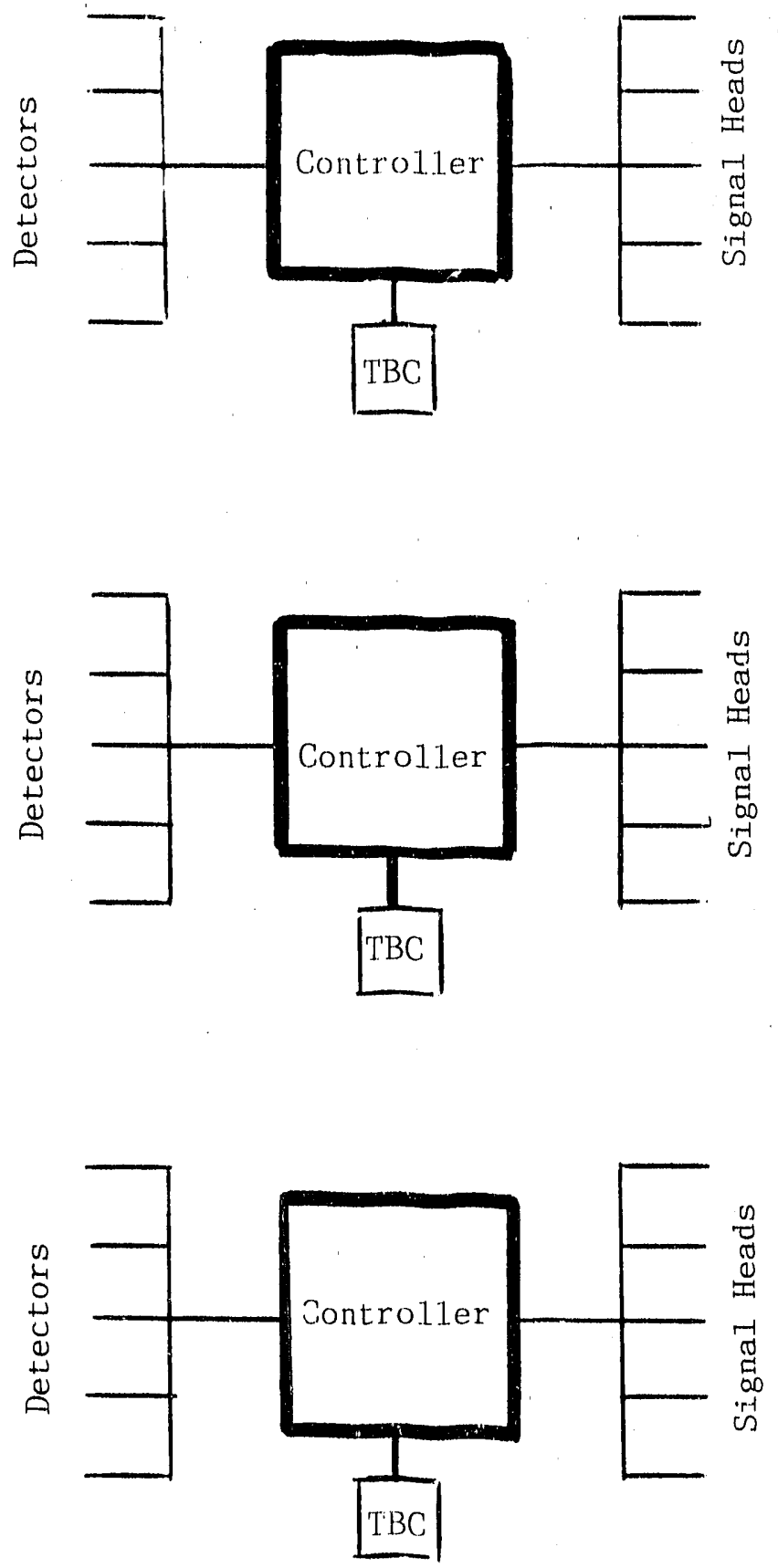

Figure 2.4: Time-based Coordinated Network 


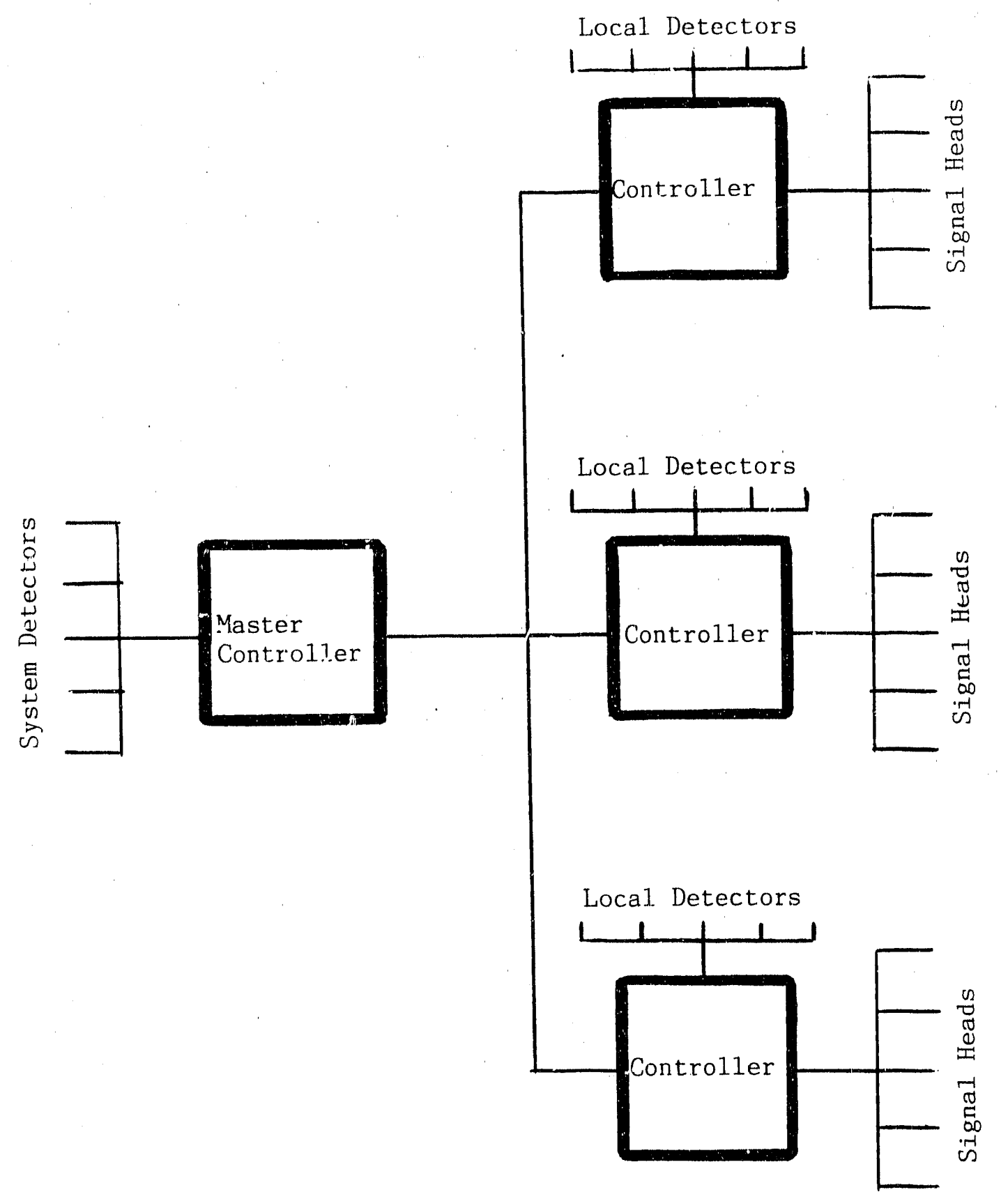

Figure 2.5: Field Master System 
The master controllex can be another signal controller (specially programmed and configured), a set of electro mechanical dials, a microcomputer, or a TBC. Capabilities of the unit rise and fall relative to its sophistication.

Field master systems can either be pre-timed or traffic-actuated (aiso referred to as semi-actuated;. Those that are pre-timed do not have local or system-level detectors. Such systems are effective in networks where the traffic conditions change predictably. Installation costs vary with the amount of cable needed. Field master systems are comparable in cost to timebased coordinated ones when the signals are spaced close together, but they are more expensive when the signals are farther apart. Maintenance costs are similar for both types of systems.

The main advantage of a pre-timed field master system is its ability to control timing plans for many ntersections from one location. It can be used effectively aling arterial st ets and in dense networks.

Pre-timed field master systems ai:e appropriate if:

1) he volumes follow predictable patterns;

2) the network is small to medium size;

3 ) Installation of a hardwire interconnection can be cost-justified, or

4) it already exists;

5) the controllers are capable of receiving synch pulses and cycle length/offset instructions; or

6) a companion investment in such controllers is planned;

7) interactive control is not important; and

8) a TBC-based system would not be adequate.

When a field master system is traffic-actuated, either system or locallevel detectors are present.

System-level detectors allow the master controller to select cycle and offset combinations based on the vehicle flows observed. Typically, the master is programmed to increase the cycle length as volumes increase, and to implement offsets that favor the heavy volume direction. For example, one choice might be a 100 -second cycle with offsets that establish a wide progression band in the inbound direction.

Local detectors allow the local controllers to operate in semi-actuated mode (see description under Section 2.1.2 above), allocating green time to the side street and other minor flows on an as-needed basis.

When both syster. and local-level detectors are present, the former are used to select cycle length-offset combinations, and the latter to allocate green time at the individual intersoctions. Because traffic-actuated field master systems can raspond to changing traffic conditions, they are useful in networks where the traffic patterns are difficult to predict.

Four disadvantages can be noted for such systems: (1) the signal timings can only be changed in the field, (2) conditions in the network cannot be observed without being in the field, (3) detectors are used heavily, and (4) costs for installation and maintenance are higher than for pre-timed field 
naster systems.

A traffic-actuated field máster systems is appropriate if:

1) the volunes are difficult to predict;

2) the network is small to medium size;

3) installation of a hardwire interconnection can be cost-justified, or

4) it already exists;

5) the controllers axe capable of receiving synch pulses and cycle length/offset instructions; or

6) a companion investment in such controllers is planned;

7) the installation of detectors "an be cost-justified; or

8) they already exist;

9) interactive control is not important; arid

10) a TBC-based system would not be adeqiate.

The cost of a field master system ranges between $\$ 10,000$ and $\$ 15,000$ per intersection. repending on network configuration and the sophistication of the contul beirig provided.

\section{2 .4 Closed-Loop System}

A closed-loop system, when fully configured, consists of two or more local controllers, each with its own detectors, a master controller, a hardwire interconrection, system-level detectors, and a supervisory microcomputer, as shown in Figure 2.6. The microcomputer is placed at some convenient location and connected to the master controller via telephone lines anc modems. A closed-loop system is very similar to the traffic-actuated field master system described in Section 2.2.3, but it incorporates a microcomputer and more sophisticated controllers.

The nicro is used to supervise system operation. Real-time traffic flow data can be displayed, timing data can be checked and changed if necessary, and detector malfunctions and other problems can be identified without visiting the retuork.

Closed-loop systems get their name from the fact that the operator can receive "feed arik" from the fic:ld on current conditions in the network. By detizition, any control strategy employing feedback is a closed-loop system. (The fieif master systems described in Section 2.2.3 do not provide such feedback uniess the operator is in the field and can physically see the condition of the network. Hence, these systems are considered to be "openloop." The traffic-actuated field master systems, however, technically do have feedback in that they can adjust signal timings in response to traffic conditions. But the difference highlighted is that the closed-loop systems put the operator into the feedback loop.)

The main advantage to a closed-loop system is its ability to monitor network conditions and performance from a remote location. This feature, until recently, was only available from the more expensive mainframe-based systems described in Section 2.2.5:

o the ability to change traffic signal timing parameters from a central location; 


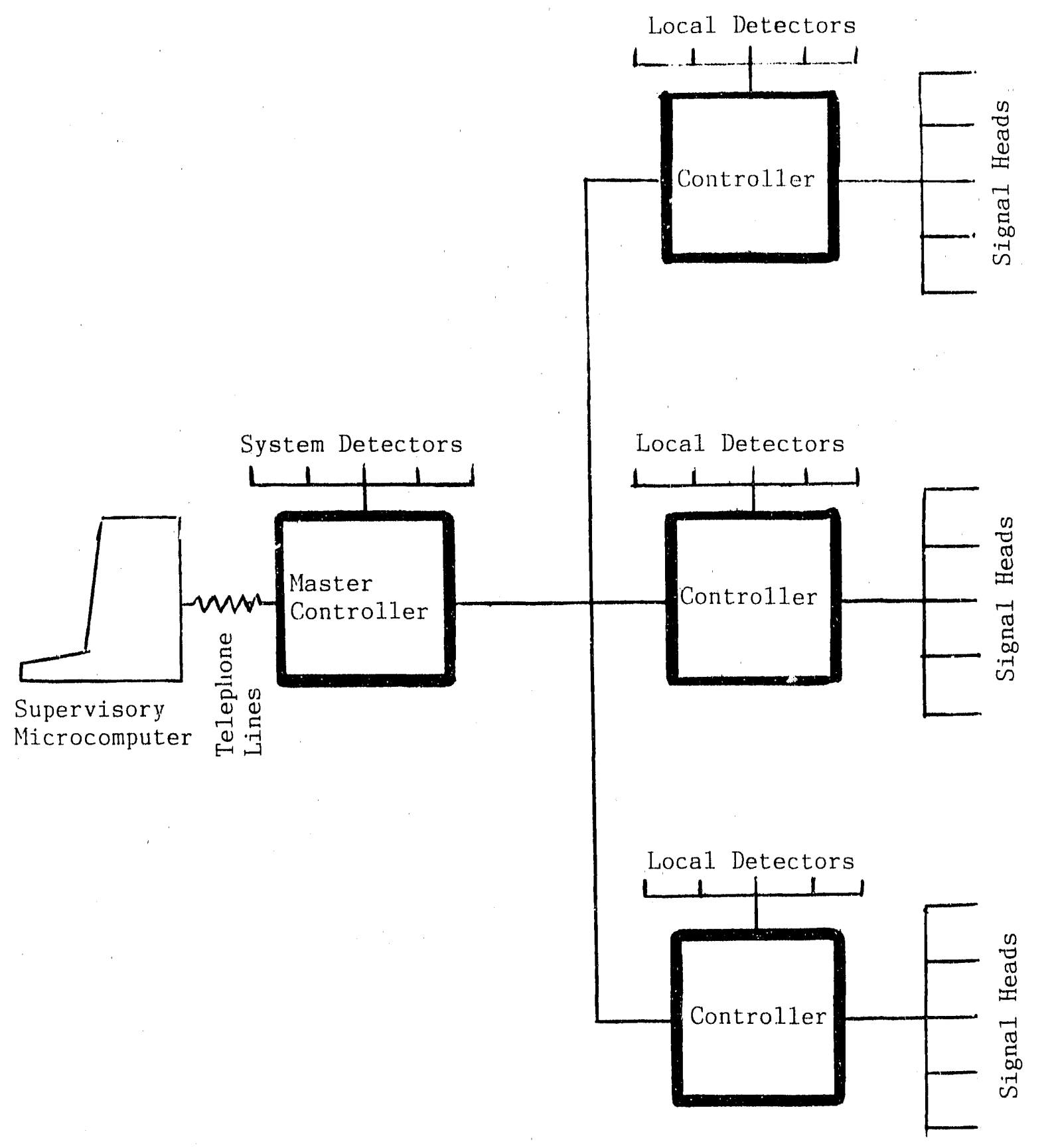

Figure 2.6: Closed-Loop Syrstem 
- the ability to monitor local hardware operation and identify failures, again from a central location; and

- the ability to monitor traffic flow data and visually display traffic volumes on a computer monitor.

The main disadvantage of closed-1oop systems is that more sophisticated controllers are required. They must be able to upload traffic detector data, timing data, and system status information (e.g., about failed detectors) from the local controllers to the master and then to the micro and download signal timing changes and other instructions from the micro to the master controller and through the latter to the local controllers.

Closed-loop systems also require heavy detectorization to generate the traffic flow inputs required to provide feedback on traffic conditions to the operator.

From the above discussion, one can see that a case can be made for closed-loop systems when:

1) the network is small to medium size;

2) it is difficult to make signal timing changes in the field (e.g., the network is at a remote location);

3 ) the traffic flows are difficult to predict; or

4) routing control is important;

5) a hardwire interconnection can be cost-justified; or

6) it already exists;

7) installation of compatible controllers (software especially) can be cost-justified; or

8) they are already installed;

9) all of the critical intersections have "full" detectorization; or

10) detectorization can be cost-justified; and

11) either a field master system or time-based coordination would not be sufficient or satisfactory.

The cost of these systems varies from $\$ 10,000$ to $\$ 20,000$ per intersection.

\subsubsection{Centralized Traffic Control System}

A mainframe-based centralized traffic control system, when completely configured, consists of two or more local controllers (each of which has its own local detectors), a mainframe computer, a hardwire interconnection, and a set of system detectors, as shown in Figure 2.7. The local controllers (and system detectors) upload traffic data and status information to the central computer; the central computer determines what timing plan should be used given the traffic flows, and it downloads timing data and other operational instructions to the local controllers. In fact, in many systems, the central computer handles all of the timing functions. The local controllers are used merely to change the signal indications. A high degree of flexibility is achieved with this approach.

Because of the immense amount of feedback coming in from the network, the operator has at his or her disposal information on signal timings, traffic 


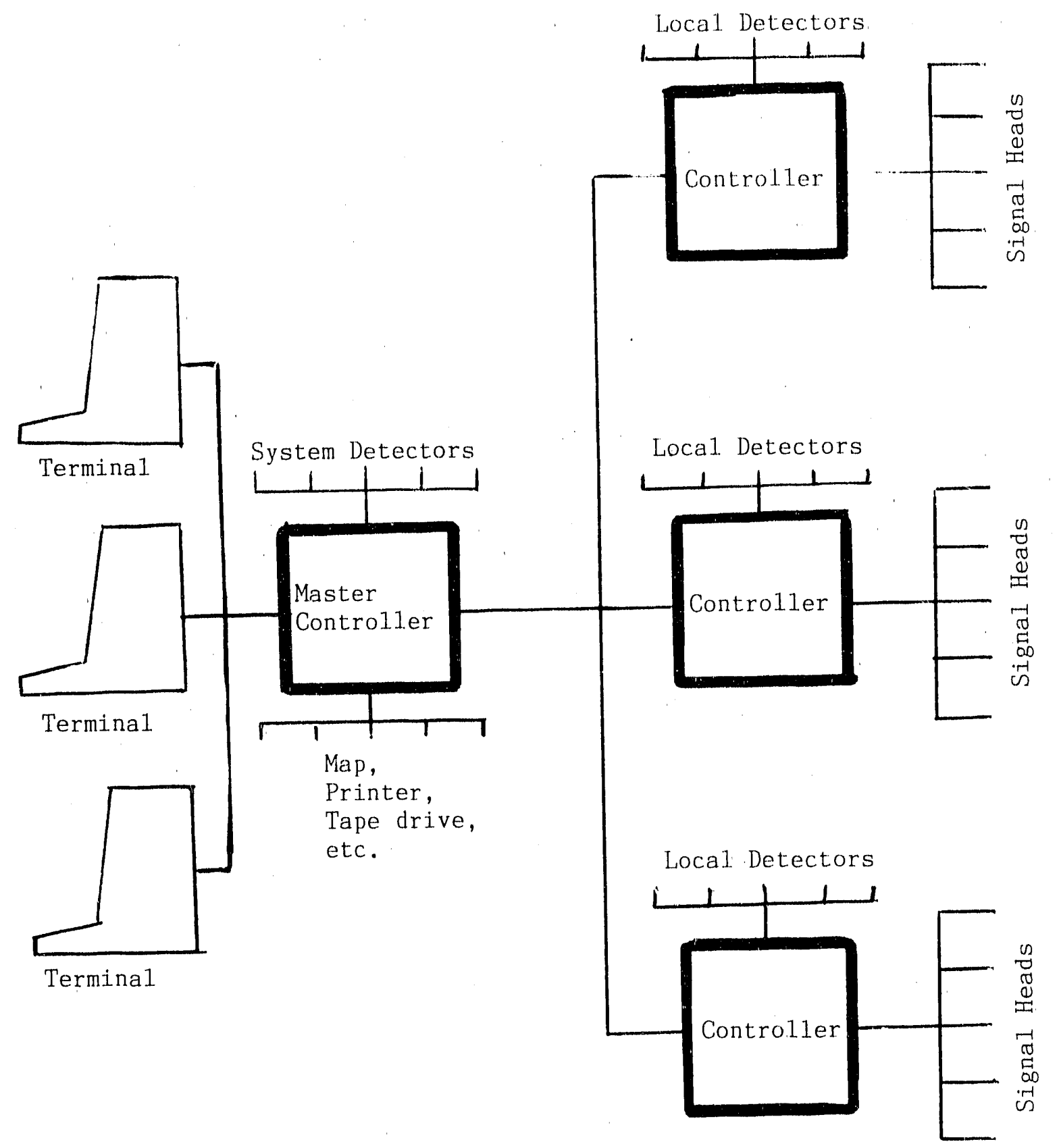

Figure 2.7: Centralized Traffic Control System 
volumes, network speeds, and system condition (i.e., malfunctions). By watching a large-scale network map or a CRT screen, he or she can assimilate large amounts of information about system status in rapid fashion. Actions can be taken using a control panel or a computer terminal. The operator can intervene in a troublesome situation, taking timely action and making wellinformed decisions. Moreover, he or she can see the results of these actions and make adjustments accordingly.

Hence, the main advantage to a centralized traffic control system is flexibility. Such systems offer practically unlimited ability to implement any signal timing plan desired or take any other action deemed necessary. Some systems can even adjust cycle times and interval lengths in real time, based on detector inputs. Centralized traffic control systems also offer the ability to monitor system performance and condition.

The main disadvantage is high cost, both for installation and maintenance. The detectors, the hardwire interconnection, and the central computer all require an nperating budget and maintenance personnel with specialized technical skills not found in most traffic engineering agencies.

Installation of a centralized traffic control system is appropriate if:

1) the net rk size is medium to large;

2) the traffic flows are difficult to predict; or

3) routing control is deemed important; or

4) centralized control is deemed important for some other reason (e.g., for special sporting events);

5) a hardwire interconnection can be cost-justified; or

6) it already exists;

7) installation of compatible controllers can be cost-justified; or

8) they are already installed or available;

9) local and/or system-level detectors can be cost-justified; or

10) they already exist;

11) the use of several field master or closed loop systems would not be satisfactory; and

12) the use of time-based coordinators would not be sufficient.

The cost of a mainframe-based centralized traffic control system ranges from $\$ 13,000$ to $\$ 25,000$ per intersection.

\subsection{SUMMARY}

Table 2.1 summarizes the criteria that have been stated in the preceding sections. The next section explores these criteria in more detail, providing a matrix that shows more precisely which option best its a given network situation. 
TABLE 2.1

TYPES OF UPGRADING OPTIONS AND THEIR APPLICATION

Type of Equipment

new controller.

detectors

time-based coordinators

pre-timed field master system

traffic-actuated field master system

closed loop system

centralized traffic control system
Application

\section{individual intersections}

the old controller cannot implement multiple timing plans or respond to detector inputs

traffic flow patterns are difficult to predict and the controller is able to receive detector inputs or a new one is being installed and pre-timed operation using multiple timing plans would not be adequate

\section{network coordination}

traffic flows are predictable, interactive control is not important, and the controller can respond to cycle length/offset commands

volumes are predictable, the network is small to medium size, installation of a hardwire interconnection can be cost-justified or it already exists, the controllers can be coordinated, interactive control is not: important, and a TBC-based option would not be adequate

traffic flow patterns are difficult to predict, the network is small to medium size, installation of a hardwire interconnection can be cost-justified or it already exists, the controllers can be coordinated,

interactive control is not important, and a

TBC-based option would not be adequate

interactive control is important, the network is small to medium size, it is inconvenient to make signal timing changes in the field, the traffic flow patterns are difficult to predict, a haruwire interconnection can be cost-justified or it already exists, the controllers are o: will become compatible with closed loop operation, all of the critical intersections have or will have full detectorization and either a field master or TBC-based system would not be sufficient

interactive control is deemed important, the traffic flow patterns are difficult to predict, the network is medium to large size, a hardwire interconnection exists or can be cost-justified, compatible controllers have been or will be installed, intersection or system-leve1 detectors can be cost-justified, the use of several field master or closed loop systems would not be adequate and the use of time-based coordinators would not be satisfactory. 


\subsection{AYPLICATIONS MATRIX}

This section presents a matrix showing the hardware option that seems "most appropriate" for a given network setting. It represents an expanded treatment of the information contained in Table 2.1.

Lest the reader think that the words "most appropriate" obviate the need for a careful alternatives analysis, bear in mind the fact that the material presented reflests only the opinions of the traffic engineers involved directly or indirectly in the project for which this report was developed and is not site-specific in focus. Other traffic engineers, for very valid reasons, may come to somewhat different cuaclusions as to what treatment option is most appropriate for a site-specific setting. Thus, a full-scale alternatives analysis, such as that described in Section 4.0, will always be appropriate before making an upgrading decision.

\subsection{THE CONCEPT}

Conceptually, the selection of upgrading options should be based on two factors: (1) the control equipment already installed and (2) the network's traffic conditions, existing or expected. Figure 3.1 shows a hypothetical matrix where the existing control equipment scenarios are on the left-hand edge and the traffic conditions across the top. Network settings are defined as combinations of these two; intersections of specific rows and columns. Entries at a specific intersection represent the signal system treatment(s) deemed most appropriate for that setting.

For example, an existing control equipment scenario might be: a network of pre-timed controllers that have never been interconnected. The traffic condition might be: rapidly increasing volumes with flow patterns that are difficult to predict. The matrix cell for their intersection would then list one or more upgrading options. Examples would include: a traffic-actuated field master system or a closed-loop system.

\subsection{DEFINITION OF THE NETWORK SETTINGS}

To implement the applications matrix concept, attributes are needed to define the network settings. Four were selected to represent the status of the equipment and two for the traffic conditions. The four for equipment status are:

1) the number (\#) of signals in the network:

o one;

- a small network (S); (e.g. 2-10)

- a medium-sized network (M); (e.g. 10-50)

o a large network (L); (e.g. more than 50)

2) the interconnection existing among them (I):

- not interconnected (N);

- previously interconnected (W); and

- currently interconnected $(\mathrm{Y})$. 


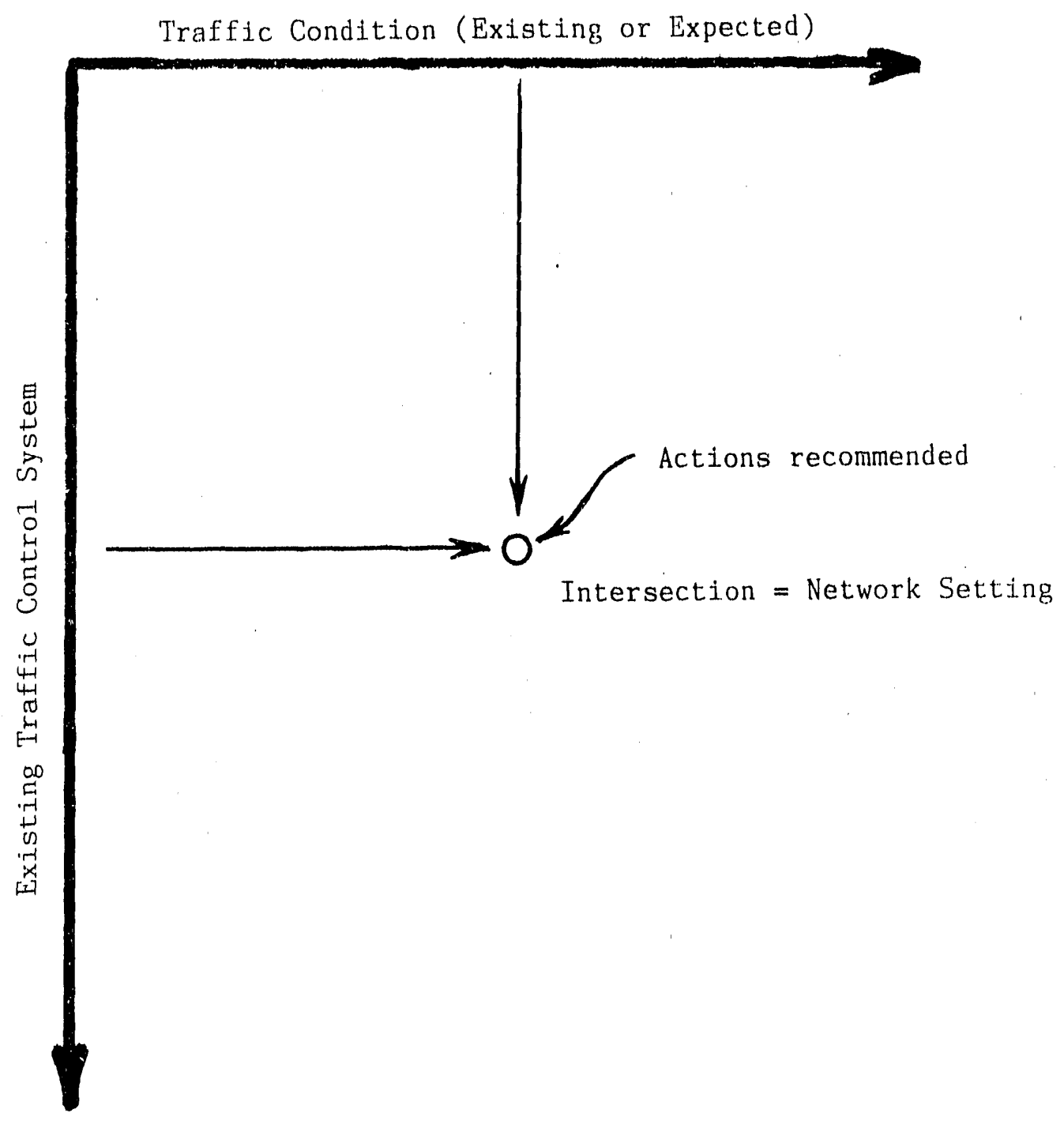

Figure 3.1: Illustrative Applications Matrix 
3) the types of detectors present in the network (D):

- none (N);

- system detectors only (S);

- intersection detectors only (I); and

o both (B).

4) the type of system oversight and control that is possible (Cntr1):

- fleld only (F); and

- remote, including real-time control ( $R$ ).

The attributes relating to the traffic conditions are:

1) the traffic flow pattern (Patrn):

- repetitive, consistent, and predictable; $(P)$ and

- difficult to anticipate day-to-day, unpredictable (U).

2) the type of traffic growth expected (Grwth):

'o a decline in traffic volumes (D);

o no growth, steady (S); and

o significant growth $(G)$.

\subsection{SYSTEM OPTIONS}

Al1 the upgrading options described in Section 2.0 have been considered potential "treatment options" for the network settings. This means the following are available:

1) Multi dial. Pre-timed Controller: a single, isolated, multiple-dial, pre-timed controller (M).

2) Actuated Controller a single, isolated contioller operating in fully actuated mode with detector inputs (A).

3) Time-based Coordination: two or more signals being coordinated without a hardwire jnterconnect using time-based coordinators and either without ( $t$ ) or with (T) local detectors at the intersections (i.e., operation in either pre-timed or semi-actuated mode).

4) Field Master System: two or more signals hardwired together, with a field master being used to control system operation, elther with system detectors alone (f) or local detectors as well (F). (Field master systems without detectors have not been considered an option since TBCs can perform the same function at lower cost.)

5) Closed-Loop System: two or more signals hardwired together, with a master controller being used to control system operation and a microcomputer being used to provide feedback so that an operator can monitor and control system performance, either with system detectors $(r)$ or local detectors (R). 
6) Centralized Traffic Control System: two or more signals hardwired together, with a mainframe computer being used both to control system operation and to provide sufficient feedback so that an operator can monitor and control system performance, either with system detectors alone (c) or local detectors as we11. (C).

\subsection{SETTINGS AND TREATMENTS: THE APPLICATIONS MATRIX}

Having presented the network settings and the treatment options, the next step is to relate these to one another through the applications matrix (see Table 3.1).

The attributes relating to equipment status are listed in the first three columns and across the top row. The number of signals (one, $S, M, L$ ) is in the first column; the interconnection condition ( $N, W, Y)$ in the second; the detector status in the third (N,S, I, B); and the system oversight capability $(F, R)$ across the top row.

System oversight has been placed across the top row for two reasons. First, it makes the matrix more compact, but second, and more importantly, it emphasizes the fact that system oversight capability can be a reflection of a desired end state as well as existing conditions. Hence that row can either be interpreted "does exist" or "is desired." For example, there might be a network whose traffic flows in the future will be quite unpredictable even though they are stable and consistent presently. Several malls and housing developments may be under construction or planned. Since the traffic engineer might think that remote system oversight would be important in such a situation, he or she might want to use Table 3.1 to confirm this fact, which is different from asking what equipment would be appropriate for an existing condition where remote system oversight is not available.

The attributes relating to traffic conditions can be found in the second and third rows of the matrix. The pattern attribute is in the second row $(P, U)$; the growth attribute in the third $(D, S, G)$.

A few examples will help the reader double-check his or her understanding of how to find network settings in the matrix. Consider the setting in the upper left-hand corner of the matrix. It corresponds to (one, N,N, F, $P, D$ ) $=$ (one signal, no interconnection, no detectors, field oversight only, predictable volumes, and declining growth). This might represent an isolated signal located at an intersection that has predictable, but decreasing volumes - - a seting that can be served adequately with a multiple-dial, pre-timed controller.

Another example is the second entry in the 15 th row. This is the setting $(M, W, N, F, P, S)$ =(medium-size network, an interconnection did exist but no longer works, no detectors, field oversight only, predictable volumes, and stable volumes). It might represent signals along an arterial that were once hardwired but the interconnection no longer works. This is a prime candidate for time-based coordinators. The TBCs can provide the coordination required, and since the traffic flows are predictable and not growing, pre-timed operation with multiple timing plans should be adequate. 
TABLE 3.1

APPLICATIONS MATRIX FOR SIGNAL CONTROL HARDWARE

\begin{tabular}{|c|c|c|c|c|c|c|c|c|c|c|c|c|c|c|c|}
\hline \multicolumn{3}{|c|}{ Env } & $\begin{array}{l}\text { Cntrl } \\
\text { Patrn } \\
\text { Vol's }\end{array}$ & $\begin{array}{l}F \\
P \\
D\end{array}$ & $\begin{array}{l}F \\
P \\
S\end{array}$ & $\begin{array}{l}\mathrm{F} \\
\mathrm{P} \\
\mathrm{G}\end{array}$ & $\begin{array}{l}F \\
U \\
D\end{array}$ & $\begin{array}{l}F \\
U \\
S\end{array}$ & $\begin{array}{l}F \\
U \\
G\end{array}$ & $\begin{array}{l}R \\
P \\
D\end{array}$ & $\begin{array}{l}R \\
P \\
S\end{array}$ & $\begin{array}{l}R \\
P \\
G\end{array}$ & $\begin{array}{l}\text { R } \\
I 1 \\
D\end{array}$ & $\begin{array}{l}R \\
U \\
S\end{array}$ & $\begin{array}{l}R \\
U \\
G\end{array}$ \\
\hline one & $\mathrm{N}$ & $\mathrm{N}$ & & m & $\mathrm{m}$ & A & $\mathrm{m}$ & A & A & - & - & - & - & - & - \\
\hline one & $\mathrm{N}$ & I & & $\mathrm{A} / \mathrm{m}$ & A & A & $\mathrm{A} / \mathrm{m}$ & A & A & - & - & - & - & - & $\cdot$ \\
\hline$S$ & $\mathrm{~N}$ & $\mathrm{~N}$ & & $t$ & $t$ & $\mathrm{~T}$ & $\mathrm{t} / \mathrm{T}$ & $\mathrm{T}$ & $\mathrm{T}$ & $t$ & $t$ & $\mathrm{~T}$ & $t$ & $\mathrm{R}$ & $\mathrm{R}$ \\
\hline$S$ & $\mathrm{~N}$ & I & & $\mathrm{T} / \mathrm{t}$ & $T$ & $\mathrm{~T}$ & $\mathrm{~T} / \mathrm{t}$ & $\mathrm{T}$ & $\mathrm{T}$ & $\mathrm{T} / \mathrm{t}$ & $\mathrm{T}$ & $\mathrm{T} / \mathrm{R}$ & $\mathrm{T}$ & $\mathrm{R}$ & $\mathrm{R}$ \\
\hline$S$ & W & $\mathrm{N}$ & & $t$ & $t$ & $t$ & $t$ & f & F & $t$ & $t$ & $t / r$ & $t$ & $r$ & $\mathrm{R}$ \\
\hline$S$ & W & $\mathrm{S}$ & & $t$ & $t$ & $t / T$ & $t$ & $\mathrm{~F}$ & $F$ & $t$ & $t$ & $t / R$ & $t$ & $\mathrm{R}$ & $\mathrm{R}$ \\
\hline$S$ & W & I & & $T / t$ & $\mathrm{~T}$ & $\mathrm{~T}$ & $\mathrm{~T}$ & $\mathrm{~F}$ & F & $\mathrm{T}$ & $\mathrm{T}$ & $\mathrm{T} / \mathrm{R}$ & $\mathrm{T}$ & $\mathrm{R}$ & $\mathrm{R}$ \\
\hline$S$ & $W$ & B & & $\mathrm{T} / \mathrm{t}$ & $\mathrm{T}^{\prime}$ & F & $\mathrm{T}$ & $F$ & $\mathrm{~F}$ & $\mathrm{~T}$ & $\mathrm{~T}$ & $\mathrm{~T} / \mathrm{R}$ & $\mathrm{T}$ & $\mathrm{R}$ & $\mathrm{R}$ \\
\hline$S$ & Y & $\mathrm{N}$ & & $t$ & $\mathrm{f}$ & $f / F$ & $t$ & $\mathrm{~F}$ & $\mathrm{~F}$ & $t$ & $r$ & $f / F$ & $t$ & $\mathrm{R}$ & $\mathrm{R}$ \\
\hline$S$ & $Y$ & $\mathrm{~S}$ & & $t$ & $f$ & $f / F$ & $\mathrm{f}$ & F & $F$ & $t$ & $r$ & $f / F$ & $r$ & $\mathrm{R}$ & $\mathrm{R}$ \\
\hline$S$ & $Y$ & I & & $\mathrm{T} / \mathrm{F}$ & $\mathrm{F}$ & $F$ & $F / f$ & $\mathrm{~F}$ & $\mathrm{~F}$ & $\mathrm{~T} / \mathrm{F}$ & $F$ & $\mathrm{~F}$ & $\mathrm{R}$ & $\mathrm{R}$ & $\mathrm{R}$ \\
\hline$S$ & $Y$ & B & & $\mathrm{T} / \mathrm{F}$ & F & $\mathrm{F}$ & $\mathrm{F} / \mathrm{f}$ & $F$ & $\mathrm{~F}$ & $\mathrm{~T} / \mathrm{F}$ & F & $F$ & $\mathrm{R}$ & $\mathrm{R}$ & $\mathrm{R}$ \\
\hline M & $\mathrm{N}$ & $\mathrm{N}$ & & $t$ & $t$ & $\mathrm{~T}$ & $t$ & $\mathrm{R}$ & $\mathrm{R}$ & $t$ & $\mathrm{~T} / \mathrm{R}$ & $R$ & $t$ & $\mathrm{R}$ & $\mathrm{R}$ \\
\hline M & $\mathrm{N}$ & I & & $T / t$ & $\mathrm{~T}$ & $\mathrm{~T}$ & $T / t$ & $\mathrm{R}$ & $\mathrm{R}$ & $\mathrm{T}$ & $T / R$ & $\mathrm{R}$ & $\mathrm{T}$ & $\mathrm{R}$ & $\mathrm{R}$ \\
\hline M & $\mathrm{W}$ & $\mathrm{N}$ & & $t$ & $t$ & $t$ & $t$ & $\mathrm{R}$ & $\mathrm{R}$ & $t$ & $t$ & $\mathrm{r}$ & $t$ & $\mathrm{R}$ & $\mathrm{R}$ \\
\hline M & W & $S$ & & $t$ & $t$ & $t / T$ & $t$ & $\mathrm{R}$ & $\mathrm{R}$ & $t$ & $t$ & $r$ & $r$ & $\mathrm{R}$ & $\mathrm{R}$ \\
\hline M & $\mathrm{W}$ & I & & $\mathrm{T} / \mathrm{t}$ & $\mathrm{T}$ & $\mathrm{T}$ & $\mathrm{T}$ & $\mathrm{R}$ & $\mathrm{R}$ & $\mathrm{T}$ & $T$ & $\mathrm{R}$ & $\mathrm{R}$ & $\mathrm{R}$ & $\mathrm{R}$ \\
\hline M & $\mathrm{W}$ & $B$ & & $T / t$ & $\mathrm{~T}$ & $\mathrm{~F}$ & $\mathrm{~T}$ & $\mathrm{R}$ & $\mathrm{R}$ & $\mathrm{T}$ & $\mathrm{T}$ & $R$ & $\mathrm{R}$ & $\mathrm{R}$ & $\mathrm{R}$ \\
\hline M & $Y$ & $\mathrm{~N}$ & & $t$ & $\mathrm{f}$ & $f / F$ & $\mathrm{~F}$ & $\mathrm{R}$ & $\mathrm{R}$ & $t$ & $r$ & $\mathrm{f} / \mathrm{F}$ & $t$ & $\mathrm{R}$ & $\mathrm{R}$ \\
\hline M & Y & S & & $t$ & $\mathrm{f}$ & $f / F$ & $\mathrm{~F}$ & $\mathrm{R}$ & $\mathrm{R}$ & $t$ & $\mathbf{r}$ & $f / F$ & $r$ & $\mathrm{R}$ & $\mathrm{R}$ \\
\hline M & $Y$ & I & & $\mathrm{T} / \mathrm{F}$ & $\mathrm{F}$ & $F$ & F & $\mathrm{R}$ & $\mathrm{R}$ & $\mathrm{T} / \mathrm{F}$ & $\mathrm{F}$ & $\mathrm{R} / \mathrm{C}$ & $\mathrm{R}$ & $\mathrm{R}$ & $\mathrm{R} / \mathrm{C}$ \\
\hline M & $Y$ & B & & $\mathrm{T} / \mathrm{F}$ & $\mathrm{F}$ & $\mathrm{F}$ & $\mathrm{F}$ & $\mathrm{R}$ & $\mathrm{R}$ & $\mathrm{T} / \mathrm{F}$ & $F$ & $R / C$ & $\mathrm{R}$ & $\mathrm{R}$ & $\mathrm{R} / \mathrm{C}$ \\
\hline L & $\mathrm{N}$ & $\mathrm{N}$ & & $t$ & $t$ & $\mathrm{~T}$ & $t$ & $\mathrm{C}$ & C & $t$ & $r$ & $\mathrm{R}$ & $t$ & C & C \\
\hline L & $\mathrm{N}$ & I & & $\mathrm{T} / \mathrm{t}$ & $\mathrm{T}$ & $\mathrm{T}$ & $\mathrm{T}$ & $C$ & $C$ & $\mathrm{~T}$ & $\mathrm{R}$ & $\mathrm{R}$ & $\mathrm{T}$ & C & $\mathrm{C}$ \\
\hline L & W & $\mathrm{N}$ & & $t$ & $t$ & $t$ & $t$ & C & C & $t$ & $t$ & $r$ & $t$ & $\mathrm{R}$ & $\mathrm{R}$ \\
\hline L & $\mathrm{W}$ & $S$ & & $t$ & $\mathrm{~T}$ & $\mathrm{~T}$ & $t$ & $C$ & $\mathrm{C}$ & $t$ & $r$ & $r$ & $c / r$ & $\mathrm{R}$ & $\mathrm{R}$ \\
\hline L & W & I & & $T / t$ & $\mathrm{~T}$ & $\mathrm{~T}$ & $\mathrm{~T}$ & $\mathrm{C}$ & C & $\mathrm{T}$ & $\mathrm{R}$ & $\mathrm{C} / \mathrm{R}$ & C & $\mathrm{R} / \mathrm{C}$ & $\mathrm{R} / \mathrm{C}$ \\
\hline L & $W$ & B & & $\mathrm{T} / \mathrm{t}$ & $\mathrm{T}$ & $\mathrm{T}$ & $\mathrm{T}$ & $\mathrm{C}$ & $\mathrm{C}$ & $\mathrm{T}$ & $\mathbf{R}$ & $\mathrm{C} / \mathrm{R}$ & C & $\mathrm{R} / \mathrm{C}$ & $\mathrm{R} / \mathrm{C}$ \\
\hline L & $Y$ & $\mathrm{~N}$ & & $t$ & $t$ & $t$ & $t$ & C & C & $t$ & c & c & $t$ & C & C \\
\hline $\mathrm{L}$ & $\mathrm{Y}$ & $S$ & & $t$ & c & C & $c / t$ & C & $C$ & $t$ & c & C & $\mathrm{c}$ & C & $\mathrm{C}$ \\
\hline $\mathrm{L}$ & $\mathrm{Y}$ & I & & $\mathrm{T}$ & C & C & $\mathrm{C} / \mathrm{T}$ & $\mathrm{C}$ & C & $\mathrm{T}$ & C & C & C & $\mathrm{C}$ & $\mathrm{C}$ \\
\hline $\mathrm{L}$ & $Y$ & B & & $\mathrm{T}$ & C & C & $\mathrm{C} / \mathrm{T}$ & $\mathrm{C}$ & C & $\mathrm{T}$ & $C$ & $\mathrm{C}$ & $C$ & $\mathrm{C}$ & $\mathrm{C}$ \\
\hline
\end{tabular}


The setting at the end of the third row is $(S, N, N, R, P, G)=(\operatorname{sma} 11$ network, no interconnection, no detectors, remote system oversight, unpredictable volumes, and growing volumes). Clearly this is one of the planning settings discussed above in conjunction with the "remote system oversight" row. It is impossible to have remote system oversight without detectors. The entry should be incerpreted as saying that if remote system oversight is desired, then a closed-loop system (R) with local and system detectors should be considered.

As a final example, consider the setting in the bottom right-hand corner of the matrix. This is $(L, Y, B, R, U, G)=$ (large network, interconnection in service, both system and local detectors present, remote system oversight possible (or desirable), unpredictable volumes, and growing volumes). Only one optiun makes good traffic engineering sense under such conditions: a mainframe-based centralized traffic control system (C). It is vital for managing the traffic flows efficiently and effectively.

\subsection{USE OF THE MATRIX}

To use the matrix for identifying alternatives, the following rules should be followed. Entries, such as " $t$ " for the 5 th row, first column; should be taken as the starting point for generating system alternatives. Where two options are listed for the same row and column combination; as is the case for row 6 , column 3 , both should be considered, in order of their appearance. To generate additional alternatives, settings that are closely related should be considered. For example, the entry shown for row 9, column 8 is " $r$ ", and the entries for row 9, column 9, which is closely related are " $r$ " and " $R$ ". Hence, $R$ should be added to $r$ as an alternative. Use of these rules is illustrated further in Section 3.8. Once the 1 ist is complete, Section 4.0 should be followed to determine which alternative best meets the needs of the network.

\subsection{PRINCIPLES USED IN DEVELOPING THE MATRIX}

A discussion about the principles used in developing the matrix is appropriate before discussing its implications. It is impricant to describe the principles because the reader needs to know if additional factors need to be considered when generating alternatives for a particular setting.

\section{6 .1 Strive for Simplicity}

The first principle was to list options that were as simple as practical For a given network setting. For example, in row 25, column 1, " $t$," timebased coordination, is listed as the preferred option for a large network that was interconnected but now has predictable, declining volumes. The logic here is that no major capital investments are needed. Time-based coordinators should be adequate. In addition, experts repeatedly underscore the importance of selecting systems which can be maintained and operated by the traffic engineering staff [11]. There have been numerous cases where overly complex systems have been installed and never utilized because they could not be maintained and/or the expertise was not available to use them properly. 


\subsubsection{Avoid Major Investments Where Volumes are Declining}

Although a logical argument can be made for investing in new hardware to save fuel in networks with declining volumes (e.g., minimizing the excess fuel consumption that occurs due to inappropriate signal timings as the volumes decline), it is very difficult to garner support for such actions. Hence, while such strategies might be logical, they have not been selected. The options listed for declining volumes, such as $\mathrm{T} / \mathrm{t}$ for row 27 , column one, minimize the investment cost or generate cost savings. Also, those portions of the existing infrastructure that have been kept (e.g., intersection-level detectors and hardwire interconnects) are considered vital to success of the traffic control system. Conversely put, those eliminated would have added cost but not value.

\subsubsection{Provide Remote Oversight Where Appropriate}

Remote performance oversight, as in a closed-loop ( $r$ or $R$ ) or centralized traffic control system ( $c$ or $C$ ), is a desirable feature to have, but not always a necessary condition for satisfactory system operation. Hence, there are settings in Table 3.1, such as row 5 , column 7 , where remote oversight is shown as part of the existing control equipment (or the desired end state) and yet remote oversight is not listed as part of the recommended system option. In this case, in fact, the recommended option is time-based coordinators without any detectors at all. Other examples can be found in settings where the volumes are stable or declining and the flows follow predictable patterns.

\subsubsection{Upgrade, Where Required}

In contrast to the principle described in Section 3.6.3, there are situations in Table 3.1 , such as row 13 , column 6 , where significant system upgrades are shown (e.g., remote performance oversight where it was not part of the existing control equipment, as is the case for this setting) if such an option has been identified as the most logical. choice.

\subsubsection{Reduce Signal Maintenance Costs Where Possible}

In keeping with the principle described in Section 3.6.1, options have been identified which reduce signal maintenance costs where preservation of all components of an existing system (e.g., the hardwire interconnect or the centralized compuier control) is not essential for the success of the control strategy.

\subsection{APPLICATION MATRIX DISCUSSION}

This section discusses the trends in Table 3.1. Section 3.7.1 reviews those pertaining to isolated signals and sections 3.7.2, 3.7.3 and 3.7.4, review those for small, medium, and large-scale networks respectively.

\section{7 .1 Isolated Intersections}

For isolated intersections, multi dial, pre-timed operation is shown as being satisfactory where the volumes are declining or steady. Actuated signals should be kept if they are already installed, with the caveat that 
pre-timed, multiple-dial controllers are an acceptable fallback option. If the flows are difficult to predict, actuated control is the indicated choice. Even if the volumes follow a consistent pattern but are growing, actuated control is listed as the preferred option because an actuated signal can adjust the cycle length and green time automatically as the volumes grow. closed-loop system is not deemed desirable, since coordination is not an issue. Such a system could be installed, but its value would be unclear. Actuated signal parameters can usually be set so that they deal effectively with a wide range of traffic volumes.

\section{7 .2 Small Networks}

For small networks, -ime-based coordinators ( $t$ or $T$ ) are appropriate if the traffic patterns are repetitive and predictable and the signals have never been interconnected. In fact, costs can be minimized in such settings by not using detectors ( $t$ ). If traffic growth is occurring, however, or if the traffic flow patterns are difficult to predict, detectors should be included (T). If remote system oversight is part of the existing system or desired, it is deemed worthwhile only when the traffic flows are difficult to predict.

If an interconnection was at one time present, it is appropriate to restore it when the traffic flow patterns are hard to predict, whether they are stable or growing (and whether remote system oversight exists or not). Otherwise, it is probably not necessary, since time-based coordinators ( $t$ or T) can deal with predictable volumes. Of course, maintenance costs can be reduced by eliminating the detectors if they are of limited value.

If the signals are presently interconnected, the interconnection should be kept if the volumes are stable or growing, especially if the traffic patterns are difficult to predict. It is also recommended that system and local detectors be installed (implied by the $F$ and $R$ where the detectors did not exist in the original system). If the volumes are declining, time-based coordinators ( $t$ or $T$ ) can be used.

\subsubsection{Medium-Size Networks}

A medium-size network is defined here as one that consists of approximately 10 to 50 signals. The main point being made is that the signal is large enough to make coordination important, but not large enough to justify a centralized traffic control system.

If the network has never been interconnected, time-based coordination ( $t$ or $T$ ) can be used. A closed loop system ( $r$ or $R$ ) is desirable if future implementation of such a system is a realistic goal. A field master system ( $f$ or $F$ ) is a fallback alternative.

If the network has previously been interconnected, time-based coordinators can be used ( $t$ or $T$ ) if the traffic patterns are predictable and the volumes are stable or declining. It is probably not cost-effective to restore the interconnection unless the traffic flow patterns are difficult to predict, in which case a closed-loop system ( $r$ or $R$ ) would be desirable. Where remote system oversight is part of the existing control equipment (or part of the desired end state), it has been recommended only when the traffic flow patterns are not repetitive because the predictable flow patterns can be 
handled with time-based coordinators ( $t$ or $\mathrm{T}$ ).

If the interconnection did exist at one time, then either a closed-1oop system ( $r$ or $R$ ) or a field master system ( $f$ or $F$ ) would be appropriate depending upon whether remote system oversight is desired or not. There may be situations where a centralized traffic control system (c or $C$ ) is appropriate if the network is large enough (say more than 40 signals) or expanding.

\subsubsection{Large Networks}

A large network is defined here as consisting of enough signals that a strong case can be made for a centralized traffic control system under stable or growing traffic conditions.

The logic behind option selections for such networks is basically the same as it is for the medium-sized networks, except that the centralized traffic control option ( $c$ or $C$ ) is substituted for both the field master (d or D) and closed-loop ( $r$ or $R$ ) options. A centralized traffic control system (c or C) brings with it remote system oversight; hence, there is no centralized traffic control system that does not have this capability.

If the network has never been interconnected and the flow patterns are predictable, time-based coordinators ( $t$ or $T$ ) can be used. If the patterns are difficult to predict, a centralized traffic control system (c or $C$ ) should be considered. Another option is to divide the network into sub-networks and use field master systems ( $f$ or $F$ ) and closed-loop systems ( $r$ or $R$ ) as appropriate. Interconnection of these sub-networks into a unified network can be done at some future point in time.

If the system was at one time interconnected, the same logic applies. The interconnected system should be put back, complete with system and local detectors (C) if the flows are difficult to predict. Otherwise, time-based coordinators ( $t$ or $T$ ), or combinations of field master systems ( $f$ or $F$ ) and closed loop ( $r$ or $R$ ) systems can be used.

Where the interconnection still exists, the centralized traffic control system ( $c$ or $C$ ) should be kept unless the volumes fall significantly or interactive control is no longer deemed important. In this case, time-based coordinators ( $t$ or $T$ ) can be used. As before, a collection of field master systems ( $f$ or $F$ ) or closed-loop systems ( $r$ or $R$ ) is also possible.

\subsection{EXAMPLES}

This section contains examples of how the matrix can be used to develop lists of alternatives for particular settings.

\section{8 .1 MWSF/PS}

This scenario involves a medium-sized network $(M)$ which at one time was interconnected (W) and had system detectors (S) which still function. Field monitoring of system performance is presently and/or is to be part of the network setting (F). The traffic conditions are predictable (P) and stable 
(S). This situation might be encountered in a city where an "on-street master system" has fallen into disrepair and is not presently functional.

For this setting, Table 3.1 shows that time-based coordinators ( $t$ or $T$ ) would be recommended, with the decision regarding local detectors being decided on the basis of cost-justification ( $T$ or $t$ ).

A closely related scenario, MWSR/PS lists a closed-loop system (R) or time-based coordination with detectors ( $T$ ) as being desirable, depending upon whether or not the hardwire interconnect refurbishment can be cost-justified.

Given these observations, the options which should be considered are $t$, $T$, and $R$, along with the "do-nothing" alternative of leaving the system as it presently is.

\section{$3.8 .2 \underline{\mathrm{SYNR} / \mathrm{PG}}$}

This scenario involves a small network ( $S$ ) which is interconnected ( $Y$ ) but has no detectors (N). Further, remote oversight of the system is desired $(R)$. Note that this cannot be an existing system because no detectors are present.

Table 3.1 shows that a closed-1oop system ( $R$ ) is the suggested alternative for this setting. It would allow the user to gain and maintain control of the traffic conditions, assuming he or she has the staff and budget to maintain the hardware.

A closely related setting, SYNF/PG, lists a traffic-actuated field master system (F) as the suggested option. nothing.

Thus the options which should be considered are $R$ and $F$, along with doing

\section{$3.8 .3 \mathrm{LWBR} / \mathrm{PS}$}

This scenario involves a large-scale network which was at one time interconnected but now is not. Both system and intersection-based detectors were present, some of which are assumed to still be functional or repairable. Further, remote system monitoring is to be part of the desired end state. (As was the case for the example in Section 3.8.2, it cannot be part of the present state because the hardwire interconnection is not now functioning.)

Table 3.1 shows that in such a situation, a set of close-loop systems ( $r$ or $R$ ) or a centralized traffic control system (c or $C$ ) are suggested. Field master systems ( $f$ or $F$ ), instead of the closed-loop systems ( $r$ or $R$ ), are also possible (see the LWBF/PS setting), or time-based coordinators in conjunction with local detectors ( $T$ ), as shown in the LWBR/DS setting.

Hence, the options which should be considered include R, C, F, T, and doing nothing. 


\subsection{CONCLUSION}

Table 3.1 provides a set of guidelines which indicate the hardware upgrades suggested for specific settings. The reader can use the table as illustrated in Section 3.8 to develop other alternatives based on closely related settings. Given these alternatives, the next section describes an industry-accepted method to follow in making the ultimate choice. 


\subsection{SELECTION METHODOLOGY}

This section presents a selection methodology which is recommended when determining which candidate system should be selected for a particular setting. It is derived almost verbatim from the chapter on "CANDIDATE SYSTEM EVALUATION" contained in the Traffic Control Systems Handbook published by the Institute of Transportation Engineers. Text that has been changed is noted in italics, and that which has been omitted is noted with dots "...".

\subsection{THE DECISION PROCESS}

The decision to implement a traffic signal control at a single intersection is a relatively straightforward matter. Existing conditions are observed and compared with established warrants to see if signal control is justified. Then, assuming warrants are sufficiently satisfied and adequate funds exist, signals of a type necessary to handle those local needs are installed.

The procedure becomes much more complex, however, when the decision involves a "system" of signals at multiple locations. Usually, some form of signal control is already in operation. Thus, the decision becomes more how to signalize rather than whether to signalize. In addition, there are a number of alternatives available for conside:-ation. Each offers attractive features over what presently exists, and each is supported by strong advocates. The decision-maker's difficult task then becomes one of analyzing the competing alternatives in an impartial manner, using some common basis for compar'son.

This illustrates the fact that control system decisions are of two types. The first one is a decision between doing nothing, or installing/improving a control system without particular commitment as to the specifics of design. The second decision deals with design matters and the selection from alternatives of a desired approach or system.

In this ... section, analysis approaches are presented that can be used as tools in making this critical decision. At this point it is assumed that traffic problem areas have been defined and analyzed...; that the decision has been made to pursue control system upgrading and/or installation; and that specific alternative systems have been defined as candidates for dealing with the recognized traffic needs....

The evaluation of alternative traffic control systems is most often based on an economic analysis. The two primary categories of economic analysis are, depending on the priceability of consequences, benefit-cost analysis and effectiveness analysis. [13] Benefit-cost analysis is appropriate to those cases wherein both system costs and principal benefits can be priced. Such an analysis then is a cost-effectiveness comparison on a monetary basis.

Effectiveness analysis on the other hand, applies to those situations where system benefits cannot be expressed in monetary terms. It has to do with social and economic benefits and adversities of system installation or improvement. The sbjective of such a cost-effectiveness analysis is to reach a specific comparison of system cost to system consequences, expressed in such non-monetary terms as benefits, returns, satisfactions, or progress toward 
goals. In contrast to the specific numerical index of economic effectiveness which results from a benefit-cost analysis, an effectiveness analysis yields only descriptive or qualitative statements of the system's ability to reach established goals.

Benefit-cost analyses perhaps have greatest application in answering questions of the first type - is a recommended system or improvement economically justified. For such analyses, benefits which are relatively easy to quantify in monetary terms include: (1) reductions in motor vehicle running, costs attributable to decreased numbers of stops and delays; (2) reductions in travel time; and (3) reductions in traffic accident costs. To these road-uscr benefits could be added other tangible benefits which accrue to the taxpayer and operating agency, such as decreased system maintenance costs. Since the benefit-cost technfque is well documented in engineering economics texts (5] and other readily accessible literature [13], it is not described in detall here.

Since system benefits are frequently difficult to quantify in dollars and cents, an effectiveness analysis approach should be cinsidered. The real variable to be measured in evaluating competing candidate systems is the relative ability of each system to perform its prescribed traffic control function. In effect, each candidate system should be compared with specific. standards of performance instead of being compared with each other. These standards of performance can be called goals or objectives and may be expressed in terms of functional requirements.

Some overriding practical factors are present in the evaluation and selection of traffic control systems. These preclude a textbook solution to the selection problem. Obviously, some investment constraint exists which can be expected to rule out some potential candidates, regardless of the extent of the benefits. Likewise, the ability and capability of the operating agency to staff and maintain the system chosen should bear on the selection.

In the following material, a recommended cost-effectiveness analysis technique which uses proxy values to measure system benefit is presented. These proxy values are called utility measures, and the evaluation procedure is referred to as a utility/cost analysis. Adapted to the analysis of traffic control systems by .. Kay in a study for .. Baltimore $[2,7,8,9]$, the procedure has ... received widespread use in other locations including ... New York State [1].

\subsection{THE UTILITY/COST ANALYSIS APPROACH}

\subsubsection{Definition of Utility/Cost}

The basic concept of the utility/cost approach has been described by Kay [10] in the following manner:

Cost/utility is a technique for measuring the 'value' of a system against its cost. The technique is very similar to cost benefit or cost efractiveness, except in the area of determining system values. Cost be:... it uses an actual value as expressed in 'dollars.' The conversion to dollar benefit is generally from a measurable quantity such as reduction in accidents or hours of delay. Cost effectiveness uses a less 
direct form of value statement but the statement generally relates to a quantifled real unit scale. As an example, effectiveness might be expressed as 'propensity for reducing accidents,' which could then be measured against cost.

Utility as an expression of value is much less obvious than either 'benefit' or 'effectiveness.' The value is not convertible to dollars or to a single expression of system effect. It is, instead, a proxy statement which results from combining all elements of system impact into a single expression. A system's utility has no direct measurable value except when compared to another system's utility. Utility as an expression of value is only usable when competing alternatives are being considered for a specific application.

A flow chart for the basic utility/cost procedure is shown in Figure 4.1. As indicated, the procedure is founded on a knowledge of existing conditions and future needs, further translated into stated objective functions or goals. These broadly defined system goals are usually too general. to permit direct analysis. The next step, then, is to develop utility measures which further define each goal and to which a qualitative rating of each system can be applied. Candidate systems are then defined, and a utility value for each is made. Comparison of system utility value and system cost produces the analysis which identifies the best system.

Each of these principal elements of the utility/cost technique is presented in further detail in the following portion of this section.

\subsubsection{Utility Determination}

\subsubsection{Goal Setting}

Definition of system goals is the first step in the utility/cost analysis. These goals serve as the general criteria for measuring and evaluating candidate systems. All pertinent factors which might influence the decision must be included. The recognition of multiple system goals represents in itself significant progress toward making a rational decision.

As an indication of typical goals, the following is a list of those used in a ... study of urban street system needs: [8]

- Traffic operations - the ability to respond to existing and future traffic requirements.

- Rellability - minimum system downtime at minimum cost of maintenance with maximum self-reporting of failures.

- Adaptability - the ability to satisfy traffic operations goals over a long period of time under dynamic conditions.

- Implementation - ease of changeover from old system to new; a minimum of problems associated with rendering the old system inoperative.

- Incidental benefits - additional functions not necessarily relating to signal control which may be performed with no loss of primary. function 


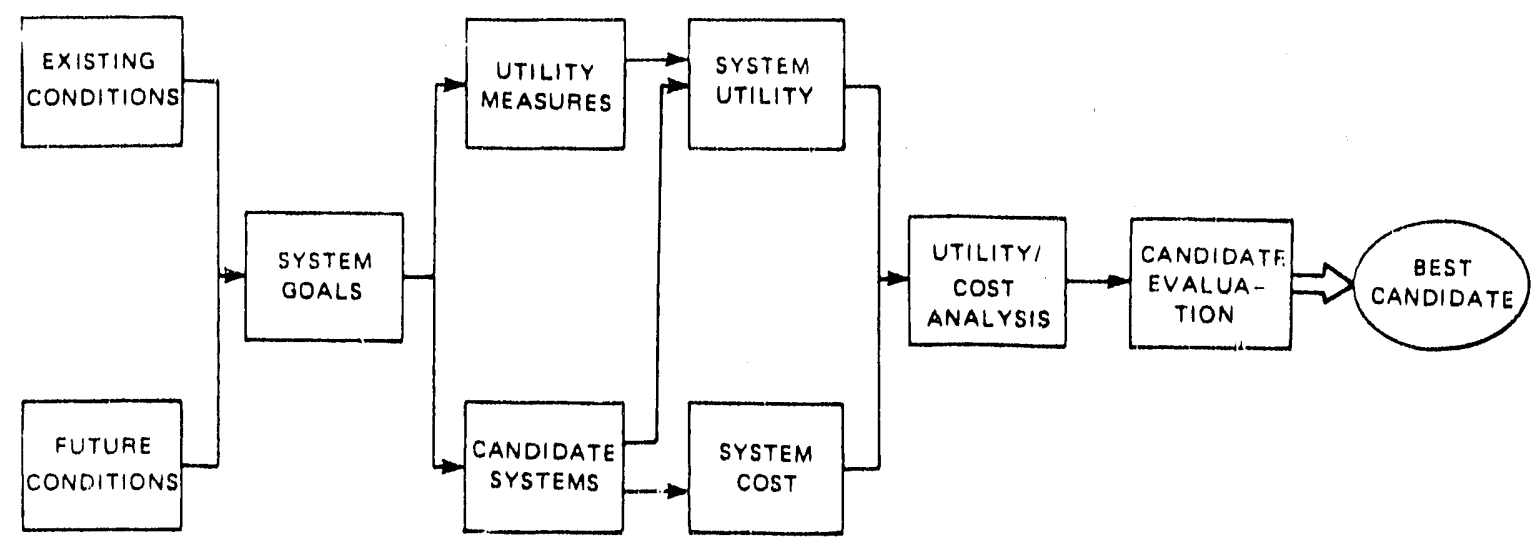

Source: Traffic Signal System Study: City of Baltimore, Summary Report; Peat, Marwick, Livingston \& Co.; February 1969 (Jack L. Kay Project Director)

Figure 4.1: Utility/cost procedure - flow chart

Source [3], p. 476 


\section{effectiveness.}

\section{2 .2 .2 Goal Welghting}

Two things must be established in the development of system goals. These are: (1) a uniform understanding of the full meaning of each goal statement, and (2) an awareness (consensus) of the importance of each goal relative to the other goals.

The assignment of relative priorities or weights must be based substantially on the judgement of the local personnel who bear responsibility for system performance, A popular, and effective, goal-weighting procedure is to have members of an advisory committee individually assign a portion of a set number to each of the various goals. Percentage points could be used, for example, where the sum of all goal weights equals 100 percent. The arithmetic mean of the committee member's assignments then determines the consensus of relative importance of each system goal. Goal weights actually used for urban streets with the above sample system goals are shown in Table 4.1.

\subsubsection{Deflnition and Welghting of Utility Measures}

As was previously stated, total system goals are too broad for detalled use. As a result, tach goal must be broken down into the individual items, or requirements, which make up the goals. These specific utility measures need to:

- be identified at a sufficiently detailed level to effectively identify the differences in system performance; and

- deal with both tangible and intangible 1tems.

With regard to relative weights, each item is obviously not of equal value, just as goals also have different values. It is likewise necessary to establish the relative importance of each utility measure within each goal. This is done in the same manner that goal. weights were established. As examples, summaries of goals, utility measures, and their relative weights $\ldots$ are shown in Table 4.2.

\subsubsection{Candidate Systems Rating}

After the candidate systems have been defined and the utility measure weights established, it is then possible to rate each candidate system with respect to each utility measure. The common practice is to use an internal rating scale of zero to 10 for each utility measure. A rating of 10 would indicate that the candidate fully satisfied the utility measure, whereas a zero ratio would indicate that the cardidate system had not met any of the requirements specified by the given utility measure. Ratings by several individuals would be averaged as before, in order to determine the consensus ratings for each candidate system with respect to each measure. This performance rating on each utility measure is then combined with the utility measure weight and individual goal weight to arrive at a single statement of ut Ilty for each candidate system.

This procedure is computationally illustrated by ... Table 4.3. 


\begin{tabular}{|l|c|}
\hline Goal & $\begin{array}{c}\text { Reludive weight } \\
\text { (percent) }\end{array}$ \\
\hline Traffic operations & $50 \%$ \\
Reliability & $20 \%$ \\
Adaptability & $14 \%$ \\
Implementation & $10 \%$ \\
Incidental benefits & $6 \%$ \\
\hline & $100 \%$ \\
\hline
\end{tabular}

Source: Traffic Signal System Study: Ciry of Baltimore, Summary Report;

Peat, Marwick, Ltwingston \& Co.;

February 1969 (Jack L. Kay Projoct Director).

Table 4.1: Relative weights assigned to system goals urban streets

Source: [3], p. 477 


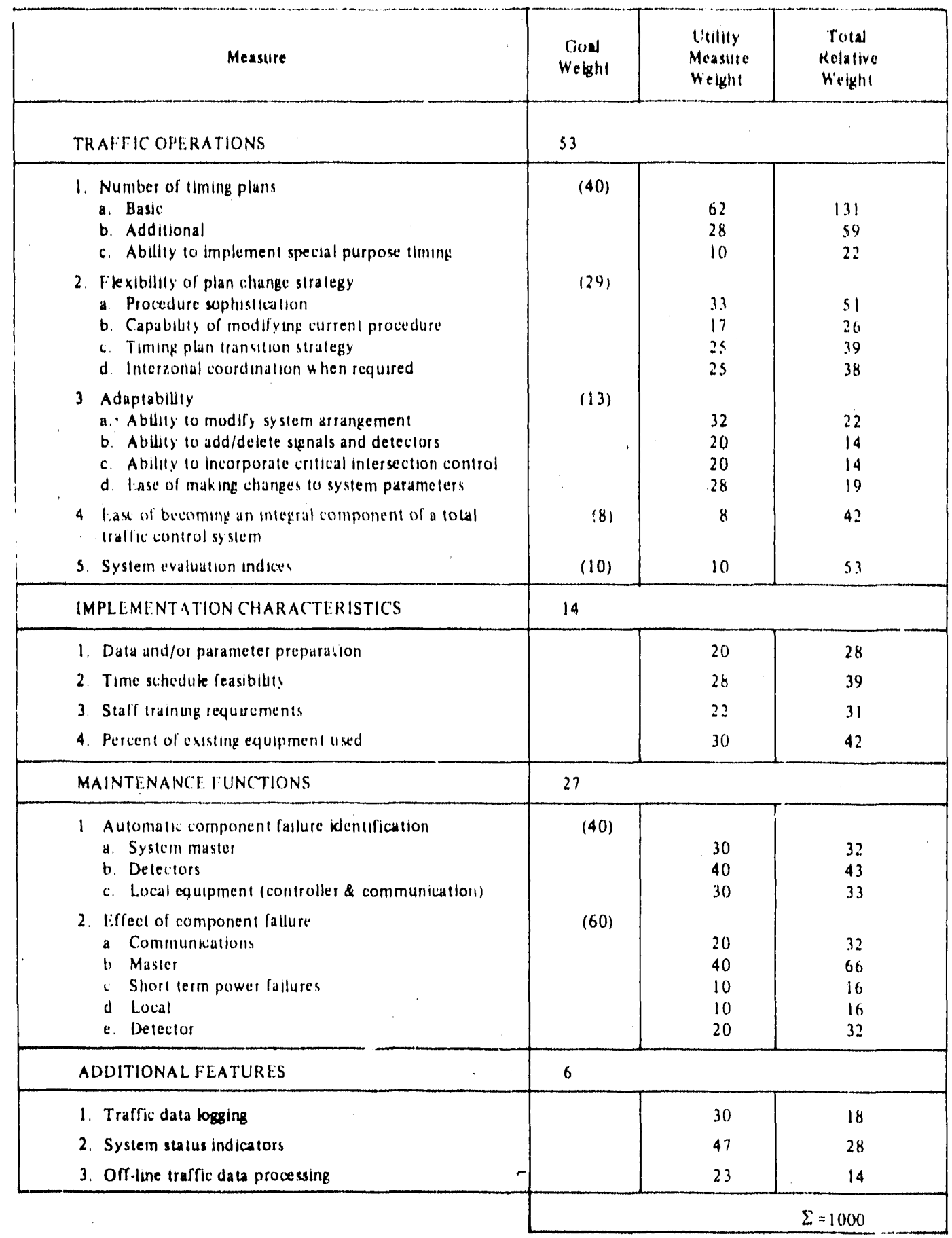

- Each 10 units equais one percent of total decisson, - . . . $131=13.1 \%$

Source. Kas. Jack L., "Cost L'tulty Analysis Precedure for Evaluating Allernative Systems," Instilute' a', Traffic Engincers. Compendurr of Papers, 42nd Annual Meeling. Neu York City, 1972, Page

141.

T'able 4.2: Relative utilit y Illasure woights

Source: [3], p. 479 


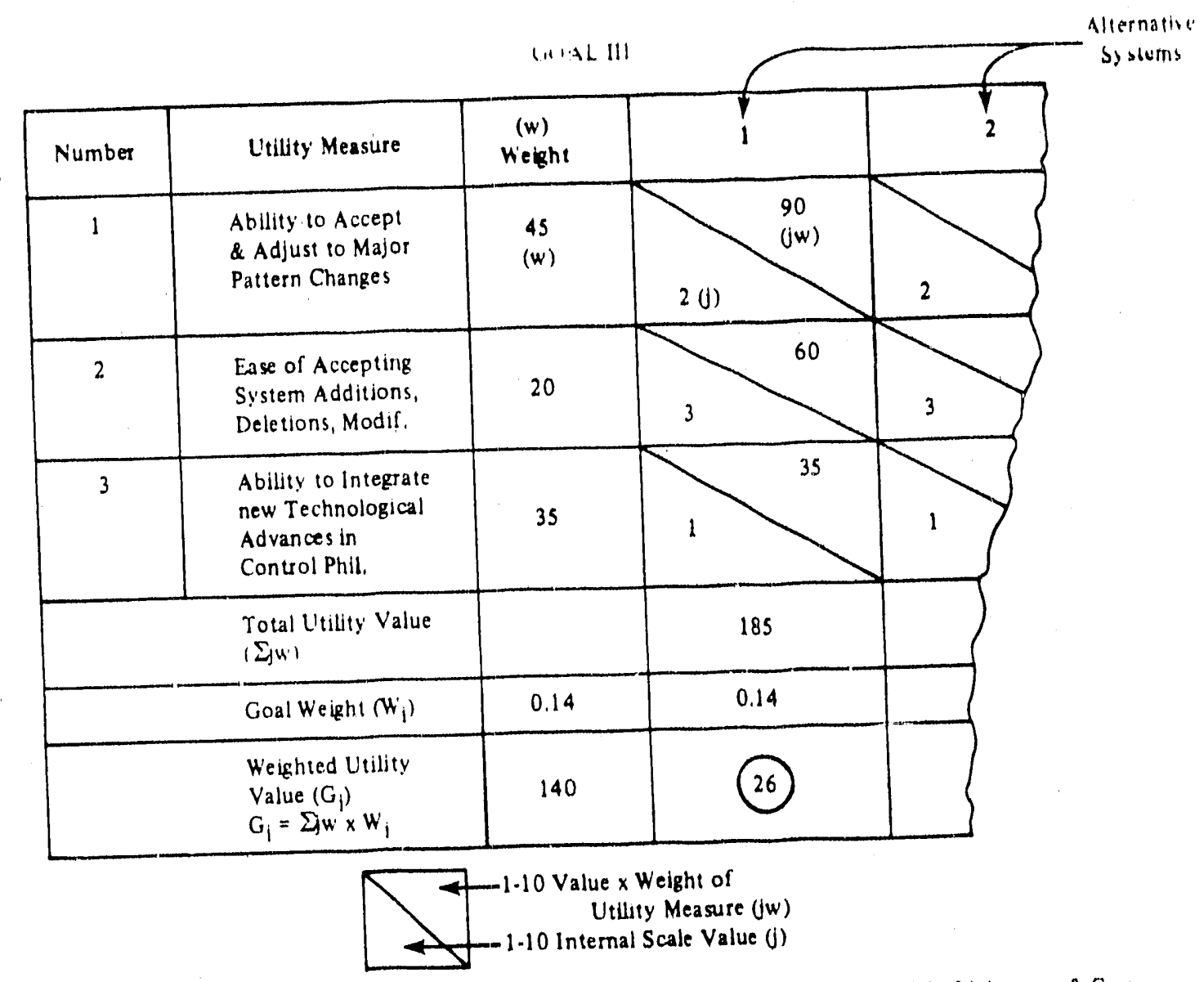

Source: Traffic Signal System Study: City of Baltimore, Summary Report: Peat, Marwick, Livingston \& Co.: February 1969 (Jack L. Kay Project Director)

Table 4.3: Sample ut ility rating procedure

Source: $[3]$, p. 480 
Where:

f - The internal scale value (rating assigned to each candidate system's fulfillment of the stated utility measure (usually represents the average of a number of individual raters))

w $\quad$ - Utility measure weight

$w_{1} \quad-$ Goal weight for goal $i$

$\mathrm{G}_{1} \quad$ - Weighted utility value for each candidate for goal 1

After all the weighted utility values for all goals have been determined, they are combined (as in Table 4.4) to give a total utility value for each candidate.

\subsubsection{Cost Analysis}

\subsubsection{Cost Elements}

The definition of candidate systems should be established to a level of detail which would permit a reasonably accurate estimate to be made of system cost. Care should be taken, however, to insure that all elements cf cost are taken into account. Such estimates would obviously include estimates of opexating, maintenance, and other associated costs. A check list of cost elements is shown in Table 4.5 .

Further, the cost estimates should encompass a significant portion of the anticipated system life - - perhaps 10 years. This technique would insure consideration of all system costs over time and prevent the making of faulty decisions in favor of low first-cost systems whose operation and maintenance costs ultimately could force total cost beyond acceptable bounds.

For purposes of comparison, it is necessary to recognize the time value of money and adjust estimated system costs to a common basis. The technique which converts future expenditures to an equivalent present worth is appropriate to use. For example, the reader might consider the candidate system cost estimate summary shown in Table 4.6. Annual expenditures for a number of items are shown and totaled for each year. To each annual cost is applied a present worth factor (pwf), for some assumed interest rate which converts future expenditures to the common basis of present worth.

\subsubsection{Sample System Costs}

The presentation of sample system costs is difficult. Experience has shown that a number of variable factors influence system cost. The reported systems costs have included a wide disparity of elements. Some projects, for example, have included signal indication hardware (poles, heads, etc.) along with the control system elements. Others have even included physical roadway improvements. Earlier systems were influenced by developmental costs and higher digital computer costs. Also, the bidder's desire to establish a market position may have influenced some projects' cost. Nevertheless, ...a cost summary for several. urban street traffic control systems is presented in 


\begin{tabular}{|c|r|r|r|r|r|r|r|r|r|r|r|}
\hline \multicolumn{1}{|c}{ Goal } & \multicolumn{9}{|c|}{ Candidate System } \\
\cline { 2 - 10 } & 1 & 2 & 3 & 4 & 5 & 6 & 7 & 8 & 9 & 10 \\
\hline I & Traffic Operations & 170 & 182 & 215 & 192 & 208 & 258 & 396 & 417 & 429 & 473 \\
II & Reliability & 89 & 94 & 97 & 81 & 133 & 97 & 109 & 128 & 130 & 142 \\
III & Adaptability & 26 & 26 & 35 & 35 & 38 & 74 & 96 & 112 & 126 & 140 \\
IV Implementation Characteristics & 100 & 98 & 75 & 75 & 40 & 62 & 47 & 41 & 16 & 10 \\
V Incidental Benefits & 8 & 8 & 14 & 6 & 14 & 30 & 46 & 48 & 54 & 60 \\
\hline
\end{tabular}

Source: Traffic Signal System Study: City of Baltimore, Summary Report; Peat, Marwick, Livingston \& Co.. February 1969 (Jack L. Kay, Project Director)

Table 4.4: Summary of system utility

Source: [3], p. 480 
CAPITAL COSTS

Field equipment

- Detectors

- Local controllers

- Cabinet

- Components

口 Modification units

- CCTV cameras and control units, housing, etc.

- Communications equipment

․ Telemetry equipment

- Conduits

- Cable (aerial, underground)

- Leased telephone lines

- CCTV control cable and signal cable

Central office equipment

- Central controller, analog or digital

- Peripheral devices

- Data storage

口 Disk

- Drum

- Magnetic tape

- Data logging

- Teleprinter

a High-speed printer

- Display

- Map display

口 CRT

- CCTV

- Operator's control panels
- 1/0 devices

- Teleprinter

口 CRT keyboard

- Card reader/punch

- Paper tape reader/punch

Software deve/opment/tailoring

OPERATING COSTS

Space

- Control center

- Equipment space

- Modifications necessary

- Environmental control (heating-A/C)

Electrical power

Staff

- Managers

- Operators

- Programmers

- Technicians

- Training

Supplies

- Paper, cards, tape, etc.

MAINTENANCE COSTS

Central office equipment

Communication equipment

Local controllers

Detectors

Software - operating systems

SPECIAL COSTS

Technical assistance

Design

Table 4.5: Cost element checklist

Source: [3], p. 608 


\begin{tabular}{|c|c|c|c|c|c|c|c|c|c|c|c|c|}
\hline & Item & $\begin{array}{c}\text { Year } \\
1\end{array}$ & 2 & 3 & 4 & 5 & 6 & 7. & 8 & 9 & 10 & Totsl \\
\hline 1. & Signal Operations & 10.5 & 10.5 & 10.5 & $10 \ldots$ & 10.5 & 10.5 & 10.5 & 10.5 & 10.5 & 10.5 & \\
\hline 2. & Master Maintenance & 20.0 & 20.0 & 35.0 & 35.0 & 35.0 & 35.0 & 35.0 & 35.0 & 350 & 35.0 & \\
\hline 3. & Flectronic Maintenance & 365.0 & 380.0 & 400.0 & 400.0 & 400.0 & 425.0 & 425.0 & 425.0 & 400.0 & $4(1) 0,0$ & \\
\hline 4. & Duct Rental & 50.0 & 50.0 & & & & & & & & & \\
\hline 5 & Interconnect Maintenance & 250 & 25.0 & & & & & & & & & \\
\hline 6. & Flectronic Construction & 15.0 & 15.0 & 15.0 & 15.0 & 150 & 15.0 & 15.0 & 15.0 & 515.0 & 515.0 & \\
\hline 7. & New Staff with Equipmenl & 35.0 & 35.0 & 3.5 .0 & 35.0 & 350 & 35.0 & 35.0 & 35.0 & 35.0 & 35.0 & \\
\hline 8. & Computer Masters & & 375.0 & 375.0 & & & & & & & & \\
\hline 9. & Added Detectors & 200.0 & 200.0 & 200.0 & & & & & & & & \\
\hline 10. & Added Operator \& Prog. & & & & & & & & & & & \\
\hline & Costs & 10.0 & 20.0 & 57.5 & 57.5 & 57.5 & 57.5 & 57.5 & 57.5 & 57.5 & 57.5 & \\
\hline 11. & Telephone Conn. Charge & 12.0 & 12.0 & & & & & & & & & \\
\hline 12. & Line Lease & 60.0 & 120.0 & 120.0 & 120.0 & 120.0 & 120.0 & 120.0 & 120.0 & 120.0 & 120.0 & \\
\hline 13. & Modify Local Cont. & 425.0 & 425.0 & & & & & & & & & \\
\hline 14. & Multiplex System & 350.0 & 350.0 & & & & & & & & & \\
\hline 15. & Technical Assistance & 150.0 & 150.0 & 100.0 & & & & & & & & \\
\hline 16. & Cont. for Master Reloc. & & & 25.0 & & & & & & & & \\
\hline & Total & 1727.5 & 2187.5 & 1373.0 & 673.0 & 673.0 & 698.0 & 698.0 & 698.0 & 1173.0 & 1173.0 & 11074 \\
\hline \multicolumn{2}{|c|}{ Present Value Factor $(6 \%)$} & $\overline{1.000}$ & 8.9434 & $\overline{0.8900}$ & $\overline{0.8396}$ & $\overline{0.7921}$ & $\overline{0.7473}$ & $\overline{0.7050}$ & $\overline{0.6651}$ & 0.6274 & $\overline{0.5919}$ & \\
\hline \multicolumn{2}{|c|}{ Present Value } & 1727 & 2064 & 1222 & 565 & 533 & 422 & 492 & 464 & 736 & 694 & 9019 \\
\hline
\end{tabular}

Use $\$ 9,000,000$

Source: Traffic Signal System Study: City of Baltimore, Final Report; Peat, Marwick, Livingston Co., licbruary 1969 (Jack L. Kay Project Director)

T'able 4.6: System cost analysis

Source: [3], p. 481 


\begin{tabular}{|c|c|c|c|c|}
\hline City & $\begin{array}{c}\text { Date } \\
\text { of } \\
\text { bid }\end{array}$ & $\begin{array}{l}\text { Number of } \\
\text { intersections }\end{array}$ & $\begin{array}{l}\text { Number of } \\
\text { detectors }\end{array}$ & $\begin{array}{c}\text { System bid } \\
\text { cost } \\
\text { (in dollars) }\end{array}$ \\
\hline Charlotte, N.C. & - & 174 & 55 & $\$ 1,250,000$ \\
\hline Baltimore, Md. & - & 900 & 1000 & $3,900,000$ \\
\hline Oklahoma City, Okla. & - & 33 & - & 133,572 \\
\hline Shreveport, La. & - & 256 & 500 & 762,000 \\
\hline L.A. County, So. Bay & - & 111 & - & 645,000 \\
\hline Denver, Colo. & - & 320 & - & 550,000 \\
\hline Atlanta, Ga. & - & 12 & - & 169,000 \\
\hline Savannah, Ga. & - & 97 & 101 & 758,000 \\
\hline Albany, Ga. & - & 60 & 60 & 670,000 \\
\hline Raleigh, N.C. & - & 154 & - & 661,000 \\
\hline Pasadena, Texas & - & 63 & 75 & 145,820 \\
\hline Phoenix, Ariz. & 1973 & 253 & 175 & 785,000 \\
\hline Lansing, Mich. & 1974 & 150 & 155 & 649,000 \\
\hline Tucson, Ariz. & 1974 & - & - & 528,000 \\
\hline Amarillo, Texas & 1974 & 133 & 94 & $1,751,723$ \\
\hline Greensboro, N.C. & 1973 & 159 & 227 & - \\
\hline Columbus, Ohio & - & 92 & 230 & - \\
\hline Laredo, Texas & 1973 & 65 & 40 & - \\
\hline
\end{tabular}

Source: [3], p. 612

Table 4.7: Reported costs of selected urban street traffic control systems 
Table 4.7. The potential value of these summaries is more to assist in arriving at first estimates of ballpark costs rather than pricing specific system elements. Detailed cost estimates must remain an individual project: activity, taking into account specific system needs and localized factors.

\subsubsection{Utility/Cost Analysis}

Ratings of candidate system utility can now be related to the estimated system cost to perform a comprehensive comparison of candidate systems. Based on data from the previously referenced ... urban street system study [7], the analysis procedure can be illustrated as follows:

- A cost summary of candidate systems (see Table 4.8);

- The system utility ratings (see Table 4.4); and

- Relationship of utility to cost for each candidate, in which the utility/cost ratio has been represented as the slope of a line from the origin point to the plotted point of system effectiveness (see Figure 4.2).

By simply dividing utility by cost, a ratio of performance per dollar invested can be calculated. This ratio for all systems is shown in Table 4.9, expressed as a decimal number. The greater the utility/cost ratio, or the closer the slope of the line to the utility axis, the more effective the system is shown to be. The conclusions drawn by Kay [9] for this example, which are presented below, are indicative of the type of analyses which can be made.... :

The best system in a simple utility/cost evaluation is the one with the highest ratio, in this case, System 4 has the poorest utility payoff per dollar invested. The analysis of utility/cost has greater impact, however, if alternates for investment are examined on a paired or three choice basis. By this technique, actual incremental utility/cost becomes more apparent.

In the Baltimore study, the City is committed to maintaining at least the present level of signal control. This results in the investment commitment shown as System 1. Alternate systems, then, should also be compared with System 1, not just the zero point from which the simple utility/cost analyses were performed.

Certain obvious conclusions can be made by inspecting [Figure 4.2] reflecting a typical analysis condition. System 5 appears to be a good choice for selection in that it offers greater utility than system 1 without increased cost. There are other candidates, however, which offer substantially greater improvement. As the purpose of considering a new system is to improve conditions as much as practical, it is doubtful that the small improvement offered by System 5 would be considered worthwhile.

System 2 is not a serious candidate in that it costs more than system 1 and does not offer significantly greater utility. System 4 is also not a good choice as it costs substantially more than systems 1 and 5 and offers less utility. System 3 is also not a good choice for investment. The utility/cost ratio for system 1 is 0.71 - the incremental utility/cost ratio from system 1 to 3 is only 0.31 . This ratio is less 


\begin{tabular}{|c|c|c|}
\hline System & $\begin{array}{c}\text { Tutal 10-yeat } \\
\text { expenditures } \\
\text { S millions }\end{array}$ & $\begin{array}{c}\text { Priwni } \\
\text { worth a 6\% } \\
\text { S millions }\end{array}$ \\
\hline 1 & 7.1 & 5.5 \\
2 & 7.6 & 5.9 \\
3 & 8.8 & 6.9 \\
4 & 8.3 & 6.5 \\
5 & 6.5 & 5.5 \\
6 & 9.3 & 7.3 \\
7 & 11.4 & 9.3 \\
8 & 11.1 & 9.0 \\
9 & 11.6 & 9.8 \\
10 & 13.3 & 11.3 \\
\hline Source: & Traffic Signal System Study: City of \\
& Baltimore, Summary Report; Peat, \\
& Marwick, Livingston \& Co.; February \\
1969 (Jack L. Kay Project Director)
\end{tabular}

Table 4.8: Cost summary - candidate systems

Source: $[3]$, p. 482 


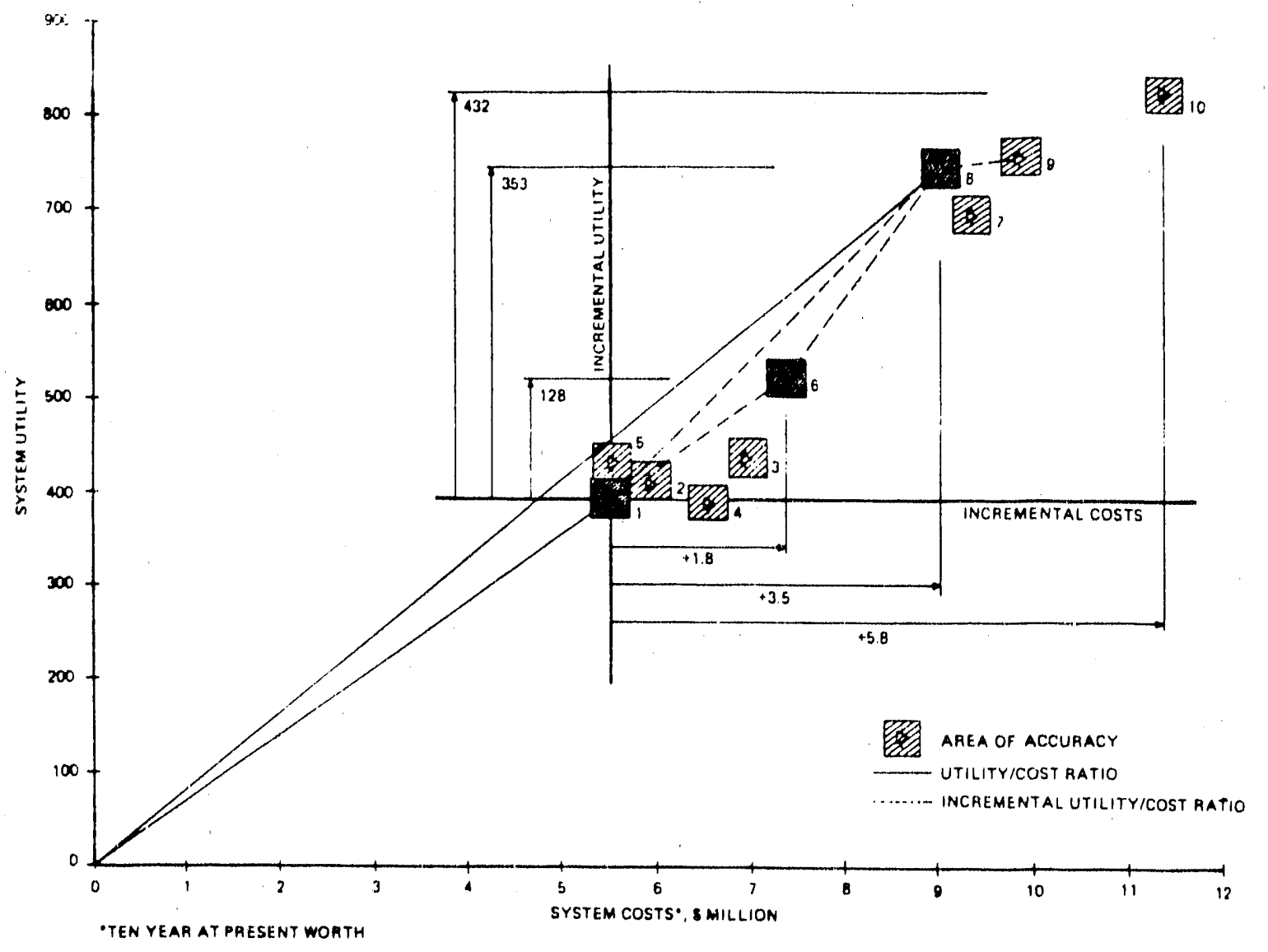

Figure 4.2: Utility/cost comparison of candidate systems

Source: 3$],$ p. 483 


\begin{tabular}{|c|c|}
\hline System & Lility icost ratio \\
\hline 1 & 0.71 \\
2 & 0.69 \\
3 & 0.63 \\
4 & 0.60 \\
5 & 0.79 \\
6 & 0.71 \\
7 & 0.75 \\
8 & 0.83 \\
9 & 0.77 \\
10 & 0.73 \\
\hline
\end{tabular}

Source: Traffic Signal System Study:

City' of Baltimore, Summary

Report; Peat, Marwick, Livingston

Co; February 1969 (Jack L. Kay

Project Director)

Source: [3], p. 484

Table 4.9: Computed utility/cost ratios 
than 50 percent as good as the rate of return on the existing system.

Candidate system 6 is a possible choice for investment. Its utility/cost ratio is essentially the same as the existing and the incremental utility/cost ratio from 1 to 6 is 0.72 or approximately equal. to the rate of return on the existing system.

Candidate System 7 is not a good choice for further consideration. It costs more than System 8 and offers less - it would be 1llogical to invest in System 7 when System 8 is available.

The next system to be considered, system 8 , appears to be an excelient: candidate for investment. Its absolute utility/cost ratio of 0.83 is the best of all candidates considered. The incremental utility/cost ratio between System 1 and 8,101 , is also good. This ratio indicates that the incremental investment required to go from system 1 to 8 provides a rate of return of 143 percent of that of investment in system 1 .

Systems 9 and 10 do not offer good opportunities for investment even though their absolute utility/cost ratios are better than that of the existing systems. Their incremental utility/cost ratios from system 8 are 0.11 and 0.34 , respectively. These incremental ratios are less than 50 percent of the rate of return of the existing investment and less than 34 percent of the incremental rate from System 1 to System 8 . In other words, Systems 9 and 10 are acceptable alternates when compared to System 1 but not when they must compete with System 8 .

Given the choices of Systems 6 and 8 , the next step is to determine if the incremental utility of System 8 over System 6 justifies the added cost. System 6 had an incremental utility/cost ratio from system 1 of 0.72 or approximately the same ratio of return on investment as system 1 . This indicates that every added dollar spent to go from system 1 to system 6 buys added utility and that the utility is gained at a rate equal to or slightly better than that offered in a continuing investment in system 1.

The earlier analysis of System 1 versus System 8 indicated that every dollar invested to go from 1 to 8 bought utility at a ratio of 143 percent that of the rate of return for System 1. The incremental utility/cost ratio from System 6 to 8 is even more meaningful. This ratio, 1.32, represents an improvement in rate of return of 183 percent over the rate gained in going from System 1 to 6 .

In the example utility/cost comparison, it is apparent that System 8 best meets the overall needs, based on a comprehensive definition of total. system utility. [9]

\subsection{System Selection Process.}

Total dependence on the utility/cost analysis results for system selection decisions is not recomended. Rather, the primary strength of this analysis approach lies in its orderly consideration of all factors which influence system preference. Also, the utilization of the technique provides a basis for communication among decision-making individuals who possess varied technical and interest backgrounds. The use of the results as an indicator of 
system preference, rather than as an absolute evaluator, is to be preferred.

In the decision-making process, those systems with higher utility/cost: ratios should be given primary consideration. Second, the incremental ratios between candidates shoild be considered. Finally, regardless of the ratios, the selected system must provide sufficlent added benefit over the existing system to warrant implementation. Likewise, the proposed system must not he so costly that it cannot be funded.

The final selection of a single traffic control and survelliance system is the culmination of a rather lengthy and detalled process. The various steps of this process and the relationship of various sections of ... this ... process are illustrated in Figure 4.3. 


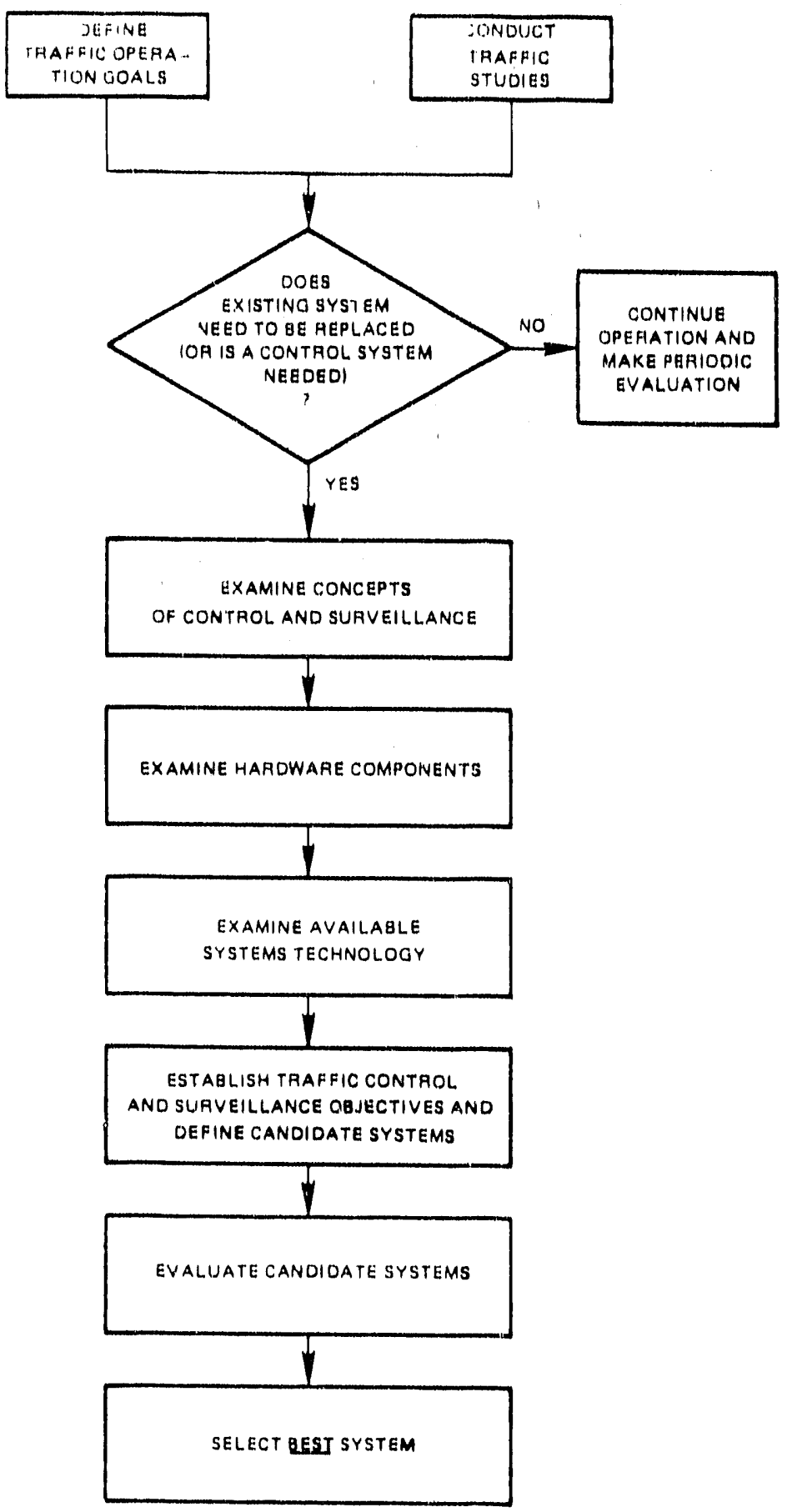

Figure 4.3: System selection process

Source: [3], p. 485 


\section{5,0 SUMMARY, CONCLUSIONS, AND RECOMMENDA'ITONS}

This report has presented a set of criterla which can be used to select replacement and upgrading options for exlating traffic signals. It has also portrayed a methodology which can be used to determine which one might best sult the needs of a specific setting. Section 2.0 provides a description of the options which are avaliable; Section 3.0 gives recommenclations as to which ones are ap ropriate for specific network settings; and Section 4.0 describes a methodology which can be employed to select the best option from among a group of competing alternatives.

Our conclusion is that the criteria and methodology should be troublefree, but they have not been tested in a real-world setting, except to the extent that they can be regarded as an extension of the best thinking of several traffic engineering experts. It: remains to be seen whether the criteria will be trouble-free when used in the field.

In light of this fact, our recommendation is that a future profect should test the criteria under real-world conditions, to ensure that they are trouble-free.

Another recommendation is that the criteria be distributed to a more widespread audience for review and comment. While this is not the same as testing the criteria in a real-world situation, the feedback would be helpful in eliminating any obvious oversights that may have occurred.

Finally, a simulation analysis, based on NETSIM, of the traffic settings and treatment options specified in Table 3.1 would be a useful exercise. This would represent the laboratory equivalent of applying the criterla to a realworld situation. The simulations could be done in parallel with or in place of the real-world tests. Such a profect would be less expensive, but it might also lack some of the real-world insight that is generated by a fleldbased application. 
(1) Bulman, D.H. (1972), "Cost Ut11tty Experlence in the New York state TOPICS Program," Institute of Traffic Erigineers. Compendium of Papers, 42nd Amnual Meeting, New Yor:k, NY, pp, 145-150.

(2) Erdman, J.W., (1973), "Procurement of a Control System for the City of Baltimore," Institute of Traffic Engineers. Compendium of Techinlcal. Papers, 43rd Annual Meeting, pp. 135-141.

(3) Federal Highway Adinintstration (1976), Traffic Control Systems Handbook, U.S. Department of Transportation, Washington, DC.

[4] Federal Highway Administration (1983), Traffic Control Devices Handbook, U.S. Department of Transportation, Washington, DC.

[5] Grant, E.L., and W. G. Ireson (1970), Principals of Engineering Economics, Fifth Edition, The Roland Press Company, New York, NY.

[6] Institute of Transportation Engineers (1987), Traffic Control Systems Handbook, Publication No. L.P-123, Washington, DC.

[7] Kay, J.L. (1969a), City of Baltimore, Traffic Signal System Study: Final Report, prepared by Peat, Marwick, Livingston, \& Co., Washington, DC.

[8] Kay, J.L. (1969b), Clty of Baltimore. Taffic Slgnal system Study: Summary Report, prepared by Peat, Marwick, Livingston, \& Co., Washington, DC.

[9] Kay, J. L. (1970), "Signal System Studies: A New Approach," Traffic Engineering, Vo1 40, No, 4, pp. 24-31.

[10] Kay, J.L. (1.972), "Cost Utility Analysis Procedure for Evaluating Alternative Systems," Institute of Traffic Engineers. Compendium of Papers, 42nd Annual Meeting, New York, NY, pp. 137-144.

[11] Stockfisch, C.R. (1972), "Guidelines for Computer Signal System Selection in Urban Areas," Trafflc Engineering (December 1972), pp. 30-63.

[12] Tarnoff, P.J., and P.S. Parsonson (1981), Selecting Traffic Signa]. Control at Individual Intersections, National Cooperative Highway Research Program Report No. 233, Transportation Research Board, Washington, DC.

[13] Winfrey, R., and C. Zellner (1971), Summary and Evaluation of Economic. Consequences of Highway Improvements, National Cooperative Highway Research Program Report 122, Transportation Research Board, Washington, DC. 


\title{
STATE-()F-THE-AR'T \\ TRAFFIC CONTROL SYSIEMS
}

\author{
Final Report
}

Prepared by

JAMES H. KELL AND ASSOCIATES

118-35 Queens Boulevard

Forest Hills, NY 11375

\author{
Prepared for \\ NEW YORK STATE \\ ENERGY RESEARCH AND DEVELOPMENT AUTHORI'TY \\ Project Manager \\ Norine H. Karins
}

1)33-EEED-AEP-88 
TABLE OF CONTENTS

$\underline{\text { Page }}$

1.0 INTRODUCTION $1-1$

2.0 TIME BASED COORDINATION SYSTEMS $2-1$

3.0 ON-STREET MASTER SYSTEMS 3-1

Pre-Timed On-Street Master Systems 3-1

Microprocessor Based On-Street Master Systems 3-2

Hardware 3-5

4.0 MICROCOMPUTER BASED DISTRIBUTED SIGNAL SYSTEMS , $4-1$

Overview $4-1$

System Components $4-5$

Local Controller $\quad 4-5$

On-Street Master $\quad 4-6$

Central Microcomputer $\quad 4-6$

Cornmunications $\quad 4-7$

System Capabilities $\quad 4-10$

Hardware $\quad 4-12$

5.0 COMPUTER-BASED CENTRAL MASTER SYSTEM $5-1$

Overview $5-1$

System Components $5-3$

Local Intersections $5-3$

Communications $\quad 5-5$

Telemetry $\quad 5-6$

Media $\quad 5-6$

Interface Hardware $\quad 5-8$

Cent-al Master $5-8$

Computer $\quad 5-8$

Interface Devices $\quad 5-10$

Display Devices $5-10$

Systern Capabilities $\quad 5-12$

Off-the-Shelf $\quad 5-12$

UTCS $5-15$

1.5 and 2nd Generation Control 5-18

3rd Generation Control $5-19$

Centralized Systems with Distributed Control Features $\quad 5-21$ 


\section{List of Figures}

Page

Figure 1 - Schematic Comparison of Basic Traffic Control Systems

$1-3$

Figure 2 - Microprocessor Based on-Street Master System

$3-4$

Figure 3 - Computer Based Distributed Signal Systems Closed Loop Concept

$4-2$

Figure 4 - Schematic of Distributed System

$4-4$

Figure 5 - Communications Link Between Subsystem Master and Local Controllers

$4-8$

Figure 6 - Graphic Representation of Time Division Multiplexing

$4-9$

Figure 7 - Schematic of Central Computerized Traffic Signal System 
james h. kell \& associates

\section{Tables}

Page

Table 1 - Typical Capabilities of Time-Based Coordination Units $\quad 2-4$

Table 2 - Capabilities of Distributed Signal Systems 4-14

Table 3 - System Diagnostics Common To all Distributed Systems 4-15 
james h. kell \& associates

\section{Exhibits}

Page

Exhibit A - System Features Common to Centralized

Computer-Based Systems

Exhibit B - Sample "ENHANCED" Oil Command 


\subsection{INTRODUC'TION}

This report is a product of the investigation of candidate systems that provide improved coordination of traffic signals. The systems described are considered state.. of-the-art and representative of generic control philosophies. The four (4) generic concepts addressed in this report are:

\section{- Time Base Coordination Systems \\ - On-Street Master Systems \\ - Microcomputer-Based Distributed Master Systems \\ - Computer-Based Central Master Systems}

The generic concepts are functional descriptions with a focus on operational characteristics -- what the system does and how it operates. A schematic comparison of the concepts is provided in Figure 1.

For consistency, the following definition of terms are used within this report:

\begin{tabular}{|c|c|}
\hline Actuated Controller & $\begin{array}{l}\text { - a traffic signal controller that responds to varying } \\
\text { traffic demands from vehicle and pedestrian detectors }\end{array}$ \\
\hline Coordination & $\begin{array}{l}\text { - a definite timing relationship between signalized } \\
\text { intersections }\end{array}$ \\
\hline Cycle length & $\begin{array}{l}\text { - the length of time required to sequence all of the signal } \\
\text { indications of the intersection }\end{array}$ \\
\hline Data Base & $\begin{array}{l}\text { - data constants and parameters generally used by } \\
\text { computer type devices in execution of a control or } \\
\text { analysis function }\end{array}$ \\
\hline Offset & $\begin{array}{l}\text { - the time difference, usually expressed in percent (*) of } \\
\text { cycle, from the beginning of main street green for one } \\
\text { intersection to the beginning of main street green for } \\
\text { an adjacent intersection }\end{array}$ \\
\hline Pre-timed Controller & $\begin{array}{l}\text { - a traffic signal controller that allocates the langth of } \\
\text { the various signal phase times in a premetermined } \\
\text { manner }\end{array}$ \\
\hline
\end{tabular}


- all electonic circuitry devoid of moving parts or vacuum tubes

Split

- a division of a cycle length allocated to each of the various phases. Usually expressed as a percent of the signal cycle. 


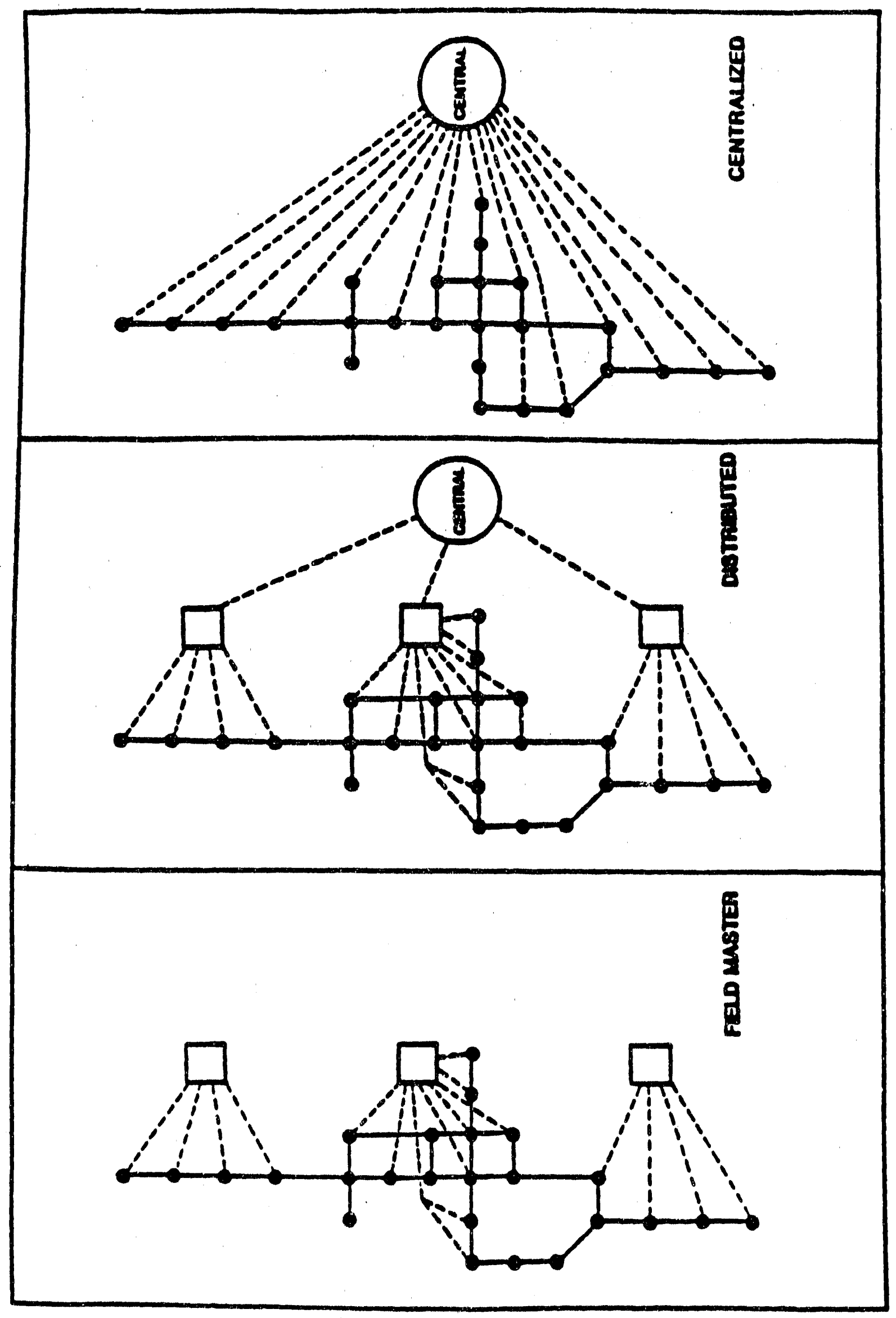

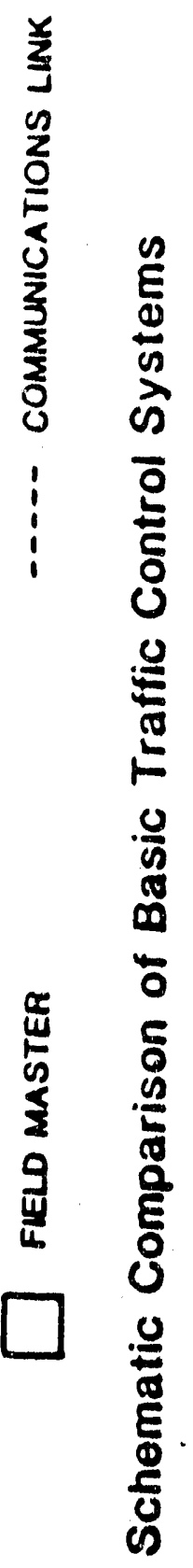

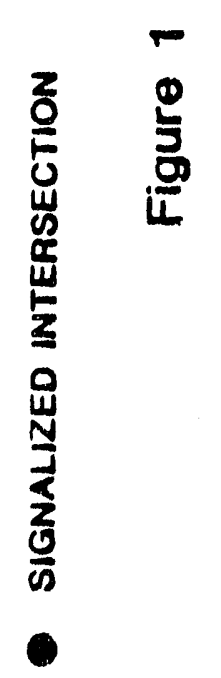




\subsection{TIME BASED COORDINATION BISARIDE}

All traffic signal systeins, regardless of their sophistication and complexity, have the same basic purpose - to provide a common time reference for all traffic signal controllers, thereby permitting the coordination of the controller's operation. One method of achieving this time reference is to simply start several very accurate clocks simultaneously, place each clock in a controller cabinet and interface each clock to the controller such that a synchronization pulse that is generated periodically by the clock is passed on to the controller. In essence, this is time-based coordination in its most primitive form.

This concept is not new, in fact, time-based coordination was the initial method used to achieve traffic signal synchronization. This was accomplished by installing synchronous motors to control the dial unit of pre-timed electromechanical controllers. With the use of synchronous motors, the timing dials on all of the controllers rotate at the same speed, thus providing the same cycle length throughout the network. By utilizing a stopwatch and a switch to start or stop the controller inotor of each local controller, desired offsets were achieved at each inter section.

The basic problem with the synchronous system just described was that it was limited to a single timing plan. Furthermore, this timing plan was lost whenever a power failure or major voltage fluctuation occurred. Thus, the system was unreliable and required considerable maintenance in the form of signal of fset resetting. This led to the development of wire interconnection systems that enabled local controllers to be operated as a system.

Because of the significant costs of interconnection in complex signal systems, many municipalities have turned to the time-based coordination concept. With modern hardware, each local intersection is equipped with time-based coordination (either internal or external) which has been programmed to implernent different timing plans at different tirnes during the day. The coordinator uses the power frequency provided by the local electric company as its time base. When power failures occur, a backup battery drives the time-based coordinator until power is restored. Some devices have the capability to operate on battery power for several days. These solid state devices are accurate time keepers, and because of their relationship to the power company 
frequency, they keep the individual controller operating in a coordinated manner with a good deal of accuracy.

A major characteristic of time-based coordination is that each local inter section is a completely independent entity that is totally dependent upon a time clock (electronic circuit) for proper operation. It does not allow for any surveillance of feedt ick information, thus there is no way to verify that the system is operating as programmed, short of a field review at each intersection. Furthermore, any timing plan or schedule changes must be accomplished at each individual location.

While the clocks are accurate when operating on the power line frequency, there are potential drift problems when they operate on backup battery power. A typlcal standby accuracy specification is 0.005 percent, or one-half second per day. Obviously a one-half second error is very small and normally quite acceptable for infrequent power line outages once the controller has been installed. The problem occurs when signal settings are installed in the shop several days before the time-based coordination unit is placed in service. These errors in timing are cumulative and can result in significant coordination problems. The offsets in particular are subject to this error.

Another problem is the difficulty of programming the time-based coordination units. This is partially offset by the ability to transfer data between units. However, if programming was as simple as advertised, then time-based coordination units would be reprogrammed frequently. Because of the time required, and the potential for error, this is not typically done.

On the positive side, tirne-based coordination offers the capabilities of multiple timing plan selection and special function device selection without the expense of hardwire interconnect. A number of different timing plans may be selected, a transition process provides for switching between plans, semi-actuated operation is available, it is possible to flash the signal or to turn special signs on and off, and it is even possible to change the signal's phasing -- all according to a time-of-day, day-ofweek schedule input by the user.

The most significant advantage of time-based coordination is that no hardwire interconnection links are required. Consequently, this type of system has been installed where the costs of interconnection seemed prohibitive. 
There are numerous manufacturers of time-based coordlnation unlts within Nor th Ainerica. Since there is no "standard" for these units, each manufacturer has Implemented the concept with different features. For example, whlle all time-based coordination units provide the necessary synchronization pulse, the number of timing plans and other outputs vary between manufacturers. A summary of the typlcal capabilitles of these varlous units is provided in Table 1.

There are two basic types of time-based coordination hardware: external and internal. Manufacturers of external time-based coordinators include the four (4) examples of TBC's used in this report:

- Setcon Model 601 IMS

- Sonex Model ZDC

- Traffic Control Technologles (TCT) Model LTC

- Winko-Matic Model TC-75

Two different models are typically provided by these manufacturers: one for pre-timed controllers and one for actuated controllers. These units, which interface with the controllers via connections at the controller cabinet backpanel, utilize standard outputs (e.g., Dia! 2, Dial 3, Offset 1-3, etc., for pre-timed controllers; FORCE OFF, YIELD, HOLD, PHASE OMIT, etc., for actuated controllers) to supervise the oparation of the controller.

The cost of the se units vary from a low of $\$ 700.00$ to a high of $\$ 3,000.00$ each, exrlusive of installation. 
TABLE 1

FUNCTION

Time of day clock

day program events

day programs

week programs

exception days

cycle/of fset/split plans

$D C$ voltage inputs

AC voltage inputs

Force off output

phase hold output

phase omit output

ped. phase omit output

signal cycles

phase splits

offsets/cycle

permissives

force offs

Largest cycle

shortway of fset

dwell of fset

interrupter of fset

printout of da ta

up/down load data

daylight saving time

internal battery backup

disconnect on failure

interna! dlagnostics

security code
SETCON SONEX TCT WINKO-MATIC

$99 \mathrm{yr} \quad 99 \mathrm{yr} \quad 99 \mathrm{yr} \quad 99 \mathrm{yr}$

$\begin{array}{llll}200 & 100 & 200 & 199\end{array}$

$\begin{array}{llll}16 & 10 & 15 & 16\end{array}$

$5 \quad 10 \quad 10 \quad 5$

\begin{tabular}{lll|l}
30 & 10 & 35 & 30
\end{tabular}

\begin{tabular}{lll|l}
$9+$ & 16 & 30 & 96
\end{tabular}

$\begin{array}{llll}8 & 12 & 12 & 8\end{array}$

$\begin{array}{llll}8 & 22 & 8 & 0\end{array}$

yes yes yes yes

yes yes yes yes

yes yes yes yes

yes yes yes yes

$\begin{array}{llll}4 & 16 & 4 & 4\end{array}$

$\begin{array}{llll}4 & 16 & 4 & 8\end{array}$

$3 \quad 16 \quad 3 \quad 3$

$2+666$

$\begin{array}{llll}6 & 8 & 8 & 12\end{array}$

$255 \mathrm{sec} .255 \mathrm{sec} .255 \mathrm{sec} . \quad 255 \mathrm{sec}$.

yes yes yes yes

yes yes yes yes

yes yes yes yes

no yes yes yes

yes yes yes yes

yes yes yes yes

yes yes yes yes

yes yes yes yes

yes yes yes no

yes yes yes yes 


\section{Internal to the controller TBC}

Many of the modern trafflc signal controllers offer tlme-based coordination features. These features are secondary attributes of the controllers and the software developed for the controller.

Manufacturers of inlcroprocessor-based controllers with optlonal Interna! timebased coordination capabillties include:

- Econollte KMC Series

- Trafflc Control Technologles LC Serles

- Eagle EPAC 300 Serles

- Traconex TMP-390

Additionally, Type 170 controllers, when provided wlth the approprlate flrmware, also possess internal time-based coordination capabillties.

The following chapters discuss this concept In further detall as a function of their respective systems.

The cost of the se units including cablnet and normal accessories varles from a low of $\$ 3,000.00$ to a high of $\$ 12,000.00$ each. 


\subsection{ON-STREET MASTER SYSTEMS}

On-Street master systeins consist of a master controller located at a slgnallzed Intersection which imposes a control regime on a serles of adjacent signallzed intersections whlch are interconnected by hardwire communication links. This type of system is typically used to control a CBD grid network or a major arterial street within an urban area. For area-wide coverage of an urban area, more than one onstreet master system is typically required.

There are two basic types of signal systems currently avallable that utllize this concept: (1) electro-mechanical pre-timed and (2) microprocessor-based. They differ significantly in their respective capabillties and degree of sophlstication as the following section indicates.

\section{Pre-timed On-Street Master Systems}

This system, which utilizes pre-timed electromechanical or solid state controllers all operating on the same background cycle length, maintains coordination by an offset synchronization pulse that is transinlted by the master controller once per cycle. In general, up to twelve slgnal timing plans are avallable, consisting of four cycle leng ths (four dials), and three offsets per cycle. Also, from one to four splits per cycle are avallable, depending on the type of controller. The selection of dials and offsets is accoinplished automatically through the use of a time clock at the master.

The communications system consists of a hardwire network whlch connects the master to each of the local controllers. Communications are generally accomplished by $A C$ voltages or more sophisticated techniques which activate functions such as cycle length, offset or phase spllts. In the most basic systems, each circult/function is assigned to a single interconnect conductor, thus multi-conductor cable is required to support the system. This interconnect wiring originates from the master and is generally connected to the same function for each of the local controllers.

There are major advantages assoclated with pre-timed on-street master systerns, particularly in terms of rellabillty, maintainabillty, and cost. This technology has been in existence for many years, and its reliabillty and maintenance requirements are well known. 
The relative simpllclty of this type of system also creates certain disadvantages. It is not responsive to changes in trafflc flow, since timing plans are selected solely on a time of day, day of week, (TOD/DOW) basis in accordance with the settings on it mechanical or solid-state time clock. Manual override of the TOD signal plan selection for holldays or special traffic problems can be effected only by visiting the master controller location.

Pre-timed, on-street master systems also have llmited flexibility. Each systein within an urban area operates independently of the others, so rellable coordination between adjacent groups is not possible except through the use of time-based, coordinated master time clocks which must be field checked periodically for accuracy. Changing timing plans is not dlfficult, but it is time consuming because offsets, splits, and cycle lerigths must be changed at each controller. Auxlliary functions are typically llimited to setting the signals on flash and turning signs on and off on a system-wide basis.

Pre-timed, on-street master systems have historically utllized three-dial electromechanical controllers. Newer systems utillze solld-state digital pre-timed controllers. Actuated controllers may also be incorporated into pre-timed systems. Each local actuated controller is connected to a coordination unit which supervises the controller's operation to maintain synchronization of the signals. The coordination units are coordinated with the master in the same manner as in the pre-timed controllers, and provide yleld Inputs to the controller at prescribed times to allow it to respond to side street traffic demands without disrupting the progression on the main street. The coordination wilits may be thought of as pre-timed controllers issuing commands to the actuated controllers forcing it to operate on a fixed cycle.

\section{Microprocessor-Based On-Street Master Systems}

Microprocessor-based on-street master systems operate basically on the same principle as thelr pre-timed counterparts described above. However, these on-street masters are also capable of traffic responsive signal plan selection via a vehicle detection subsystem, in addition to TOD/DOW. Older systems typically use analog computers and electromechanical controllers to provide rudimentary flexibillty.

The advanced traffic responsive systems are designed primarily for use on arterials, although some systems can be used in small grid networks. Sampling detectors are used on the arterial to measure traffic flows. Slgnal timing data are set 
at each local intersection. Minimum green periods, actuated extension periods, and clearance intervals are typically set on the local controller. Maximum split, offset, and cycle lengtius are set on an internal or external interface/coordination unit. Electronic signals are received from the on-street master. These signals provide the synchronization leference time and select thi timing plan (split, of iset, and cycle length) to be in effect. A flow diagram of a typical microprocessor based on-street master system is shown in Figure 2.

A major function of the on-street master is to select the timing plan, which is typically a combination of cycle, offset, and split. The typical master employs a control technique of "cycle and offset selection". With the addition of roadwayinstalled detectors to measure traffic flow, the system has a means of comparing the need to change timing plans as a function of actual conditions. The system has preset within it a limited number of timing plans that can address the needs of various traffic flows. As traffic flow levels change throughout the day, the various associated timing plans can be brought into operation by the master controller in response to these changing conditions.

The master selects a cycle length based upon threshold logic assigned by the system operator. This logic typically uses demand indicators such as volume, occupancy, speed or density to select longer or shorter cycle leng ths based on actual traffic conditions. Additionally, the master also determines which direction has the heaviest flow in order to establish a preferential offset in the direction needed. Each cycle length commonly has a pre-determined split associated with a particular cycle length.

The common aspects of all plan construction schemes is that cycle length, splits and offsets are chosen independently, based on threshold logic using traffic demand as measured by sampling detectors. The number of available tirning plans depends on the system manufacturer. Typical capabilities include 3 to 6 cycle lengths, 3 to 5 offsets, 3 to 4 splits, 12 to 20 sampling detectors, plus flash and free operation and special functions,

Communications between the master and each intersection can be accomplished using multi-conductor cable or voice grade telephone lines (jurisdiction-owned or leased) using either low or high voltage signals ( $A C$ or $D C$ ) or tones. These communication lines typically consist of AWG $\$ 22$ or larger gauge twisted wire pairs. In the case of voice tone types of communications, one or two pairs comprising a channel are connected to individual intersections, although a single channel can be 


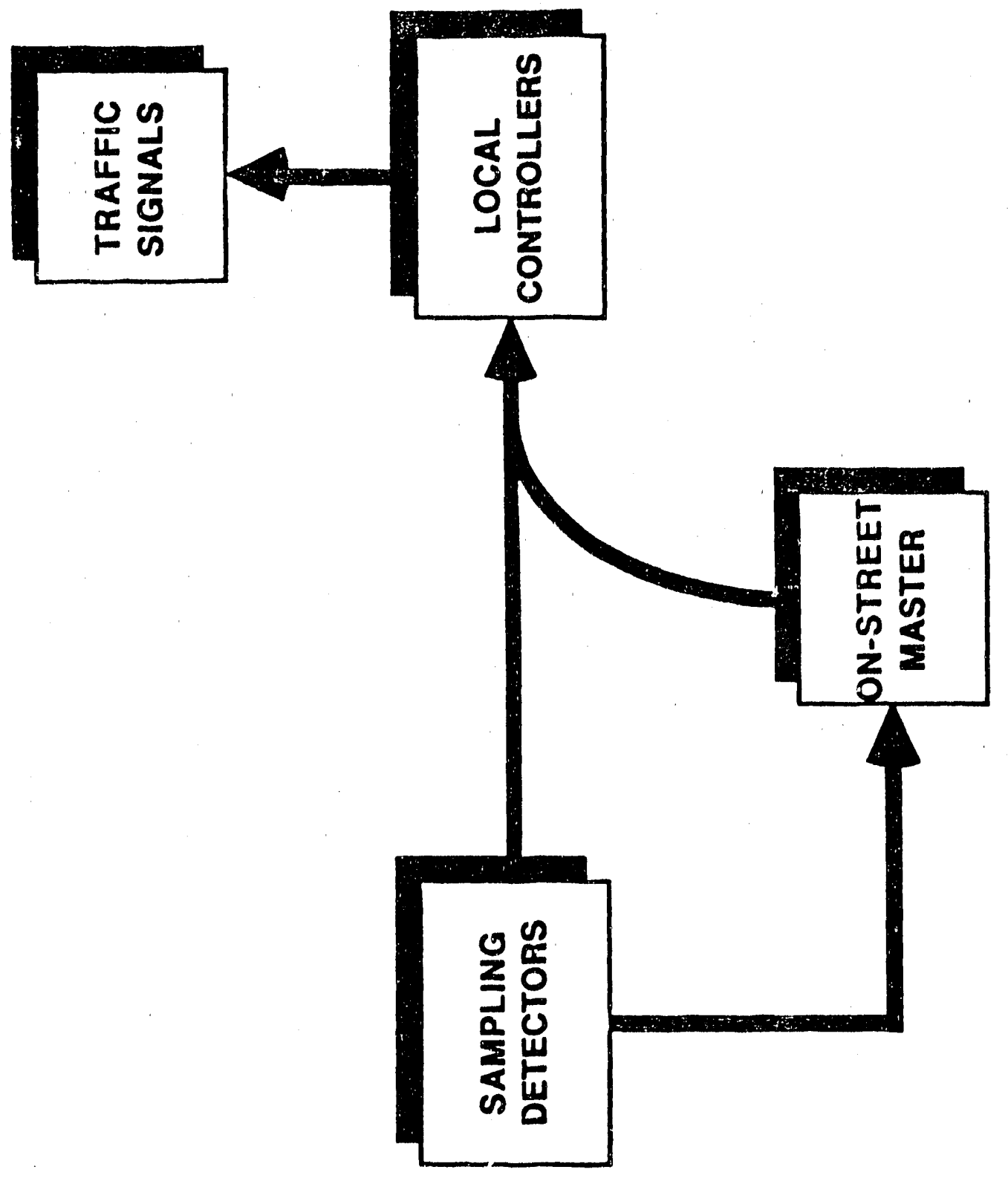

OV 
configured to control as many as twenty intersections. By the addition of internal modules in some systems, the master can be used with Time Division Multiplexing, Frequency Shift Keying (TDM/FSK) communications, which is detailed in Chapter 4. As an example, from the master to each local controller, the data transmitted includes a synchronization pulse, as well as dial, split, and offset selections. The only data typically transmitted from the field to the master are detector pulses from the sampling detectors.

With most systems, manual commands can be entered at the master to override TOD signal plans and call timing plans for special events or for adverse weather conditions. This external command capability also allows the master to be used as a submaster, relative to another field master, thereby providing the means for coordinating intersections controlled by different masters. However, this more compiex configuration of operation is not extensively practiced.

The master may also contain logic to identify a continuous call from a detector, flag the detector as failed, and exclude the failed detector data from subsequent calculations. Other than this rudimentary form of error correction, minor malfunctions of the hardware and erroneous signal timing data can only be detected by on-site observations of the local controller and master hardware. Furthermore, all changes to signal timing plan parameters and traffic responsive threshold values must be accomplished on-site at the local intersection and/or the master.

\section{Hardware}

Most major manufacturers of $t_{1}$ affic signal control hardware offer microprocessor-based, on-street systerns. Some examples include:

$\begin{array}{ll}\circ & \text { Eagle MARC } \\ \circ & \text { Econolite KMC-10000 } \\ \circ & \text { TCT MiOO } \\ \text { L LFE Automatic KB200 }\end{array}$


- Traconex HMM 200

- Transyt 3800

Costs for a basic system excluding the insiallation and interconnect communications wiring is $\$ 10-15,000.00$ per intersection. 


\subsection{MICROCOMPUTER BASED DISTRIBUTED SIGNAL SYSTEMS}

\section{OVERVIEW}

This type of system is closely related to the one that uses a microprocessorbased, on-street master, but has significant enhancements that provide a number of benefits. Specifically, distributed systems provide the following capabilities that, until recently, were exclusive attributes of larger-scale, centralized, computer-based systems including:

- The ability to change traffic signal timing parameters from a central location;

- The ability to monitor local hardware operation and identify hardware failures from a central location;

- The ability to monitor traffic flow data and visually display traffic flow movemients on color graphics consoles.

As described in the previous section, on-street master systems are essentially "open loop systems" - data is transferred from the sampling detectors to the master and then to the local controller, but little to no feedback is received from the local controller back to the master, or from the master to the traffic engineer's office. Thus, the communications between the control hardware and the traffic engineer is not complete, hence an open loop. (Refer to previous Figure 2.)

A distributed signal system, unlike an on-street master system, has a central microcomputer as part of the control hardware. This addition of the central microcomputer "closes the loop" in the system's communications. Data is transferred from the sampling detectors to the master via the local controllers; the local controllers and sampling detectors report to the central microcomputer via the master; and the central microcomputer transmits information to the master and to the local controllers (via the master). A flow diagram for this process is shown in Figure 3 . 


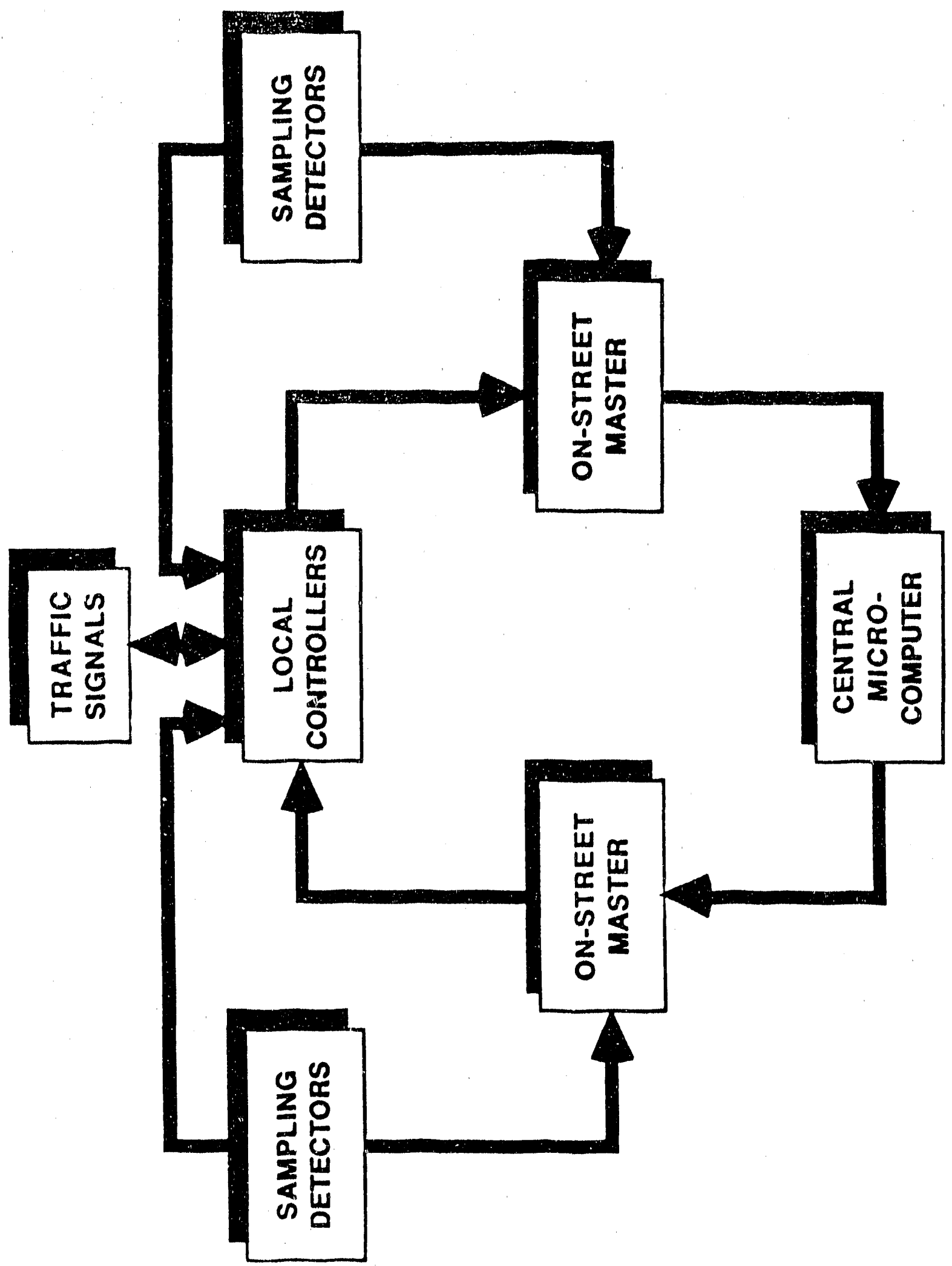


These closed loop signal systems are often referred to as ihlerarchical distributed" systems because the system logic and decision making capabilities are distributed among three major levels, or hierarchies, as follows:

\section{- Local Controllers/Supervisor \\ - On-Street Masters \\ - Central Microcomputer}

Distributed signal systems have become possible as a result of the recent developments in microprocessor-based controllers and personal computers. Microprocessor technology in both the on-street masters and local controllers has allowed new techniques in interfacing, system monitoring, and data processing.

In addition to the three levels of control, the communications links and sampling detectors make up the distributed system concept. Figure 4 shows a typical closed loop system equipment configuration. A digita! signal is transmitted from the onstreet master to the local controller which provides it with a complete timing plan for that intersection. This mode of operation is referred to as "downloading". The controller locally computes transitions and implements the timing plan until a new pliii is received. A system synchronization signal is also provided as required. In the case of a master or communications failure, the local controller will either implement one of several standby plans (a time-based coordination feature) or cont inue to use the existing plan.

A microcomputer is furnished at a central site to monitor the field located masters and to permit adjustment of system timing parameters from a single location. The microcomputer can also be utilized for interrogating the local controllers ( $v$ ia the on-street masters) to ascertain the tiring parameters which are stored in the controller's memory. This is referred to as "uploading". 


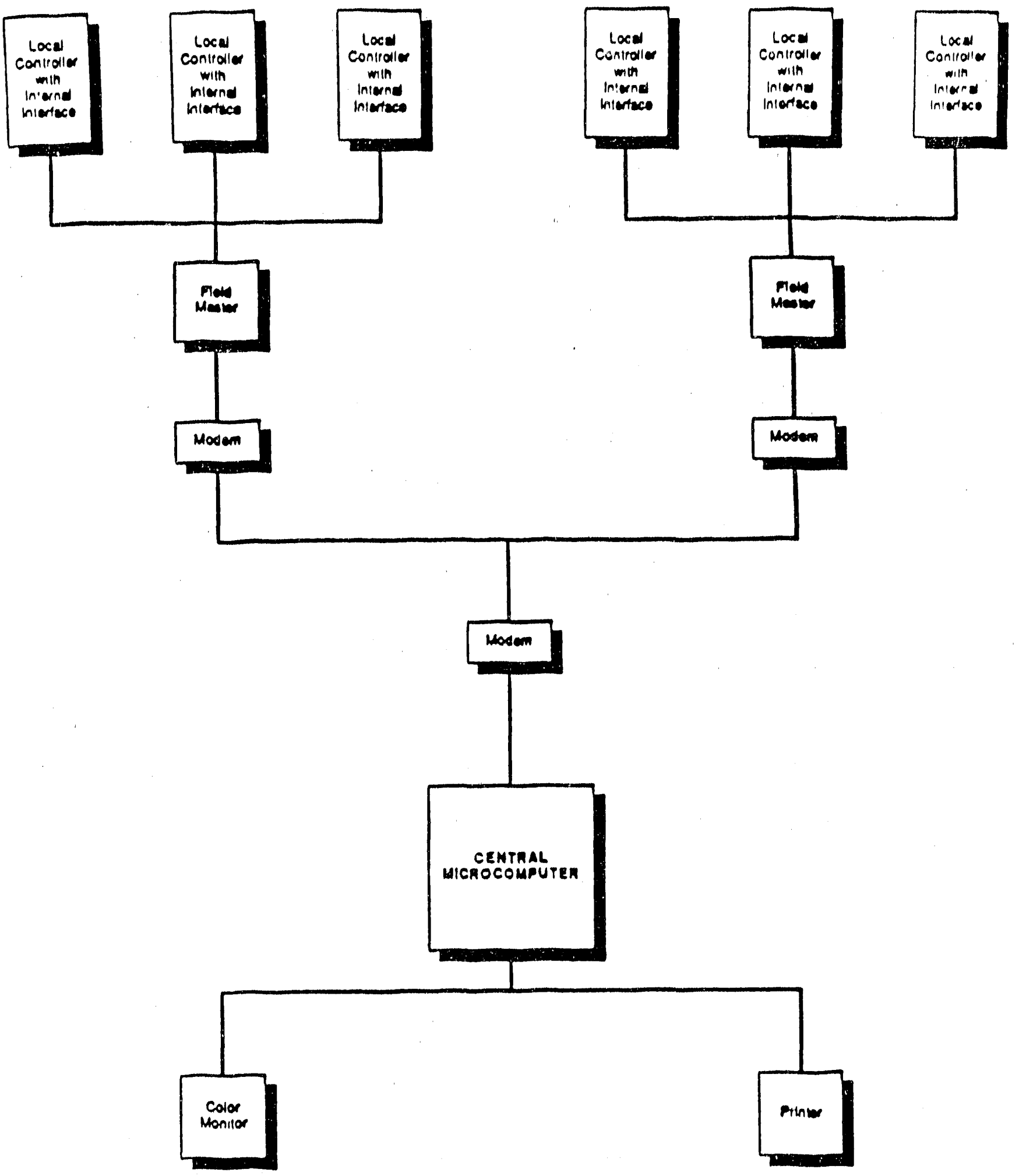

Flour 4 SCHEMATIC OF DISTAIBUTED SYSTEM 


\section{SYSTEM COMPONENTS}

The various control levels of a distributed signal system (l.e., local controllers, on-street masters, central microcomputer) and the communications links are discussed as follows.

\section{Local Controller}

The local controller provides the first level of control. It is typically a microprocessor-based actuated device which generates signal displays at the intersection according to the signal timing plan in effect, and collects and processes data from sampling detectors. The local controller receives commands frorn the master via a coordination/interface unit.

The coordination interface unit takes the electronic output transmitted by the master and converts it into commands for the local controller. The coordination/inte, face unit is capable of storing several timing plans, and is equipped with a time-base coordination feature. Time-base coordination, synchronized with the master and/or the central microcomputer, provides back-up timing plan capability in the event of a communications loss or a failure at a higher level (e.g., on-street master). Although the features and capabilities of the coordination/interface units vary from manufacturer to manufacturer, their functional concepts of operation are similar, and many have programmable memories to increase their flexibility.

Most manufacturers of distributed systems provide an internal coordination/interface unit consisting of a module (or modules) which are inserted into the controller's frame. In addition to generating timing plan functions and providing time-based coordination backup capabilities, these internal interface units also permit downloading and uploading of all timing parameter data - that is, in addition to system tirning parameters (e.g., cycle, split, offset), controller settings such as MIN GREEN, WALK, YELLOW, MAX, etc., which may also be modified and monitored from a remote location. A major drawback of internal coordination/interface units is that each one is designed and constructed to operate with a specific controller. This makes the system proprietary in that it becomes tied to a single controller model for the initial installation as well as subsequent expansions.

It is noted that at least one closed loop system provides an external coordination/interface unit. These external interface devices are designed for use 
with many types of controller equipment. However, they have fewer capabilltles than their internal counterparts. For example the external local supervisor generates timing plan functions; but time-based coordination, downloading/uploading of controller parameters (e.g., min green, yellow, walk, etc.) and certain survellance functions may not be provided. Most of the distributed systems currently on the market, however, do not provide external interface units. In these systems, the internal device must be utilized along with the specific controller model for which it was designed and constructed.

\section{On-Street Master}

The on-street master is the focal point of a distributed signal system. All commands from the central facillty flow through the masters to the local controllers. The on-street master or subsystem master provides the approprlate electronic output to supervise the local controllers, and performs all system monitoring functions.

The on-street master is a microprocessor-based device that has the ability to select and implement signal timing plans. The signal timing plans can be scheduled to occur on a TOD/DOW basis, in response to current traffic conditions as measured by sampling detectors (traffic responsive) or selected manually. Other functions of the subsystem master include transmission of downloaded timing parameters to local controllers, and monitoring of local intersection operation and sampling detectors to identify equipment failures. Most masters also have the ability to store the detector data and performance information to generate reports on existing traffic conditions, system status, and measures of effectiveness, in addition to failure reports. The master will transmit this information to the central microcomputer as required.

\section{Central Microcomputer}

The central microcomputer is typically an off-the-shelf personal computer such as the IBM PC and is located in an office environinent. The central microcomputer communicates with the on-street master(s), which then function as an intermediary for data transfer between the central microcomputer and the local controllers.

The central microcomputer does not control the system, per se, but serves as a clearinghouse for information. Data on any signalized intersection in the systern can be requested at the central microcomputer. The central control rquipment receives, 
processes, and displays data from the on-street masters on traffic flow conditlons and system performance. The downloading of all operating parameters to the on-street masters as well as local Intersection timing data may be accompllshed from the central facillty. The timing data are typically disk resident at the central facllity and are formatted and then downloaded vla the communications network. The system software provides error checking on the modifled data. The central microcomputer also provides fallure messages and generates system reports, and issues a system-wide time reference.

In addition to the microcomputer, the central facillty is also typically equipped with a monochrome or color monitor, a medium speed printer, a floppy disk drive, a hard disk drive, and approprlate communications inter faces and modems.

\section{Communications}

The communications network of a distributed system consists of two elements: a central to on-street master link, and an on-street master to local controller link. Communications between the on-street master and local controller normally consists of a two-pair (four-wire) full duplex channel. This channel is common to the master and each intersection as shown in Figure 5. One pair of the channel is used for transmitting information from the master to the controllers. The other pair is utllized for transmitting from the local controllers to the master. The communications media may be jurisdiction-owned cable or leased circults from the telephone company. (Note: Broadband communications are possible, but are generally not used for this type of system.

The telemetry typically utilizes TDM/FSK (Time Division Multiplexing/Frequency Shift Keying) methods to communicate at a rate of 1200 baud (bits per second). Frequency shift keying is the binary form of frequency modulation (FM) in which the frequency of the transmitted carrier is varled to represent elther a 0 or 1. Time division multiplexing divides the channel into separate and distinct time slots as shown in Figure 6. Each time slot is generally occupled by a message for a single controller, and each device connected to the circuit is given a unique address. A polling technique is used to designate the intended reciplent of a given packet of data even though the message containing specific controller data is received by every 


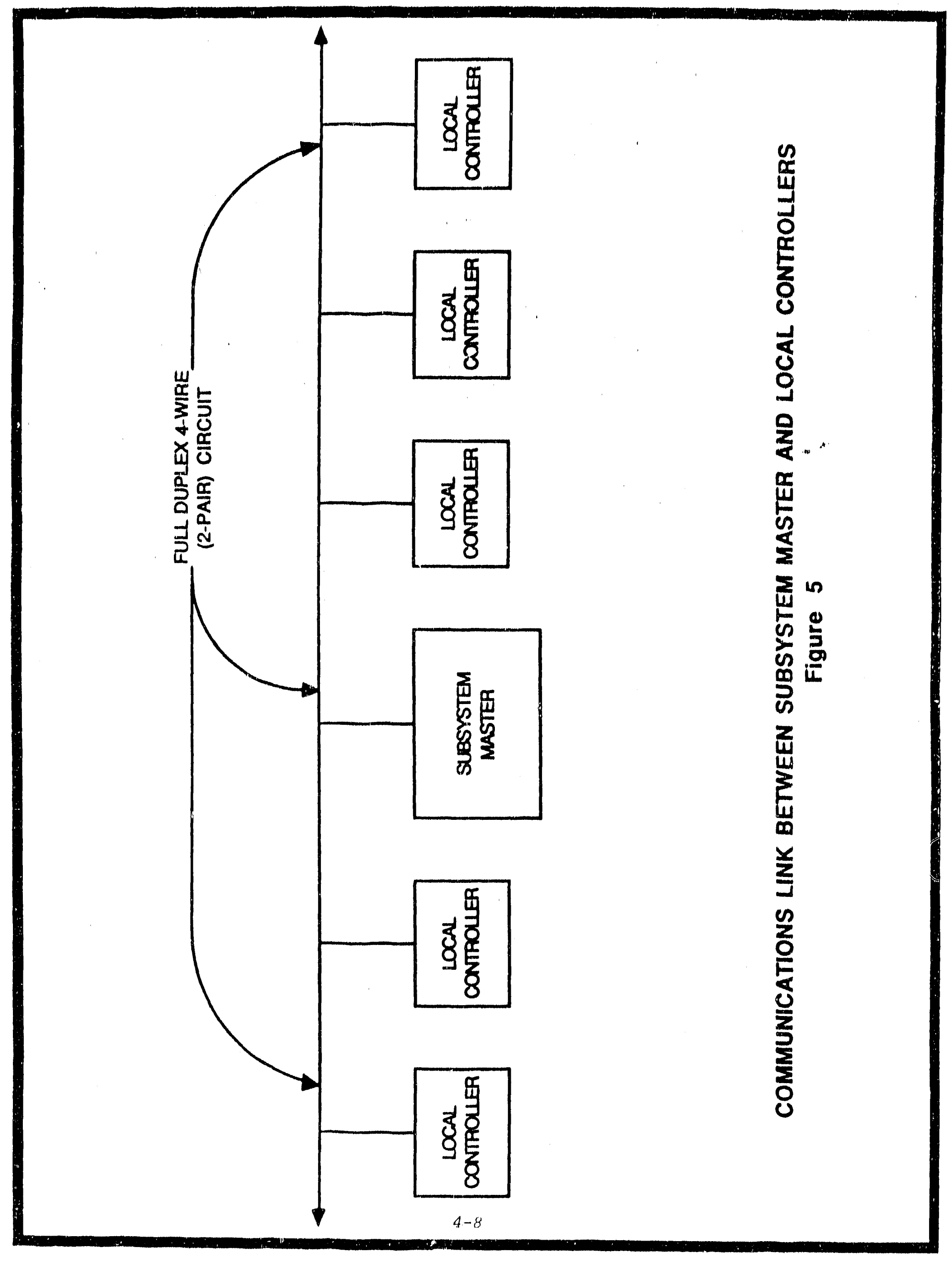




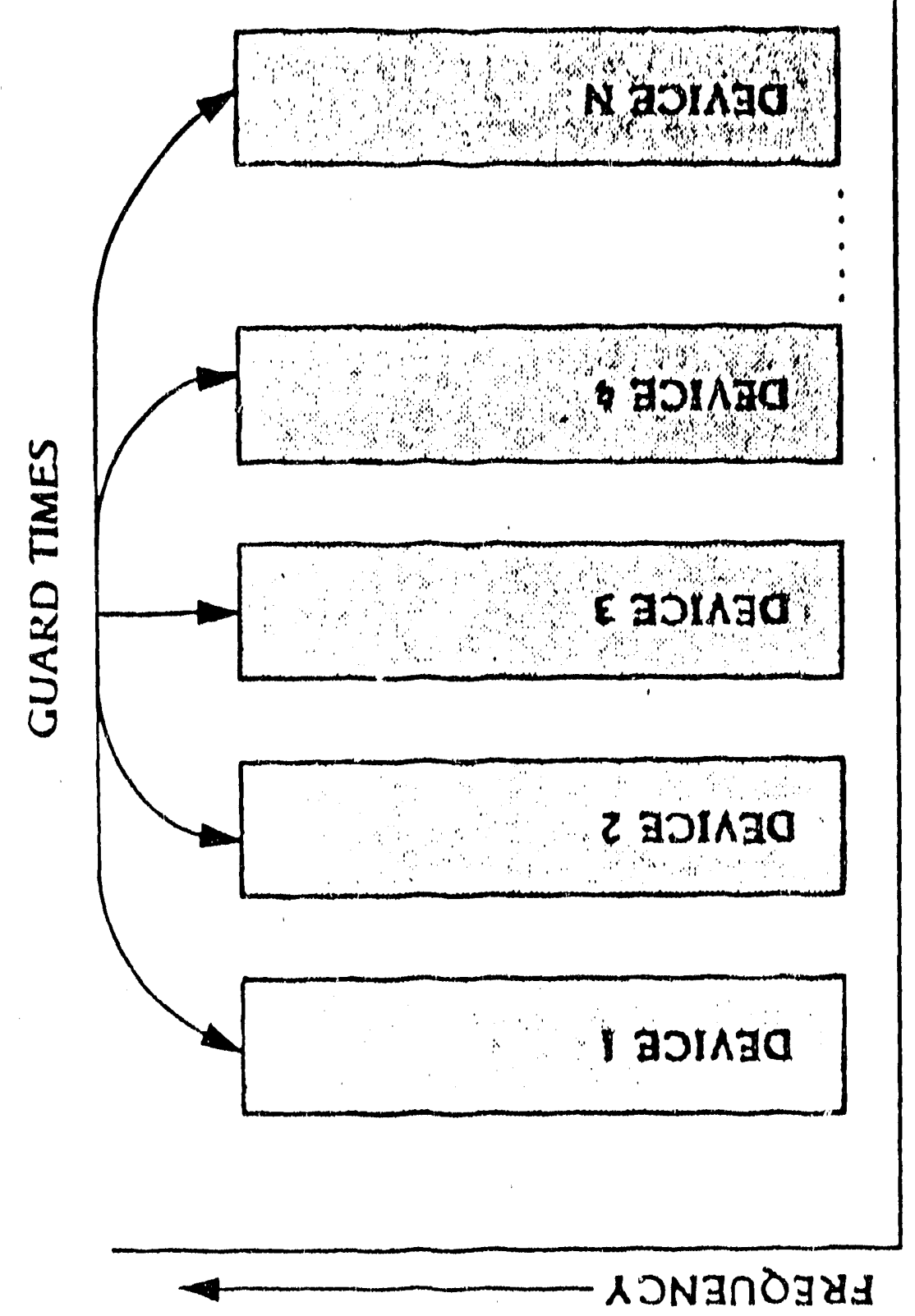

4

$\frac{1}{2}$
$\frac{1}{4}$
$\frac{1}{5}$
$\frac{2}{2}$
$\frac{2}{0}$
$\frac{2}{0}$

$\infty$

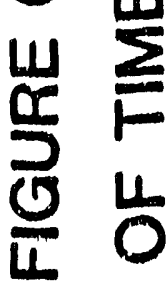

$\frac{2}{6}$

5

II

$\infty$

UI

罟

a.

c)

()

$I$

a.

$\alpha$

$\alpha$

$(5$ 
local controller on the line. The local controller responds only If its address matches the message address. Communications between the master and all local controllers typlaally occur on ance-per-second basis.

Communlcation between the subsystem masters and the central microcomputer occurs on an as-requlred basls; for example, where there is a need to modlfy timing plan parameters, Interrogate local controllers, or recelve Information on system malfunctions or survelllance data. The communlcations link consists of a standard touchtone or pulse dlal telephone line -. one (1) lline for each subsystem master. Autodial modems are utllized at the central facillty and at each on-street master to establlsh the communication link as requlred for the transmission of data. Dedicated cable pairs may also be utllized in lieu of leased dlal-up clrcults.

\section{System Capabilities}

The capabllities of distributed signal systems vary slightly between different manufacturers. The characteristics of these closed-loop systems are summarlzed in Tables 2 and 3 at the end of this section. As prevlously noted, one key feature of this system concept is the ability to make changes to system parameters from a central facillty. In fact, changes can be made from any place having a telephone. This capabilliy is best illustrated by way of an example.

Suppose the intent is to change the interval lengths for phase $A$ at Intersection 16. The procedure would be to edlt a flle stored in the central microcomputer. ine edit procedure would assure that the new or changed values would be within an acceptable range specillic to each lnterval (e.g., yellow intervals less than 3 seconds would not be permitted). Once the change is mads in the the, the on-street master would be called using automatic dial-up communications software and modems. When the connection is made, the new Interval lengths, contained in the recently edited data file, is transmitted to the on-.street master. After receiving the new timing data, the on-.street master automatically transters the data to the approprlate local controller.- In this case, the controller at Intersection 16. The total time required to download the data once the file is edited and the connection made is a few seconds.

Tobin asured that th ? timing datat wers transferred correctly, the engineer may wish to verify local tirning. lo do this, he/she would establish telephone contact and recuest that the dala trom a local interention be: transmitted back to central. The

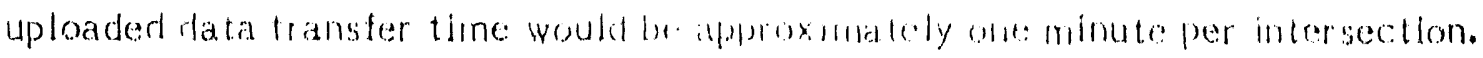


The reporting of failed field equipment at the central facility is another capability of distributed signal systems. The failure of a local detector amplifier can bi used as an example. The on-street master or local controller may continually r.unitor each primary detector looking for two conditions -.. no activity or maximum presence. If either condition is found, the detector is then noted as having failed. When a detector failure, or any identified hardware failure, is noted, the on-street master automatically dials the central facility to report the failure. The master continues to call until a connection is completed. Similar error detection is available for sampling detectors, telemetry, and controllers.

Jith distributed systems, field equipment monitoring actually occurs at the master or local controller levels. The system depends on field equipment to detect failure conditions and to relay this information on to the central microcomputer. This "closed loop" approach is a significant improvement over simple on-street systems yet is not as thorough as a central system's since the central microcomputer must rely on the field equipment to report failures. For example, a system configureci with multiple masters may miss failure conditions associated with individual masters if inbound communications are disrupted. This condition may go unnoticed until an operator tries to manually initiate communications.

Other fearures and characteristics of distributed signal systems include:

- Communication cable requirements and costs are reduced when compared to centralized systerns by preprocessing data and by concentrating data transmission.

- These systems have a high level of lail-safe capability. With the time-base coordination capability at the local intersections, an onstreet master or the central microcomputer can malfunction with little or no disruptive affect on traffic flow.

- The "building block" structure provides for greater implementation flexibitiy, but with corresponding operating inflexibility and limitation. That is, signal groupings are "fixed" by the communications cable routing and connections to the on-street master controlling the signal group. Regrouping of signals requires field chang:- to the communications network which may not be practical oncr the initial configuration has been installed.

Multiple permissive periods (variable YIELDD) are provided.

The amount, detail and presentation formis (e.g., status, failures, log, traffic fle system information a, measures of effectiveness, et-.) are limited as compared ... cen ralized systems.

$$
4-i i
$$


- Coordination between signal groups is limited.

- Management of a system which includes more than three or four masters can be difficult due to the single user nature of the system.

- The storage and manipulation of data at the central microromputer is burdensome with a large system (i.e., 100 or more intersactions). The response time is also leng hed with a large system since only one master can communicate with the central microcomputer at any given time.

- Large scale maps (or system and area wide displays on a color monitor) remain in the exclusive domain of the centralized systems. A distributed system has neither the communications network nor the processing capability required for a real-time large-area display. However, since each intersection green is monitored by the on-street master, it is possible to display real-time green returns on a color graphics monitor from a single intersection. That is, all intersections in the system can be displayed, but the display is limited to one intersection at a time.

\section{Hardware}

Functionally, all distributed signal systems are similar. A major dichotomy exists, however, in their mechanization. Most systems available today are offered by controller manufacturers. These manufacturers have developed unique proprietary hardware and software. After each system is initially installed, the same hardware or some form of an adaptor must be used in any future expansion. This in turn, limits future competitive procurement. Suppliers of proprietary systems include:

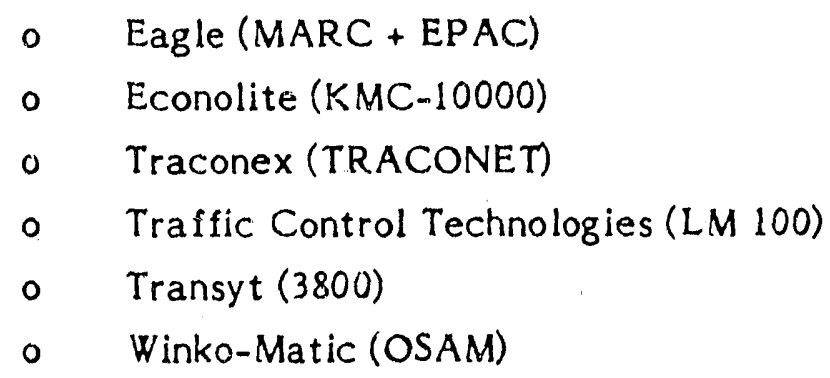

As previously noted, most of the se systems are functionally dependent on the use of an internal interface module. Thus, each system is essentially tied to a single controller model. In fact, only Transyt currently prorides a stand alone inter face unit for integrating with other NEMA solid state controllers. This unit then allows 
downloading/uploading of data that includes system coordination parameters (but not controller operational parameters). On the positive side, some manufacturers (e.g., $\mathrm{TCT}$, Winko-Matic) do have plans for developing a similar external interface for integrating other controllers into their systems in the near future, but some reservations exist until such future enhancements are actually developed and proven.

Tables 2 and 3 summarize a comparison of technical attributes between the distributed systems mentioned.

The cost of these systems varies from a low of $\$ 10,000.00$ to a high of $\$ 20,000.00$ per intersection. 


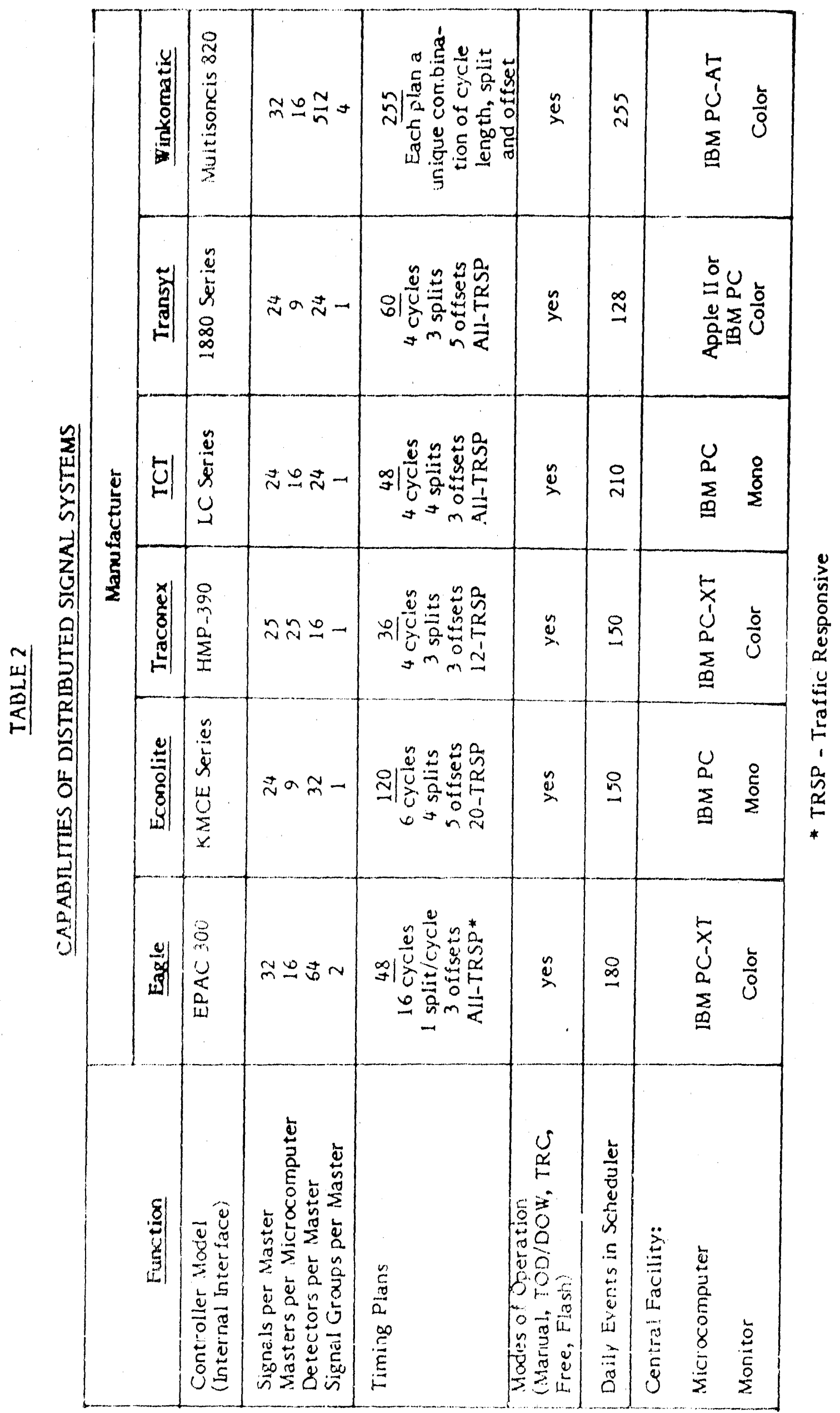




\section{TABLE 3}

SYSTEM DIAGNOSTICS COMMON TO ALL DISTRIBUTED SYSTEMS

- MASTER

- SAMPLING DETECTORS

- No Calls

- Excessive Calls

- Erratic Operation

- CONTROLLERS

- Following Commands

- Proper Cycling

- Preemption

- Flash (manual, conflict)

- COMMUNICATIONS

- Loss of Signal

- ERROR MESSAGES

- Saved on Disk

- Printed

- Secondary Call 


\subsection{COMPUTER-BASED CENTRAL MASTER SYSTEM}

\section{OVERVIEW}

The operating phillosophy of a computer-based central master system is very different from that of a distributed master system. With a central computerized system, decision making is concentrated at the central computer with the local intersections performing load switching and minor timing logic. Cycle lengths, splits, and offset selections are made by the central computer. The computer "selects" the appropriate ciming plans by either a traffic-responsive algorithm, TOD/DOW activity schiedule, or manual intervention. These systems also provide for flashing operation of individual intersections as well as "special functions" for controlling other devices such as variable message signs and lane-use control signals.

A schematic of a computerized signal system is shown in Figure 7. System detectors, which are typically tied to nearby controllers, measure the volume and occupancy on selected roadway links throughout the system. These traffic flow data are transmitted from the local controllers to the central computer via a communications network where they are utilized by the central computer to select the timing plan (combination of cycle, split, and offset) which minimizes traffic delays.

Computerized systems currently in operation in North America make this selection from a set of timing plans which have been developed by the user and prestored in the computer's memory. Selection is accomplished either by a TOD/DOW schedule or a traffic responsive matching algorithm which compares the current traffic demand (as measured by system detectors) with sets of "signature" data for each detector -- each set of signature data corresponding to a specific timing plan. The timing pattern best suited to meet the existing traffic conditions is then selected and implemented. More sophisticated systems exist which do not utilize predefined timing patterns. Instead, they use the real-time traffic flow ditsa to generate timing plans and automatically implement these newly-de reloped plans on the street. With some of these systems, the normal concept of a timing plan (i.e., combination of cycle length; split, and offset) is fairly nebulous and has been abandoned for all practical purposes. 


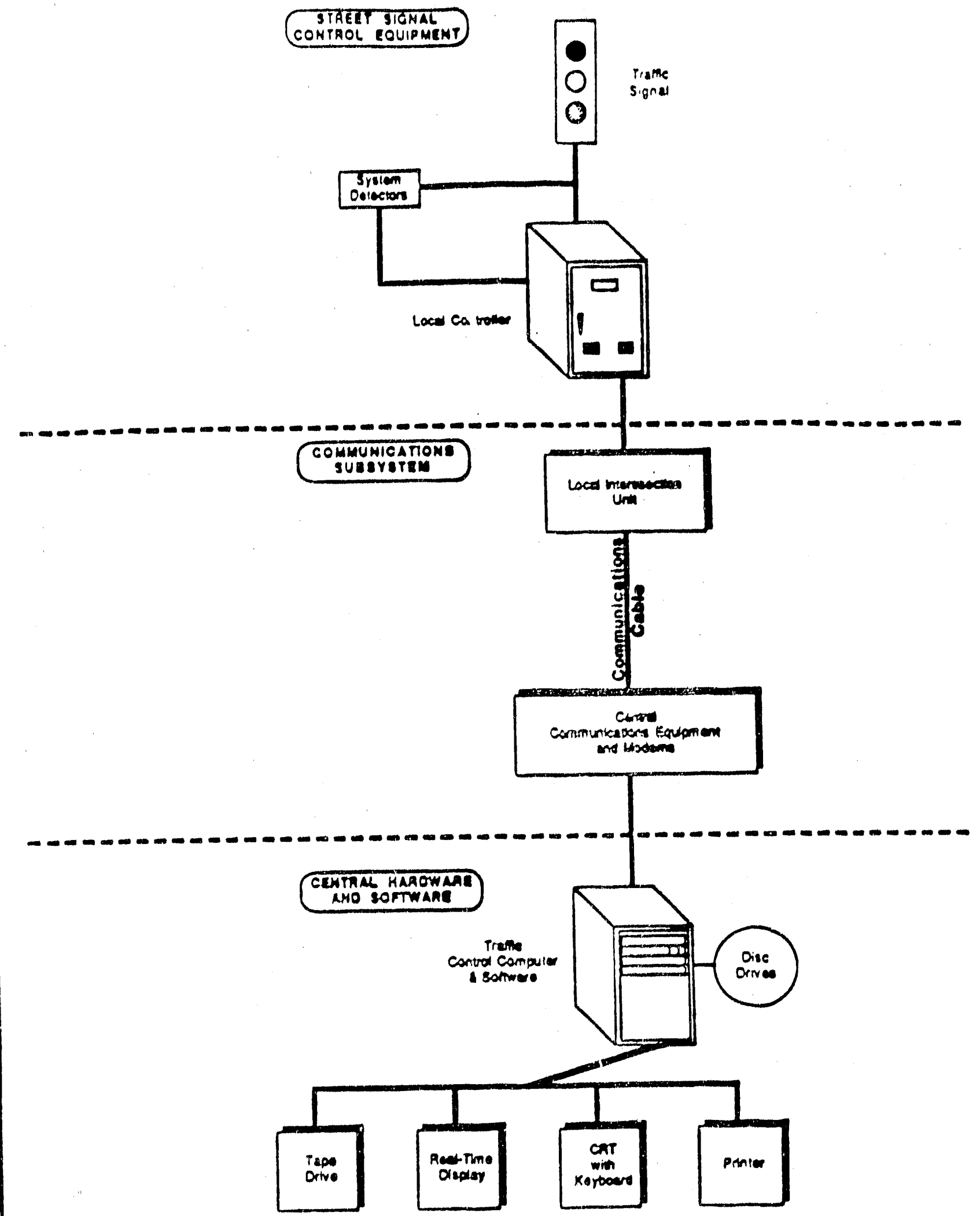

FIgURO 7 SCHEMATIC OP CENTAAL COMPUTERIZLO TRAPFIC SIONAL SYSTEL 
Implementation of the timing plan is accomplished by way of "command" messages which are sent from the central computer to the local controllers via the communications network. These messages are typlcally transmitted at least once per second to assure that the proper cycle length, split and offset are maintained at each controller. Additional control commands may also be lssued as required to activate flashing operation or other special functions.

The central computer also monitors the operation of the system. In addition to detector data, real-time status information (e.g., current green phase, preempt condition, flash, etc.) is transmitted from each local controller back to the centra! computer at a rate of once per second. This return information is monitored by the central computer to ensure that each system element is functioning properly. If any equipment is not operating in accordance with predefined criterla, the systern flags the error, alerts the operator to the malfunction, reports the nature and characteristics of the failure, and then continues operating in a degraded mode (l.e., the signal may be dropped to an off-line status until the error condition has cleared).

The central control site is typically located in the offices of the Traffic Engineering Department. It also functions as the coordinating center for the individual elements of the system and provides the person-system interface via a CRT with keyboard, printer, and real-time system display.

\section{SYSTEM COMPONENTS}

A computer-based central master system can be divided conceptionally into three major subsystems; local intersections, communications and central master. Each of these is described in detail in the following sections with particular emphasis on the alternatives which may be considered.

\section{Local Intersections}

Ore of the major advantages of computer-based central master systems is that, in general, any type of controller can be made to function within the system, including: 
- Electromechanical pretimed

- Solld-State digital pretimed

- Solid-State/microprocessor actuated (NEMA)

- Type 170

The a!ternatives which appear to be most appropriate are (1) solld-state pretimed and (2) NEMA-actuated. Pretimed controllers are computer-controlled by one of two techniques: interval control and dial control. With interval control, the system issues ADVANCE commands for each interval in the cycle. Selection of interval lengths is done by the central facility. The advantages of this technique are that it is relatively simple to install in the fleld and it provides maximum flexibility in setting interval durations. On the negative side, when the equipment malfunctions or misses an ADVANCE command, unreasonably short or long intervals may be displayed for one cycle.

The dial control scheme designates one of the controller's dials as the "computer dial", with cycle length and intervals set for the minimum safe phase times and clearances. Another dial is set for standby (off-line) operation. The last green/walk interval for each phase (i.e., the interval before clearance) is designated as a "HOLD" interval. These intervals start and time normally, but the controller will not advance to the next interval until the HOLD command from the computer is released. By releasing the HOLD command at appropriate points in the cycle, the computer generates the desired cycle split and offset. A major advantage of this control is that all clearance and dummy intervals are timed locally. Because of this, a malfunction of the communication equipment cannot cause an erratically timed signal display and the error monitoring can be relatively simple. As a general rule, dial control is the preferred method.

With an actuated NEiMA controller, the system typically issues HOLD, YIELD, and FORCE-OFF ccmmands to achieve the desired cycle length, split and of fset. A HOLD is issued continuously while the controller is on-line. The controller will rest in the coordinated phase until a YIELD command is issued. This permits the controller to service any and all non-synchronized phases which may have been called. Each of these non-synchronized phases is serviced until it gaps out or a FORCE-OFF command 
Is issued by the system. In the event minor phases are skipped or gapped out early, all the unused cycle time is typically allocated to the coordinated phase. The local controller performs all timing of clearance intervals.

It is noted that an important element of NEMA controllers is standardization. In particular, the NEMA (National Electrical Manufacturer's Assoclation) approach has been to standardize the hardware interface. Since the computer interface to the controller is typically through a separate remote communications unlt (RCU), little modification to the local controller is normally required. Thus, NEMA actuated controllers of different makes and models can be located within a computerized system with minimal rewiring. Conversely, pre-NEMA solid state controllers, depending on manufacturer and model, can require significant rewiring modifications for system interface. Generally, it is more technically reliable and cost effective to replace these controllers with the more recent NEMA controllers.

\section{Communications}

The communications subsystem ailows the central computer to communicate with the various pleces of field hardware. This element of the traffic signal system consists of the communications cable media, telemetry mode, the central computer interface, and the local controller interface. The transmission functions include:

- Commands sent from the computer to the local intersection controiler.

- Monitor (or status) messages sent from the local intersection controller back to the computer. A major element of the monitor message is often system detector information.

- Protocol and error checking components of the control and monitor messages (address, start/stop, parity, checksum, etc.).

The type and quantity of data to be transmitted has a significant affect on the telemetry mode, the media, and the design of the other elements of the commurications network. 


\section{Telemetry}

Nearly all central computerized signal systems utllize TDM/FSK for telemetry. (Refer to the discussion in the previous chapter.) Message transmission between the central computer and the local controllers typlcally occurs once per second, al though some systems without sophlsticated error checking/correction procedures, transinit a message twice every second to ensure reliability. Data transmissions may be made in half-duplex mode (1.e., data flow is allowed in either direction, but operates in only one direction in a given time frame); or full-duplex (l.e., data flow allowed in both directions simultaneously) thereby avolding echo and excessive channel turnaround delays. Baud rates (bits per second) for computerized systems are generally 1200 , depending on the data loading and flow configuration.

\section{Media}

The most common transmission medlum for central computer-based slgnal systems is voice-grade interconnect cable. This can be achieved via three basic approaches:
- User-owned cable network (twisted-pair cable)
- Leased circuits (Type 3002 circuits)
- Combination of user-owned and leased circuits

(Note: Other media have been used in traffic signal systems, including dedicated coaxial, leased CATV, and fiber optics.)

A twisted-pair communications channel typically consists of one pair of wires operating half-duplex or two pairs of cable (four-wire) operating full-duplex. In fullduplex operation, one pair is used to send command messages from the computer to the local controllers; while the second pair is used to receive messages from the local controllers. With half-duplex communications, a single pair of conductors is ised to send messages in both directions. The communications channels are configured with between 4 and 16 controllers on each channel, depending on the type of system and whe ther uploading/downloading fea tures are included. 
Except for rellabillty, leased telephone clrcults can be used interchangeably with user-owned, employlng the same modems and hardware, and with multiple controllers operating on the same channel. Both techniques may be utilized in the same system.

The trade off for rellabillty is cost. The inltlal capital costs for a user-owned "network can represent a substantial part of the overall system cost, especlally when the cable is installed under existing roadways and sldewalks in new condult. L.eased llnes have the advantage of lower Installation costs. There is, however, the recurring leasing fee which, being established by tariff and subject to change, cause substantial uncertainty concerning future costs. The monthly costs of leased lines in some systems have escalated to the point that these systems have converted to other forms of communication.

Some telephone companies offer a special tarlff, whereby a percentage of the monthly fee is extracted over the llfe of the system and lumped into a single up-front charge. While these speclal tarlffs are based on and financially equivalent to the telephone company's standard tariff for 3002 volce-grade circuits, they offer the advantage of significantly lower monthly charges. Furthermore, the compensating one-time cost is ellgible for FHWA participation.

Another concern with leased lines is maintenance. In some situations it may be difficult to ascertaln whether communication problems are the responsibility of the traffic system owner or the telephone company. With a user-owned cable network, the maintenance responsibility is always clear -- it falls on the owner.

In light of the recurring costs associated with leased telco channels (which are. ineligible for Federal participation), as well as the unpredictabllity of future iate increases, and the maintenance concerns, many agencles have avolded leased line communication alternatives. There are nevertheless instances where leased channels are more cost-effective -- for example, when a special tarlff can be utilized for computerized systems as noted above in areas where no facilities for user-owried cable exist, or signalized locations which are located a considerable distance from the control center and require amplification. Additlonally, leased-channels are convenient to install and provide flexibility for modification and future expansion. 


\section{Inter face Hardware}

As prevlously noted, in a volce-grade cable network (user-owned or leased), the communlcatlons channels are configured with between 4 and 16 controllers on each channel, depending on the system. Since many communications channels are typlcally Involved in a centralized signal system, a Communications Control Unit (CCU) is normally used to reduce the processing load on the central computer. The CCU provides an interface between the modems and the central computer.

The local controller interface consists of a transcelver, modem, arid the necessary hardware and sof tware to interface with the local controller. This Remote Communications Unit (RCU) is typlcally a stand-alone device which is installed in each controller cabinet and wired to the back panel of the local controller via a connector and harness to permit interchangeabllity. In addition, direct communication with some newer NEMA controllers and all Type 170 controllers is also possible if compatible controller communications firmware is installed.

\section{Central Master}

The central master facillty typically includes a computer (1.e., central processing unit) and peripherals, interface devices, and display devices. Each major component of the central master subsystem is discussed below.

\section{Computer}

There are three primary parameters used when describing the processing capabilities of the central hardware:

- Machine Speed - this is a composite measure of the computer's capability to perform all of the required calculations within a specific time.

- Machine Storage - this is a measure of the computer's ability to retain the required programs and data during system operation.

- Input-Output Capacity - this is a rieasure of the computer's abillty to transmit and receive information to all externa! devices including peripherals. 
Recent computerlzed slgnal systems have typlcally utllized minl-computers such as the Perkln-Elmer 3200 serles, the DEC MICROVAX Il, and the Data General Nova and MV4000 Serles. Most minl-computers today are process orlented, 32 blt machines with a direct resident memory addressing capabillty of at least 6 megabytes. They are house $f$ in cablnets ranging from desk top size to 60" (HD $\times 24^{\prime \prime}(W) \times 30^{\prime \prime}$ (D) equipment $\operatorname{rack}(s)$.

Main memory is defined as the storage device that can hold data or instructions for Immedlate retrleval by the central processor. The amount of memory is dependent on the requirements of the traffic applications software and any "background" programs desired by the user. Computerized signal systems of 250 intersections which utllize software written primarlly in assembler language may require only up to 512 kilobytes of main memory. Fortran-based software, however, typlcally requires 1 to 6 mega,bytes of memory. Main memory is usually provided in the form of plug-in solidstate modules. A battery back-up is typically provided to protect the memory data in the event of a power fallure.

Sriftware support usually includes a real-time multl-tasking operating system, a multi-terminal support program, high level language compiler(s) (le FORTRAN, "C"), a macro assembler, a mathematics library, text edltor, media-to-media copy utillty routine, and a modest assortment of other utllity routines. These programs are in addition to the traffic applications sof tware.

Peripheral equipment can include the following items:

- Disk drives and controllers for data storage. Typically, 80 to 300 megabytes of storage are provided. Multiple drives are of ten used to allow easy copy and back-up operations, plus added security; a redundant drive in case a disk failure is experienced.

- Magnetic tape drive for off-line storage, back-up, and sequential data logging of system data.

- Line and character printers, for hard copy reports and output from background programs. Line printers typically have a speed of 300 lines per minute, whlle character printers provide 120 characters per minute. 


\section{Inter face Devices}

Interaction between the operator and the computerized signal system is typically accomplished by way of a terminal or personal computer (PC) which allows input and output via an electronic video screen (CRT monitor) and typewriter-like keyboaid. Un!ike distributed master systems, most central systems include multi-user capability. This allows several users (maybe at different locations) to access the system simultaneously and without conflict. One CRT/keyboard is normally dedicated to the operation of the system. System messages (status, failures, etc.) are output to this device. In most systems, these messages and statistical reports can also be output to one of the printers. Operator commands and other traffic parameters are input from the keyboard (e.g., start-up, shutdown, select control modes, select displays, etc.).

A second CRT terminal or PC is often provided in the central facility as a secondary input device or backup for the main CRT. Additional CRT's may be hardwired at various locations (e.g., the signal maintenance shop) or connected via modems to provide personnel with displays and reports to aid them in diagnosing equipment problems and failures.

\section{Display Devices}

Display devices, such as wall maps or high-resolution color monitors are utilized to portray the "real-time" operation of the system and/or individual intersections, and to provide status information. Information provided by the se devices includes:

- Layout of the system network, including streets, jurisdictional boundaries, major geographical elements (e.g., rivers, lakes, mountains, etc.) and traffic generators or other points of interest (e.g., large shopping malls, fire sistions, auditoriums, etc.).

- Intersections in a flash or pre-empted mcde.

- Detectors actually being processed or detectors in a failed condition.

- Actuations of detectors in a representation of real-time.

- Main street "green"; noting when the primary street has been given right-of-way. 
- Display of the appropriate detector lights of all locations which exceed (or are below) user specified threshold values for average speed, volume, or occupancy.

The above information is very useful to the personnel who must operate and maintain the system, but it can also portray the system to the external world. It has the potential to provide an understanding of the system to policy makers and administrators who must weigh transportation funding considerations against other community needs. The real-time display can also be extremely useful in explaining the traffic signal system to the public. Additionally, for the professional journalist who will initially describe the system to the public, the display device can be used as a very effective educational tool as well as good public relations.

A color graphics display provides significantly more information than a map. The color graphics may display the map of an area, the system, or a specific arterial. In this particular display mode, the CRT can indicate the operating status of the intersections and system detectors in much the same manner as a large display map.

Using an interactive device (e.g., graphics tablet, mouse, keyboard, etc.), the operator can identify a particular intersection to be displayed in greater detail. The CRT then displays the approximate geometric layout and lane markings of the specific intersection. It also shows the real-time green, yellow, and red displays for vehicular and pedestrian signals. In addition to the intersection layout and signal displays, the CRT screen simultaneously displays other per isient information including the date, intersection number, current timing plan under which the intersection is operating. cycle length and running time indication, offet, phase splits, and intersection stixtis (e.g., on-line, stand-by, preempt, flash, etc.).

Color graphic output also tends to be more flexible. As the radway network changes, a display map becomes outdated and requires artwork changes. On the other hand, the intersection and area layouts on the color CRT car. be altered as necessary by the operator. The operator is also able to easily create new displays for those signalized intersections which will be integrated into the signal system in the future. Color graphics typically use 19 or 25 -inch high resolution screens, although video projection screens are now being used in conjunction with color graphics in some systems. 
SYSTEM CAPABILITIES

Features which are common to the vast majority of central computer-based systems are listed in Exhibit A. Additional functions and capabilities are usually possible depending on the requirements of the user. The extent and "quality" of these system capabilities are, for the most part, a function of the traffic applications software. Significant differences exist between the available software packages in terms of their operation, hardware requirements, and features as summarized below:

\section{Off-the-Shelf}

Current manufacturers of "off-the-shelf" centralized computer-based systems include:

$$
\begin{array}{ll}
\text { - Eagle - COMTRAC } \\
\text { - Winko-Matic - Multisonics VMS }
\end{array}
$$

These systems provide all the basic features listed in Exhibit A. The software is written in the assembly language of a specific computer which, in essence, marries the system to that particular computer (e.g., Eagle's COMTRAC is implemented on a Data General Nova 4/C). The software and remote communications units are proprietary -that is, the rights are owned by the supplier. As a result, the system documentation tends to be incomplete (to protect the suppliers' investment) and can be difficult to use.

Another drawback with these systems is that, as with most "off-the-shelf" items what one buys is what one gets. In general, it is not possible to obtain any additional features or capabilities that may be required. 
EXHIBIT A - SYSTEM FEATURES COMMON TO CENTRALIZED

COMPUTER-BASED SYSTEMS

- System Size - 250 to 1000 signals for a single computer configuration.

- Timing Plans - the number of available timing plans exceeds the requirements of any typical jurisdiction.

- Traffic Responsive Plan Changes - differences exist between systems in the algorithm logic; the number of timing plans available for TRSP at any one time may be limited.

- Time-Of-Day/Day-Of-Week Schedules - typically, provides a method to select timing plan implemented by the time-of-day and/or day-of-the week.

- Operator Manual Override - allows operator to select a specific timing plan and to specify cycle lengths, splits offsets, flashing, etc. for individual controllers as required for special circumstances.

- Coordination Between Signal Groups - when adjacent groups are operating on the same cycle.

- Timing Plan Transition

- Ability to Interface with Various Controller Types - controllers integrated through installation of external RCU

- Special Function Capability - implement flash, variable message signs, variable phasing, recall functions, etc.

- Ability to Change/Update Timing Plans from Computer - the majority of systerns do not require system shutdown to accomplish this. 


\section{EXHIBIT A (continued)}

- Hardware Failure Detection - monitors the perfornance of controllers, detectors and communications hardware; many systems automatically "retry" failed hardware to bring them back on-line.

- 24 Hour Unattended Operation - continuous operator supervision is not required.

- Automatic Restart After Power Failure - the ability of some systems to provide this feature is often a function of the length of the power failure.

- Real-Time Display - map and/or color graphics.

- Traffic Flow Measurements - volume and occupancy data from detectors; some systems develop system Measures of Effectiveness (MOE) such as speed, stops, queues, and delays for each detectorized link; permanent count stations are of ten provided.

- System Status and Other Reports - examples include failure, hardware status, log of timing plan changes, etc.; reports may provide information on current saturation or a summary of a day's activities.

- Data Processing Capability - running traffic engineering and other programs in background with the system on-line. 


\section{UTCS}

The development of UTCS (Urban Traffic Control Systein) software was initiated by the Federal Highway Administration to develop a baseline traffic applications software package written in FORTRAN. The intent was that this software could be implemented on any computer which supported FORTRAN for a fraction of the costs associated with designing and implementing new software for each application. This has been accomplished to a large degree.

In general, a UTCS system provides greater and expanded functions as compared to proprietary oft-the-shelf systems. Specifically, UTCS provides the following features:

- Enhanced error monitoring, failure processing, and automatic failure recovery.

- Increased surveillance capabilities and detector data processing; including count stations and system measures of effectiveness (e.g., speed, stops, queues, delay, etc.)

- Enhanced special function capabilities.

- Additional reporting capabilities.

- Enhanced real-time displays (e.g., higher resolution color graphics, additional displays, interaction with background programs).

- Improved traffic responsive operation.

- Complete user-oriented documentation.

There are two basic UTCS software packages available from FHWA: the Extended Version, which was released in 1979, and the Enhanced Version which was released in 1983. The baseline Enhanced package, having been developed based on the previous experiences with the Extended package, possesses significantly more capabilities than the baseline Extended package. However, through numerous applications, the Extended package has been significantly modified and improved such that both UTCS packages can be considered equivalent in terms of the functinns and features provided, and the corresponding costs.

Two major differences remain between the Extended and Fnhanced versions: detector data processing and the operator interface. The Enhanced version providess 
greater capabilities with respect to the processing of data from system detectors -specifically, checking the data for possible errors and utilizing the data to develop measures of system effectiveness and related reports. This enhanced data processing requires a significant amount of computer time. As a result, the Enhanced version has encountered processing time problems in several applications. To resolve these problems, it has been necessary to rewrite certain routines or to convert a portion of the FORTRAN code to assembler language.

Another significant difference between the Enhanced and the Extended Versions stems from differences in operating interface and dialogue. The Enhanced Version incorporates a command driven Operator Interface Language, or OIL. OIL is advantageous in that it allows system commands to be quickly implemented by a skilled operator. The operator has only to type a single sequence of command parameters to accomplish any selected operation. To accomplish the same with the Extended Version, the operator must step through a sometimes long dialogue of questions and answers, in which each question is posed as a choice from a list (i.e., "menu") of predefined selections. This can become tedious if similar control function operations are required for several locations. The menu approach, however, is advantageous to new or occasional operators because it's self-teaching style does not require the memorization of command codes nor the need to have reference documents close at hand. Examples of an Enhanced OIL command sequence is shown in Exhibit B.

The UTCS Extended and Enhanced Versions are only baseline software packages. They typically require modifications in order to meet specific user requirements. Additional routines are also necessary to make the UTCS software fully operational, inc'uding interface software which serves as the link between UTCS and the computer's operating system and communications software which causes commands and status information to be transmitted to and received from the field devices. These and other routines are coded in assembly language of the particular computer on which the UTCS package is ported.

Several firms currently provide UTCS-based systems. These "system managers" take responsibility for providing a fully operational signal system, including software 
EXHTRIT A - SAMPLE "ENHANCED" OIL COMMAND

LEVEL 1 SELECTIONS:

1. SYSTEM CONTROL

2. STATUS DISPLAY CONTROL

3. MAP DISPLAY CONTROL

4. SYSTEM SHUTDOWN
5. SYSTEM START UP

6. HISTORY FILE TRANSFER

7. WEATHER AND SPECIAL EVENTS

8. FUNCTION SCHEDULER

MAKE A LEVEL 1 SELECTION

\begin{tabular}{ccc}
\multicolumn{3}{c}{$* *$ * TRAFFIC SYSTEM STATUS * * } \\
COMMUNICATIONS & CONTROLLERS & DETECTORS \\
NORMAL & NORMAL & NORMAL
\end{tabular}

Initial Menu Display

LEVEL I SYSTEM CONTROL

LEVEL 2 ACTIVATE

LEVEL 3 TRAFFIC CONTROL

LEVEL 4 SECTION 16

LEVEL 5 TRAFFIC RESPONSIVE

EXECUTE REQUEST OR CANCEL?

* * traffic System STATUS * *

$\begin{array}{ccc}\text { COMMUNICATIONS } & \text { CONTROLLERS } & \text { DETECTORS } \\ \text { NORMIAL } & \text { NORMAL } & \text { NORMAL }\end{array}$

Command Completion 
modification (based on UTCS), system integration, testing, training and documentation. These systems management firms include:

- JHK \& Associates

- Computran

- PRC (F.R. Harris)

- Sonex

\section{5 and $2 \mathrm{nd}$ Generation Control}

Off-the-shelf systems and the UTCS Extended and Enhanced Versions are control concepts referred to as First Generation Control ( $1 \mathrm{GC})$. Under IGC, the signal timing plans are developed by traffic engineering personnel and the resulting timing parameters (cycle length, split, of fset, etc.) are then manually converted to the proper format and entered into the system's data base for subsequent selection and implementation. This is basically a library table look-up procedure, sometınes called pattern matching technique, in which the pre-determined signal plans are selected based on a set of traffic conditions (TRSP) or a time of day/day of week schedule.

A more advanced control strategy, referred to as Second Generation Control (2GC), has also been developed. Under $2 \mathrm{GC}$, the timing plans are developed by the system through the use of 5 minute to 15 minute traffic volume and occupancy data acquired from system detectors, and the timing parameters are automatically developed and implemented by the system in the subsequent 5 to 15 minute interval, respectively. The advantage of this strategy over $I G C$ is a significant reduction in labor required to develop signal timing plans and input data into the comfuter. A major disadvantage is that no mechanism is provided for these timing plans, newly developed by a computer model, to be analyzed by traffic engineering per sonnel before they are implemented -- a situation that can lead to unpredictable results on the street.

A compromise between these two concepts, known as 1.5 Generatir Control, has recently been developed. With $1.5 \mathrm{GC}$, signal timing plans are developed automatically by the TRANSYT-7F program using current traffic flow data as collected by the system detectors. However, the plans are not implemented until they have undergone an engineering assessment and a determination has been made that the 
plans are superior to the old ones. This strategy offers the labor saving advantages of $2 \mathrm{GC}$, but retains the feature of First Generation control of implementing prestored signal timing plans.

$1.5 \mathrm{GC}$ is much more than just an automated method of developing and updating signal timing plans. It provides the means (e.g., time space diagrams) to quickly evaluate the timing plans to answer "what if" questions. It also provides the means of automatically updating the system data base to reflect the new timing plans, thereby eliminating the drudgery of accomplishing this manually.

A major disadvantage of 1.5 Generation Control is the extensive detectorization required. To obtain sufficient data for developing rellable timing plans, it is necessary to install an average of 1-2 system detectors per signalized intersection. Not only does this increase installation costs, but also places additional burdens on maintenance personnel to keep the detectors operational. A $1.5 \mathrm{GC}$ system is currently being installed in Los Angeles by JHK \& Associates.

\section{3rd Generation Control}

$3 \mathrm{GC}$ is basically a dynamir form of control with signal timing parameters changing continuously in response to changes in traffic conditions. A $3 \mathrm{GC}$ system has not as yet been installed in North Amurica. However, a package called SCOOT (Split, Cycletime, Offset Optimization Technique), developed by the British Transport and Road Research Laboratory in conjunction with British traffic control industries, has been implemented successfully in a number of small systems in England.

SCOOT operates by constantly measuring the pattern of vehicle demands and continuously changing the signal timings so that they match the developing traffic situation. Manual intervention is minimized and the need for regularly updating a plan disappears. The basic structure of this $3 \mathrm{GC}$ system is similar to that of the established Transyt method of calculating fixed time plans. Both methods incorporate a traffic model which predicts delays and stops caused by specific signal settings. The model is used by the "signal optimizer" to identify beneficial changes to signal timings. Howevor, unlike Transyt, in which average delays are calculated from historical traffic flows, the SCOCi model uses data obtained from the system's detectors. The: results of optimization can, therefore, be carried out in real-time and transmittris directly to the local controllers. 
The data collected from the $3 \mathrm{GC}$ system detectors (typlcally a minimum of 4 per intersection) is used to calculate cyclic flow profiles for each link. Each profile consists of a histogram that records how the traffic flow rate varies during one cycle of the upstream signal. Using these profiles the system's model predicts the behavior of the queue of vehicles at each downstream stopline, taking account of platoon dispersion. SCOOT then calculates an index of the efficiency of traffic movement similar to Transyt's calculation of Performance Index.

When SCOOT is operating, the on-line computer contains a set of timings that determine when the signals will turn green and red within a cycle length that is common to all signals in an area of the road network. This set of timings is equivalent to the plan data in a IGC system. In normal oparation, the SCOOT "signal optimizer" makes frequent but small changes to the set of timings to adapt the plan to variations in traffic changes.

This form of control is considered to be most effective when traffic demands are highly variable and traffic volumes approach the maximum capacity of the intersections involved. Hence, 3GC systems such as SCOOT should typically be applied only to the dense core of a given network, such as a CBD. At the time of writing, however, assessments of the performance of SCOOT under research conditions have not yet been made in a dense signal network. The published results are based on networks of small numbers of signalled intersections long separated by relatively long link lengths. It is known that the traffic model which SCOOT uses is suppressed under congestion situations, but it is not clear from published material exactly how such a situation is modelled.

It is well established that installing a $3 \mathrm{GC} / \mathrm{SCOOT}$ system requires fine tuning of the system parameters in order to calibrate the model for the given geographical and dynamic traffic conditions. Early experience with SCOOT installations indicate that this may well be substantial. Changes in the network would require recalibration of the model, but the proprietary nature of the system software and the reticence of British Government/Industry to disclose details of the model make it very difficult to estimate the work involved. It may well be that the approach which is promoted by those firms installing SCOOT, that of treating SCOOT as a "black box" and discouraging buyers from learning how it works, means that an operating agency would not be able to recalibrate such a system without the assistance of the installing contractor. 
A related drawback is that SCOOT now not yet been tested under North American driving conditions.

The very nature of $3 \mathrm{GC} / \mathrm{SCOOT}$-type systems demands extensive detectorization and heavy dependence upon a centralized system, with associated vulnerability to equipment malfunction. Only extensive operational experience will enable assessment of the real impact of these characteristics.

Final!y, one of the major justifications for $3 \mathrm{GC}$ systems is the assumption that fixed time plans based on historical data must "age" and become inefficient. Research work carried out by the University of Newcastle, England has indicated that, in fact, TRANSYT calculated plans have a high degree of tolerance to non-incident related variations in traffic flow. This means that timing plans stay effective for a number of years unless major changes in flow patterns occur e.g. due to geographical changes in the network, which, in any case, would demand recalibration of the $3 \mathrm{GC}$ model.

Given the tolerance of historically calculated timing plans, the case for $3 \mathrm{GC}$ then rests upon reduced skilled labor costs due to the elimination of the "manual" timing plan preparation task. However, the implementation of the $1.5 \mathrm{GC}$ system concept, which automates TRANSYT data input, tackles and effectively solves this problem.

To summarize, while the concept of $3 \mathrm{GC}$ is, in theory, a worthy goal, the combination of advances in current pre-calculated signal timing plan systems and the drawbacks of existing available 3 GC systems preclude the establishment of an overwhelming case for $3 \mathrm{GC}$.

\section{Centralized Systems with Distributed Control Features}

With this type of central system, many of the data processing responsibilities and computations are removed from the central computer and "distributed" among the field hardware and peripherals. All the features and capabilities of centralized UTCS systems (including multiuser system access) are provided, but instead of the traditional secorid-by-second transmission of control data, the timing plan data are downloaded to the local controllers and stored in a microprocessor-based RCU (or internal to the controller with some newer NEMA and Type 170 controllers). These stored timing plans are then implemented through plan selection commands sent from the computer to each controller. The RCU also summarizes system detector data over a one minute or one cycle period before transmitting the information back to the computer. This 
results in reduced data downloading and reduced computer processing. Each RCU also has time-based coordination capabilities. If valid communications with the centrai compute: are losi, the inter section automatically reverts to local control; but, there is no discontinuity in progression. Thus, elal orate backup coordination systems found on many centralized systems are not needed with a distributed processing system.

While downloaded/uploaded data are transmitted to/from the computer and the local controllers on aiı as-needed basis, return messages (e.g., real-time display, controller status) are transmitted from all controllers to the computer on a cince-per-second basis. This permits a full sys lem-wide graphic representation of real-time controller status (map and/or color graphics) as weli as independent and continuous monitoring for failures by the central computer.

Continuous monitoring also makes these systems compatible with high levei control methods su'ch as $1.5,2$ nd, 3rd GC whether they are installed with the initial system installation or at a later date.

The reduced data loading and reduced computer processing means that a less powerful computer is required "resulting in reduced installation and maintenance costs.

An example of a distributed configuration of this type is the Series 2000 provided by JHK \& Associates. The system has been installed in Eugene, Oregon and Portland, Oregon; and will be installed in New Haven, Connecticut and Chula Vista, California.

The Series 2000 software makes use of the latest general purpose computer technology but, since it is written in FORTRAN, it is not tied to any one manufacturer's equipment. This approach allows for competitive hardware procuremerit contracts. Additionally, the RCU's are compatible with any pretimed NEMA controllers. Estimated costs are from a low of $\$ 13,000$ to a high of $\$ 25,000$ per inter section. 


\title{
FINDINGS OF THE FIELD HARDWARE REVIEW AND RECOMMENDATIONS
}

\author{
Final Report \\ Prepared by \\ JAMES H. KIILL AND ASSOCIATES \\ 118-35 Queens Boulevard \\ Forest Hills, NY 11375 \\ Prepared for \\ NEW YORK STATE \\ ENERGY RESEARCH AND DEVELOPMENT AUTHORITY \\ Project Manager \\ Norine H. Karins
}

1033-EEED-AEP-88 


\section{FINDINGS OF THE FIELD HARDW ARE REVIEW AND RECOMMENDATIONS}

An investigation of the traffic control equipment currently used at each of the demonstration project sites was conducted with representatives of the respective cities. Attachment $A$ details the equipment found at each of "he signalized intersections within the demonstration site. The following summarizes the investigation and provides recommeridations relative to the demonstration hardware.

\section{WHITE PLAINS (MAMARONECK AVENUE)}

This demonstration site is an arterial route consisting of 12 signalized intersections controlled by pretimed and actuated equipment. A modernization program is scheduled to replace several of the older controllers with contemporary solid state devices during the spring. The resulting arterial system would consist of the following equipment types:

No.

\section{Equipment}

1 - Marbelite MD3 solid state actuated controller

7 . Marbelite M30 Pretimed electro-mechanical controllers

1 - Marbelite M20 SVA Semi vehicle actuated electro-mechanic controller

1 - Safetran ST330 solid sate actuated controller

2 - Safetran STz 800 solid state actuated controllers

\section{YONKERS (SOUTH BROADWAY)}

This demonstration site is also an arterial route and consists of 12 signalized intersections controlled by pretimed or semi actuated equipment operating pretimed. The following types of equipment are in use:

No. Equipment

9 - Narbelite M30 Pretimed electro-mechanical controllers

3 - Marbelite MT 2SRMP solid state semi actuated controller; with 3 dial elertro-mechanical coordination units 


\section{TROY (6TH AVENUE)}

This demonstration route is also an arterial but lies within a grid network. The route consists of 8 signalized intersections controlled by non-NEMA solid state actuated and pretimed electro-mechanical equipment. The following types of equipment are in use:

No. Equipment

6 - General Electric 2TTF pretimed electro-mechanical controllers

2 - Crouse Hinds DCC solid state actuated controllers

The estimated procurement cost of the replacement equipment is as follows:

$\begin{array}{lrrr} & \begin{array}{c}\text { Control } \\ \text { Equipment }\end{array} & \begin{array}{c}\text { Sipport } \\ \text { Equipment }\end{array} & \text { Total } \\ \text { White Plains } & \$ 18,000 & \$ 2,000 & \$ 20,000 \\ \text { Yonkers } & 60,000 & 7,500 & 67,500 \\ \text { Troy } & \$ 60,000 & \underline{2,500} & \underline{62,500} \\ \text { Total } & \$ 138,000 & \$ 12,000 & \$ 150,000\end{array}$

The support equipment is defined within the individual specifications for the control equipment. In general, this support equipment is that necessary to operate the new control equipment for the duration of the project, including controller modules, testing devices, electronic relays, etc. 
For the furposes of this demonstration project and as a general guide for future projects, the existing signal controller hardware attributes that as a minimum were acceptable to allow the installation of a stand-alone TBC were defined as follows:

For electromechanical pretimed equipment:

1. Location warrants non-actuated operation

2. Reliable signal operation

3. Remote dial stop of fset capability

4. Synchronous motor timing dial

5. Cabinet sized for installation of a Time-based Coordinator (TBC)

6. Back panel access to control and TBC wiring terminations

7. Adequate spares and local support to continue operating during the required research period.

For solid state actuated equipment:

1. Location warrants actuated equipment

2. Reliable signal operation

3. NEMA compatibility

4. Phase hold, force off, inhibit maximum ter rnination, call to nonactuated, and walk rest modifier functions

5. Back panel access to control and TBC wiring terminations

6. Adequate spares and local support to continue operating during the required research period.

The minimum acceptable controller attributes were compared to the known existing equipment attributes for each of the demonstration project sites. The following reflects this comparison. 


\section{WHITE PLAINS}

Approximately one half of the controllers within the demonstration site are solid state devices. The level of local support, controller features and cabinet sizes are such that it was determined that this equipment meets the minimum acceptable attributes.

The pretimed controllers are supported by the municipality and exhibit the minimum acceptable attributes to be used with small time-based coordinators.

The City has undertaken a signal equipment replacement program with serviceable, if not new, controllers and cabinets. This approach attempts to place equipment in the field where it best serves a need. Many of the installations result in a mix of equipment brands that are not necessarily compatible with each other but, provide all of the minimum acceptable attributes required of the demonstration project. Mamaroneck Avenue has such a mix of equipment. This equipment philosophy in concert with the in-house maintenance capabilities to support various brands of control equipment, indicates that an added device such as the time-based coordinator should be used at this site. The City is agreeable to installing and maintaining the TBC as well as supporting this type of operation.

\section{Recommendation}

It is recommended that time-based coordinators be used for this demonstration site. The estimated cost for this equipment is approximately $\$ 1500$ per intersection. The total estimated cost for the $t$ welve (12) intersections within the site is approximately $\$ 20,000$, including support equipment.

\section{YONKERS}

Most of the controllers within this demonstration site are older pretimed equipment. This equipment is not fully supported and in some cases lacks all of the required parts necessary to meet the minimum acceptable attributes. The remaining equipment is a one-of-a-kind controller designed as a direct replacement for and interchangeable with even older electro-mechanical, semi actuated controllers manuacturad during the 1960's. This equipment meets none of the minimum acceptable attrilutes. 
Additionally, this existing equipment was included in a interconnected system some time in the past. The interconnect as well as the control equipment is not in a condition to provide reliable coordinated control today. The controllers fail at least one of the minimum acceptable attributes test defined for each category of equipment. The City is currently undertaking a program to install Type 179 controllers at other locations within the city. They have the staff to support this equipment and would not further burden their resources with the installation of twelve (12) Type 170 controllers. Indications are that they may standardize on this controller in the future.

\section{Recommendation}

It is recommended that Type 170 controllers, with public domain (no cost to the project) NY State standard 170 controller software (ITAP4C) be provided for the twt.ve (12) intersections within this demonstration site. The estimated cost of this controller in cabinet is approximately $\$ 5,000$ per intersection. The total estimated control equipment cost for the twelve (12) intersections within this site, including support equipment, is approximately $\$ 67,500$.

\section{TROY}

The General Electr: Type F pretimed controllers used in Troy are reported to be manufactured during the 1950's. Additionally, interconnect features needed to meet the minimum acceptable attributes are not consistently available on the ones in Troy. The Crouse Hinds DCC controllers are no longer manufactured and exhibit certain maintenance and operational problems in addition to not meeting the minimum acceptable attributes for actuated equipment.

\section{Recommendations}

It is recommended that the project replace all of the controllers and cabinets within this demonstration site with NEMA equipment that includes internal time based-coordination. The support and maintenance that may be provided by Troy is more aligned to that required for NEMA controllers. The estimated cost for these intersections is aproximately $\$ 7,500$ per intersection. The total estimated ost 
for the eight (8) intersections, including support equipment, is approximately $\$ 62,500$.

\section{CONCLUSIONS}

The three approaches to providing time base coordination of traffic signals represent the technology available today. Additionally, the traffic signal controllers that will be in place, as a result of this project, within the demonstration site (Pretimed, NEMA, Type 170) are representative of the control equipment found in use across the United States.

The three municipalities and the demonstration sites lend themselves to the three hardware types for this project. All three have agreed to support the respective hardware recommended for installation. The total estimated equipment costs for the three demonstration sites is approximately $\$ 150,000$.

It is envisioned that each municipality would provide installation and support of the equipment during its life. Further, some training in the use and maintenance of this equipment is included in the cost estimates. RPI should purchase the equipment under a bid procurement process that will allow purchase orders to be issued to the successful bidder.

The cities should agree to install and maintain the equipment in the time required and to provide information to the project relative to the maintenance history of the piece that it replaces as well as the new equipment during its life. 


\section{ATTACHMENT A}

\section{NYSERDA DEMO Project Field Equipment Inventory}

\section{In Troy NY 6/27/88:}

1) 6th and Hoosick St:

DCC 4 phase controller, 220 loop amp, flasher, pole mount 40 " cabinet. Detectors non-operational, some ped push buttons work.

2) 6th and Jay:

DCC 4 phase controller, base mounted cabinet, 220 loop amps, flasher. Concrete foundation would require pedestal mounting of new cabinet.

3) 6th and Middleburg:

GE type 2TTF pretimed controller, small wood pole mount cabinet, no peds, no flasher, 70 " cycle.

4) 6th and Duow:

GE type 2TTF pretimed controller, small wood pole mount cabinet, no peds, no flasher, 70 " cycle.

5) 6th and Ingails:

GE type 2TTF pretimed controller, small wood pole mount cabinet, no peds, no flasher, 70 " cycle.

6) 6th and Glen:

GE type 2 TTF pretimed controller, small wood pole mount cabinet, no peds, no flasher, 70 " cycle.

7) 6th and 101st:

GE type 2TTF pretimed controller, small wood pole mount cabinet, no peds, no flasher, $70 "$ cycle.

8) 6 th and Florence:

Not an intersection, flashing beacon. Not included. 
9) 6th and 102nd:

GE type 2TTF, small wood pole mount cabinet, no pe 's, no flasher, 70" cycle.

In White Plains 6/28/88:

1) Marmaroneck Ave. and Livingston:

Safetran 330, 36"+ pole mount cabinet, time clock, flasher, wired for RCU, 90" cycle.

2) Mamaroneck Ave. and SO. Broadway:

Marbelite M30 jones plug controller, 1 dial, small pole mount cabinet, flasher, 90 " cycle.

3) Marmaroneck Ave. and Dekalb:

Marbelite M30 MS, conflict monitor, flasher, 30" pole mount cabinet, 90" cycle.

4) Mamaroneck Ave. and Bloomingdale Kd:

Marbelite M30 MS, 30" pole mount cabinet, fan, flasher, 90" cycle.

5) Mamaroneck Ave. and Bryant:

Safetran 28008 phase controller, base mount cabinet, flasher, 3 dial coordination unit.

6) Mamaroneck Ave and Heatherbloome:

Marbelite M30 jones plug controller, wood pole mount cabinet, flasher, $90 "$ cycle.

7) Mamé sneck Ave. and Gedney:

Marbelite M20 SVA controller, small wood pole mount cabinet, loop detectors, ped push button, Synchrolizer, 90" cycle. Cabinet with existing equipment is too small for TBC installation, change cabinet and controller recommended.

8) Mamaroneck Ave and Ridgeway:

Marbelite M30 jones plug controller, pole mount cabinet, flasher, 90" cycle. Plans are to change out for Safetran 2800 controller $w /$ base mount cabinet. 
9) Mamaroneck Ave and Rosedale:

Marbelite M30 MS controller, 30" pole mount cabinet, flasher, 90 " cycle.

10) Mamaroneck Ave. and Purdy:

Safetran 28008 phase controller, base mount cabinet, 3 dial coordination unit, 90 " cycle but currently running free.

11) Bloomingdale and North Driveway:

Marbelite MD3 controller in pole mount cabinet.

12) Bloomingdale and South Driveway:

Marbelite M30 jones plug controller.

In Yonkers 6/29/88:

1) S. Broadway and Highland:

Marbelite M30 jones plug controller, 3 dials 1 dial operation, standard metal pole mount cabinet, peds, $90 "$ cycle.

2) S. Broadway and Ludlow:

Marbelite M30 jones plug controller, 3 dials 1 dial operation, standard metal pole mount cabinet, peds, 90" cycle. Possible 179 installation by city.

3) S. Broadway and Morris:

Marbelite M30 jones plug controller, 1 dial 1 dial operation, standard metal pole mount cabinet, peds, 90 " cycle.

4) S. Broadway and Mclean:

Marbelite M30 jones plug controller, 2 dials 1 dial operation, standard metal pole mount cabinet, peds, 90 " cycle.

5) S. Broadway and Post:

Marbelite MT2SRMP controller, 3 dial coordination unit, ped crossing $T$ intersection with one-way street going away from Broadway, 3 dials 1 dial operation, 2 metal pole mount cabinets; one for controller, one for coordinator, $90 "$ cycle.

6) S. Broadway and Randolph:

Silne as 非 5 
7) S. Broadway and Redland:

Marbelite M30 jones plug controller, 3 dial 1 dial operation, relays for fire preempt (fire house on side street) standard metal pole mount cabinet, peds, 90" cycle.

8) S. Broadway and Lawrance:

Same as $\# 5$

9) S. Broadway and Valentine La.:

Marbelite M30 jones plug controller, 3 dials 1 dial operation, standard metal pole mount cabinet, peds, $90 "$ cycle.

10) S. Broadway and Rockledge Pl.:

Marbelite $\mathrm{M} 30$ jones plug controller, 3 dials 1 dial operation, standard metal pole mount cabinet, peds, $90 "$ cycle.

11) S. Broadway and Fanshaw:

Marbelite M30 jones plug controller, 2 dials 1 dial operation, standard metal pole mount controller, peds, $90 "$ cycle.

12) S. Broadway and Caryl:

Marbelite M30 jones plug controller, 3 dials 1 dial operation, standard metal pole mount cabinet, peds, 90" cycle. 

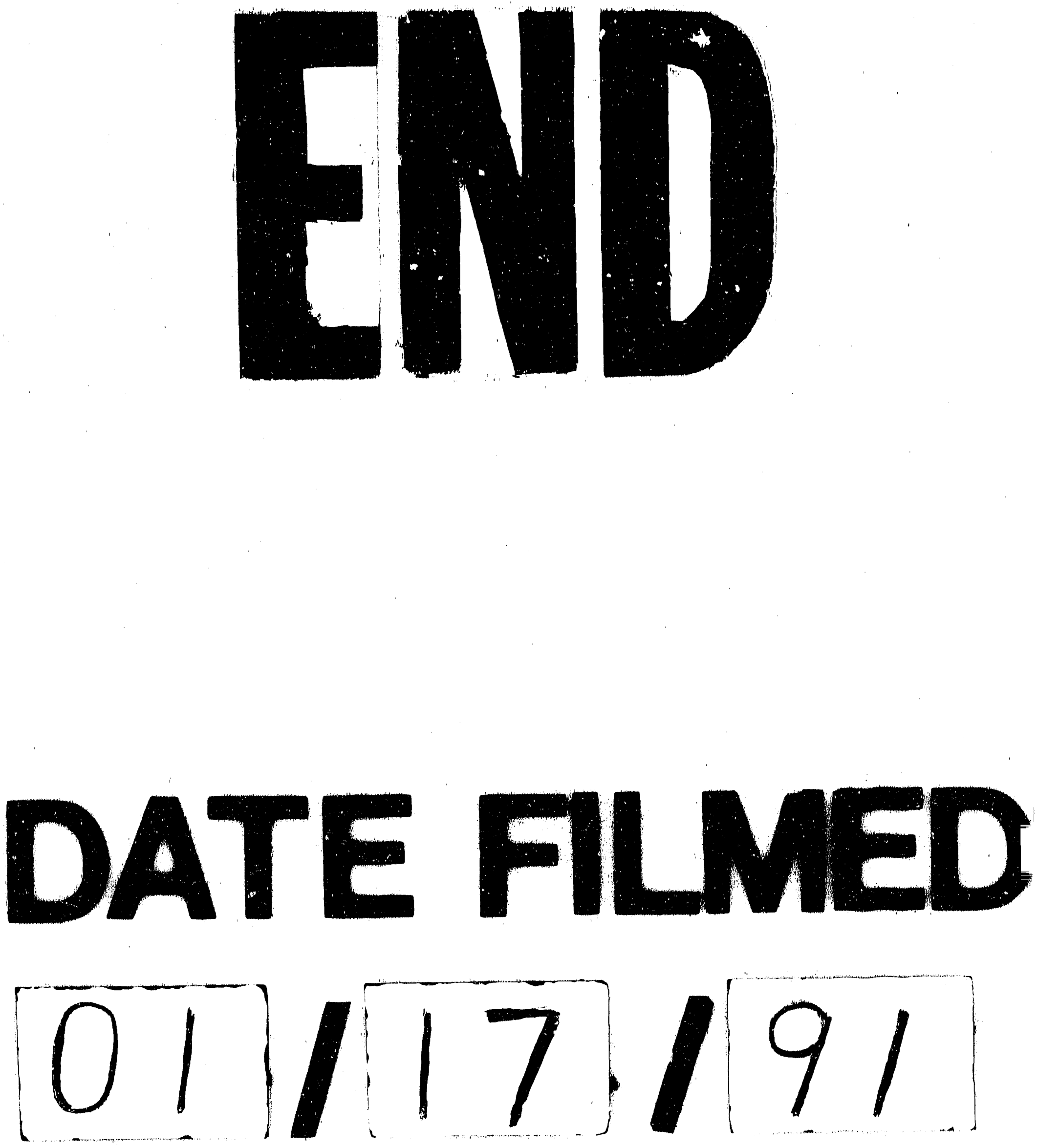
